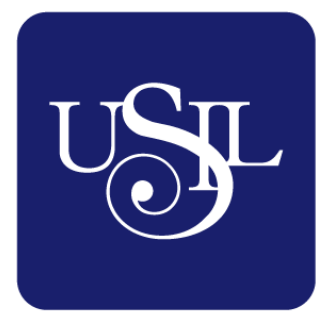

UNIVERSIDAD

SAN IGNACIO

DE LOYOLA

ESCUELA DE POSTGRADO

Maestría en Gestión Pública

\title{
SUNAT: INCENTIVOS PARA AMPLIAR LA BASE TRIBUTARIA EN EL SECTOR DE MICRO Y PEQUEÑA EMPRESAS, GENERANDO VALOR PÚBLICO
}

Tesis para optar el grado de Maestro en Gestión Pública

\author{
LILÍ HILDA BARDALES ROJAS \\ MIRIAM ESTHER TRONCOS VILLALTA
}

Asesor

Luis Fernando Peredo Rojas

Lima - Perú

2018 

SUNAT: INCENTIVOS PARA AMPLIAR LA BASE TRIBUTARIA EN EL SECTOR DE MICRO Y PEQUEÑAS EMPRESAS, GENERANDO VALOR PÚBLICO 
A nuestros padres, esposo e hijos por su apoyo incondicional. 
A nuestros profesores de la Maestría en Gestión Pública y, en especial al Dr. Luis Fernando Peredo por su orientación, asesoramiento y apoyo. 


\section{RESUMEN EJECUTIVO}

El presente trabajo tiene como objetivo implementar una política pública para generar incentivos que alienten al sector de Micro y Pequeñas Empresas (MYPEs) informales a formalizarse, y con ello lograr la ampliación de la base tributaria, siendo la SUNAT la impulsora de esta política que debe ser sostenible en el tiempo, en el marco de una gestión estratégica con creación de valor público; para lo cual es preciso asegurar que se satisfacen las tres pruebas del triángulo de Moore (1998): a) La estrategia es valiosa en términos sustantivos, b) La estrategia tiene el apoyo de la autoridad del entorno político autorizador, a quien se le rendirá cuentas y, c) es operativa y administrativamente viable.

Según datos oficiales del Instituto Nacional de Estadísticas e Informática (INEI, 2015), entre los años 2010 y 2015, aproximadamente el 19\% del PBI del Perú era generado por actividades informales -cifra por encima del promedio de la región de América Latina (13.5\%)- asimismo la absorción de mano de obra por el sector informal en el año 2015 alcanzaba al 56\% de la PEA; es decir, que utilizando cerca de las tres quintas partes de la cantidad de trabajo, el valor agregado del sector informal representa menos de la quinta parte del PBI, lo que nos sugiere fundamentalmente su baja productividad y deficiente asignación de recursos.

De la revisión y análisis de los antecedentes y normativa para promover la formalización de las MYPE, particularmente a partir de la promulgación de la Ley $\mathrm{N}^{\circ} 28015$ "Ley de Promoción y Formalización de la Micro y Pequeña Empresa" en Julio de 2003, se determina que, si bien han sido varios los intentos del Estado de reducir la economía informal, a la fecha no se observa una mejora sustancial.

Una estrategia desaprovechada fue la implementación del Plan Nacional MYPE, aprobado en mayo del 2006. Dicho documento fue estructurado en tres ejes estratégicos, con líneas de acción para cada uno de los estratos MYPE identificados en el Plan (Mype de acumulación, Mype de subsistencia y Nuevos emprendimientos). Sin embargo, ciertas líneas de acción, de suma importancia, como las referentes al aspecto financiero, fueron generalizadas para los tres segmentos, sin considerar las diferentes capacidades de las 
MYPEs para afrontar y cumplir con los altos costos de financiamiento; aspectos como aquel, así como la falta de una clara responsabilidad para el seguimiento y monitoreo, no permitieron que el Plan tuviera el éxito esperado.

A través de los resultados de la Encuesta Nacional de Empresas 2015, se puede obtener información sobre las principales necesidades de las MYPE. Así por ejemplo, en el año 2014 los tres principales factores que restringieron el crecimiento empresarial fueron: la informalidad, la demanda limitada y la dificultad de financiamiento; asimismo, se revelaron carencias respecto a la falta de habilidades y capacidades de gestión principalmente en microempresas y, la excesiva regulación tributaria.

En base a lo antes señalado, se formula el siguiente problema, que se pretende revertir con el presente proyecto: "Las intervenciones de política para promover la formalización de las micro y pequeñas empresas en los últimos años no ha tenido el impacto esperado, debido a que no se adecuan mayormente a las limitaciones, necesidades y riesgos específicos de estas unidades económicas, además de carecer de un monitoreo adecuado, que impide ampliar la base tributaria".

Planteándose como objetivo general el de "Incentivar la formalización de las Micro y Pequeñas empresas (MYPE) en el país”, con los objetivos específicos siguientes:

- OE1: Promover el acceso a crédito financiero a tasas de interés competitivas en el mercado.

- OE2: Proponer la exoneración del pago de impuestos a las microempresas que se formalicen con el programa, por un período de dos años.

- OE3: Simplificar el trámite de formalización y constitución de empresas a un costo cero.

- OE4: Diseñar un programa de capacitación orientado a mejorar la competitividad, con énfasis en tres aspectos: Gestión de la excelencia, apertura de mercados y administración de recursos humanos.

Dado que esta política busca ampliar la base tributaria con empresas que puedan cubrir los costos de ser formal, es preciso postergar a las microempresas de subsistencia y focalizarnos en las MYPE de acumulación. En ese sentido, primero se determinó a partir del 
universo afectado (MYPE informales, 2016), el porcentaje de MYPEs de subsistencia $(77,6 \%)$ y el de MYPEs de acumulación (22,4\%). A partir de este último grupo (población objetivo), ascendente a 442, 683 empresas con ventas superiores a 17 UIT - considerando que el valor de 17 UIT es el volumen de ventas mínimo para cubrir el costo de una Canasta Básica de Consumo (CBC)- se procedió a diferenciar dos estratos según el volumen de ventas; MYPEs de acumulación simple:] 17 - 50 UIT] y MYPEs de acumulación ampliada:] $50-1700$ UIT].

Formulándose las estrategias siguientes:

- Estrategia - OE1: Se plantea la creación de un fondo de financiamiento para la canalización de créditos a las micro y pequeñas empresas de acumulación ampliada por un período de 3 años, a una tasa de interés referencial de $10 \%$ en promedio anual, con la participación de entidades financieras nacionales e internacionales.

- Estrategia - OE2: aplicar exoneración tributaria a las microempresas de acumulación simple que se formalicen con el programa durante los dos primeros años, empezando a tributar al tercer año de su formalización.

- Estrategia - OE3: Se mantiene la exoneración de los gastos registrales y se reduce el costo de los gastos notariales para las micro y pequeñas empresas que se formalizan y constituyen como persona jurídica.

- Estrategia - OE4: Implementación de un Programa de capacitación integral para los conductores de las MYPE, sobre la base de una plataforma virtual para la capacitación masiva (campus virtual MYPE) y la participación de Universidades e institutos en la provisión de la capacitación presencial.

Se determina la sostenibilidad de la política propuesta bajo el enfoque de gestión estratégica con creación de valor público, al cumplir con las tres dimensiones del triángulo estratégico de Moore: Dimensión Sustantiva, se determina que la informalidad es un problema de interés público, que afecta a un importante sector de la población con necesidades insatisfechas; Dimensión Política, se identificaron los actores afectados por la política y se ha logrado el balance político con las estrategias adecuadas para los actores con tendencia negativa; Dimensión Operativa, se establece que la política es viable con el apoyo 
y recursos de diferentes instituciones públicas involucradas con el problema de la informalidad en el país.

El impacto de la política se observa en la ampliación de la base tributaria, no sólo reflejada en un incremento del número de empresas registradas en SUNAT, si no que éstas pertenecen a los estratos de acumulación con mejores condiciones para impulsar su crecimiento empresarial y mejorar su competitividad, en consecuencia, mayor rentabilidad y capacidad para asumir los costos permanentes de la formalidad, entre éstos el pago de los impuestos tributarios. Así, de implementarse la política, se generará un incremento en la base tributaria del segmento MYPE de 13\% en el primer año, $15 \%$ en el segundo y $17 \%$ en el tercer año, así como el incremento de la recaudación MYPE en 11\% en promedio anual durante los tres primeros años del programa.

Entre las conclusiones y recomendaciones podemos mencionar que, la estrategia de simplificación de procesos y facilitación implementada por la SUNAT no es suficiente para incentivar la formalización de las MYPE; asimismo, se recomienda que la SUNAT debe operar un cambio en su Plan Estratégico Institucional a fin de incorporar objetivos y actividades orientadas a promover los incentivos propuestos para la formalización de las MYPE, mejorando la percepción de éstas y de la ciudadanía en general, de que la institución está comprometida con la sostenibilidad y crecimiento de aquéllas, como base fundamental para una efectiva ampliación de la base tributaria e incremento de la recaudación. 


\section{ÍNDICE}

RESUMEN EJECUTIVO O........................................................................ 6

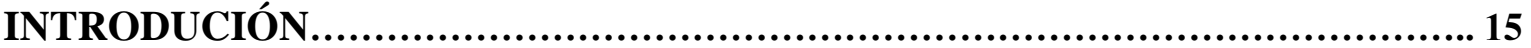

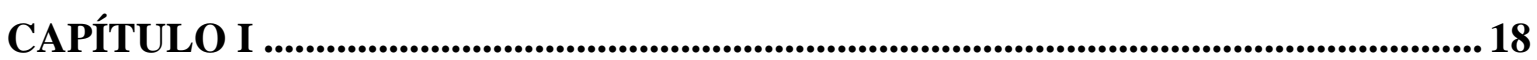

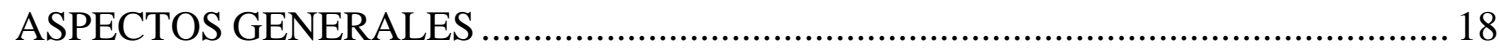

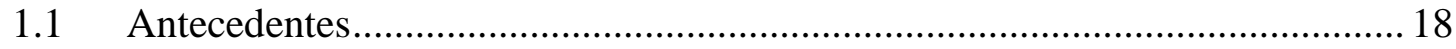

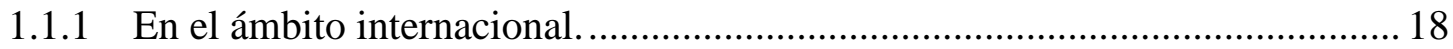

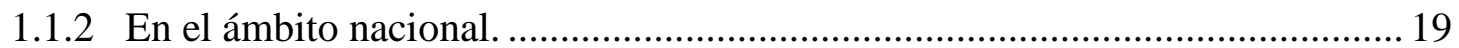

1.1.3 La recaudación tributaria y la base tributaria en el Perú. ……………………... 23

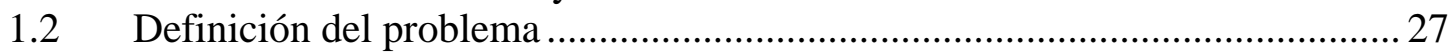

1.2.1 Objetivo General del Proyecto. ....................................................................... 44

1.2.2 Objetivos Específicos del Proyecto. ………………………………………..... 44

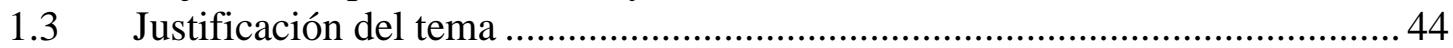

1.4 Alcances y limitaciones ............................................................................. 47

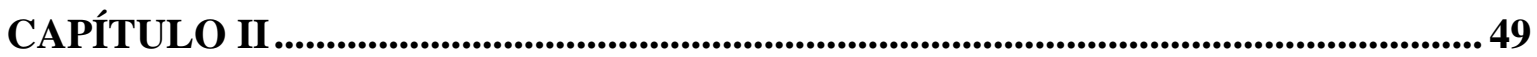

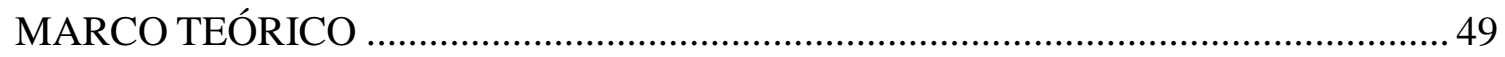

2.1 Creación de valor público en la gestión pública............................................. 49

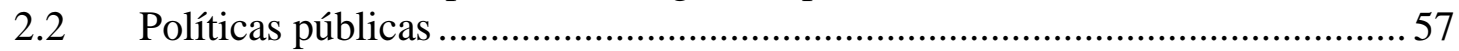

2.1.1 Definición de políticas públicas. ................................................................... 57

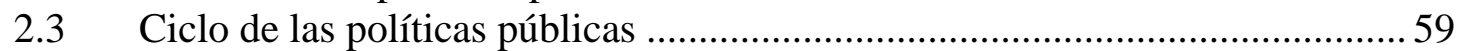

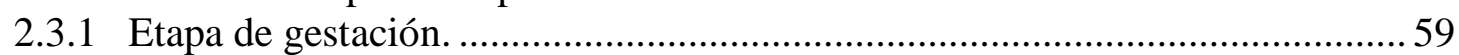

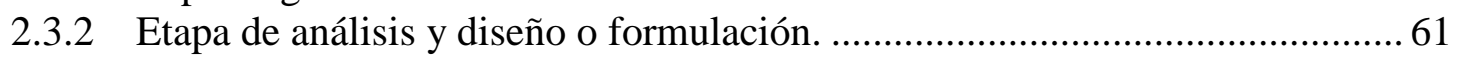

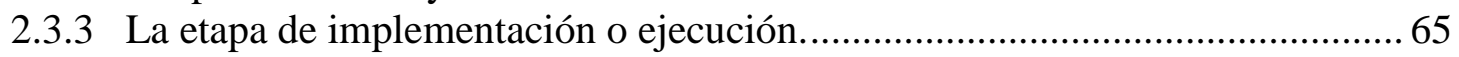

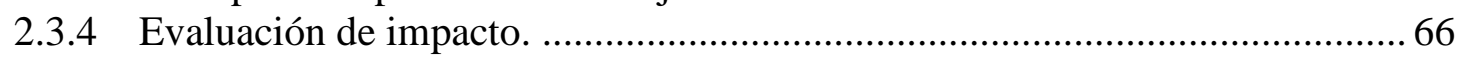

2.4 Enfoque integrado de políticas públicas ............................................................. 67

2.5 Planificación estratégica del sector público..................................................... 77

2.5.1 Componentes del proceso de planificación estratégica....................................... 78

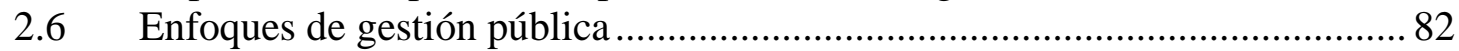

2.6.1 Tendencias de la Gestión Pública................................................................... 82

CAPÍTULO III ...................................................................................................................8

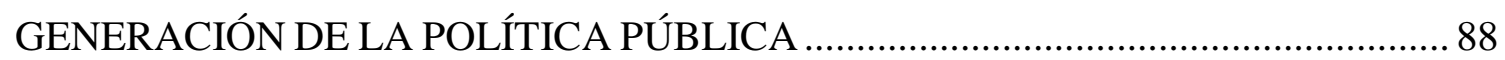

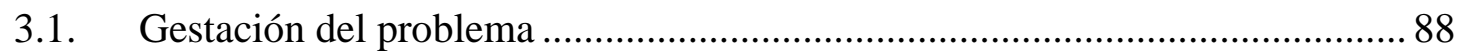

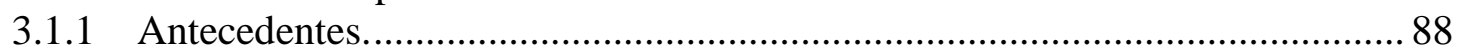

3.1.2 Contexto interno y externo - agenda gubernamental ....................................... 93

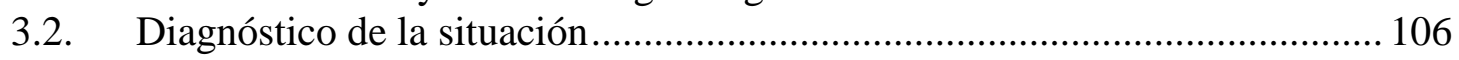

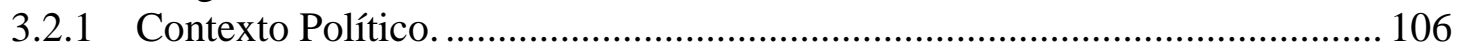

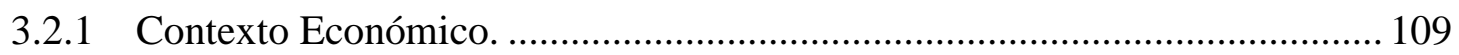

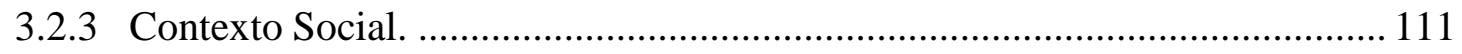

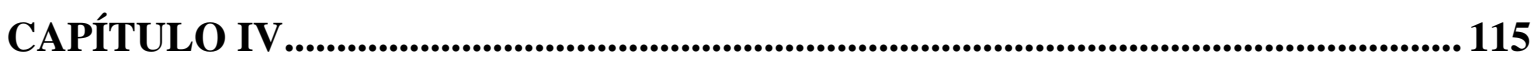

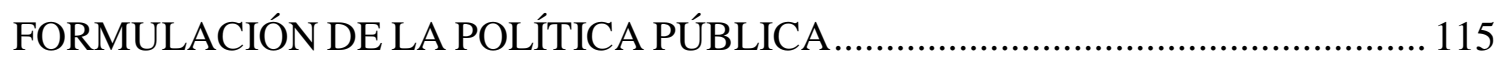

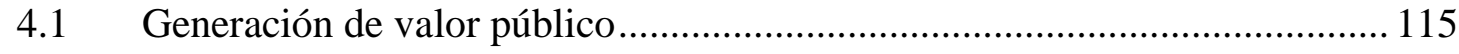

4.1.1 Dimensión Sustantiva de la Política................................................................ 116

4.1.2 Dimensión Operativa de la Política........................................................... 117

4.1.3 Dimensión Política de la Política. ............................................................... 120

4.2 Enfoque integrado de políticas públicas ...................................................... 132 
4.2.1 Identificación de Políticas de Apoyo............................................................... 132

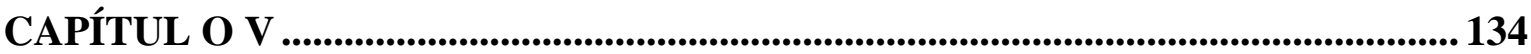

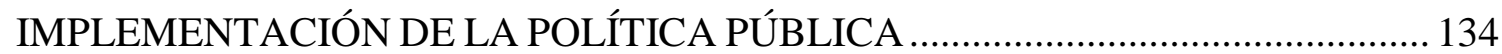

5.1 Planificación estratégica de la política con enfoque de valor público........... 134

5.1.1 Elaboración de la Gestión Estratégica de la Política......................................... 134

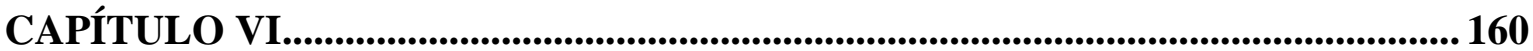

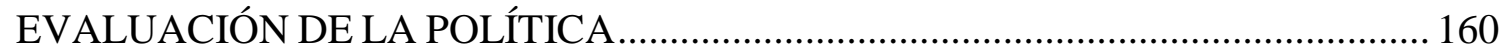

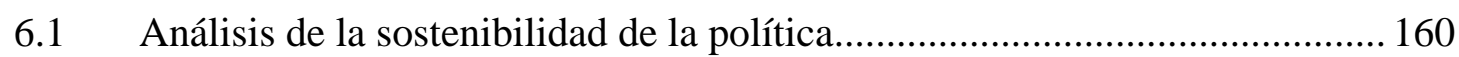

6.2 Evaluación del impacto de la política......................................................... 160

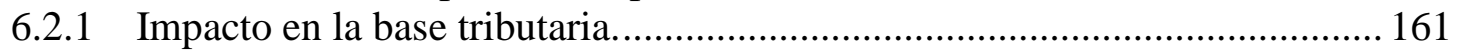

6.3 Evaluación de las Autoridades de la Institución Pública de la Política Pública

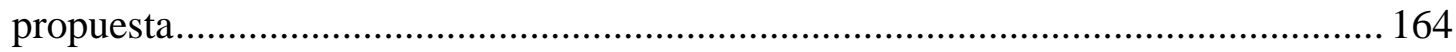

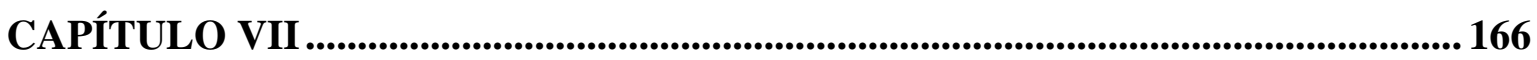

EL ROL DE LAS ORGANIZACIONES DE LA SOCIEDAD CIVIL - OSC EN LAS

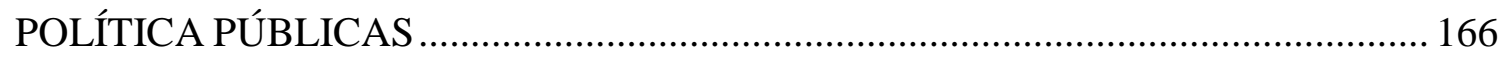

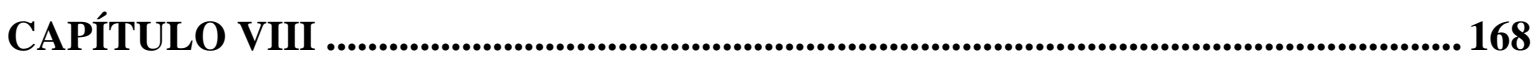

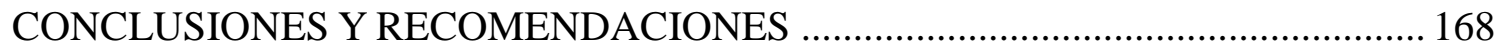

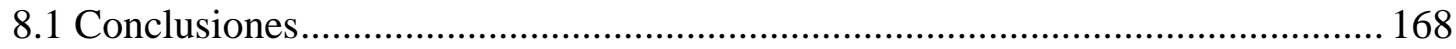

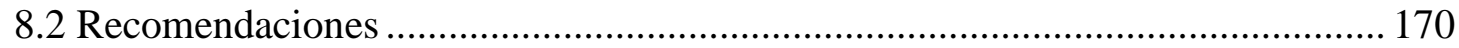

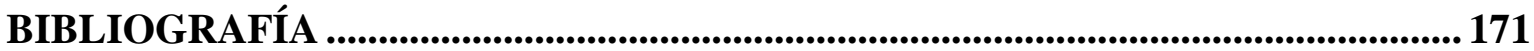

\section{ÍNDICE DE GRÁFICOS}

Gráfico 1: Ingresos tributarios del Gobierno Central............................24

Gráfico 2: Ingresos tributarios del Gobierno Central, 2007-2016_................25

Gráfico 3: Ingresos tributarios del Gobierno Central,2015......................26

Gráfico 4: Distribución de las unidades productiva de la Economía Peruana.......30

Gráfico 5: Evolución PBI Sector Informal, 2007-2018_...........................30

Gráfico 6: Participación del empleo informal por sector............................31

Gráfico 7: Participación del sector informal en el PBI............................32

Gráfico 8: Distribución de unidades productivas informales..........................32

Gráfico 9: Perú: Empresas según tamaño de ventas, 2014 (\% del total de empresas) 33

Gráfico 10: Perú: Empleo informal por tamaño de empresas...........................34

Gráfico 11: Régimen MYPEs Tributario, enero- abril de 2017.....................43

Gráfico 12: Factores determinantes de la competitividad sistémica..................70

Gráfico 13: Fases del proceso de Planificación Estratégica............................79

Gráfico 14: Actividades de planificación y tipos de indicadores.......................81 
Gráfico 15: Dinámica de la Oferta de Oficinas y créditos, 2011-2015.............95

Gráfico 16: Constitución de empresas en línea.....................................106

Gráfico 17: Unidades Informales No Agropecuarias y Razón por la cual No se ha

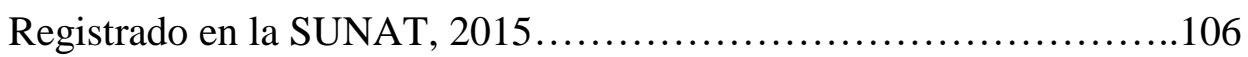

Gráfico 18: Productividad laboral por hora trabajada............................110

\section{ÍNDICE DE CUADROS}

Cuadro 1: Primera lámina de la Línea de Acción $N^{\circ}$ 1.4. : Promoción y Acceso a Servicios..................................................... 38

Cuadro 2: Primera lámina de la Línea de Acción No 1.3.1. : Servicios de Desarrollo Empresarial del Plan MYPE 2005-2009...........................39

Cuadro 3: Características Mipymes.......................................40

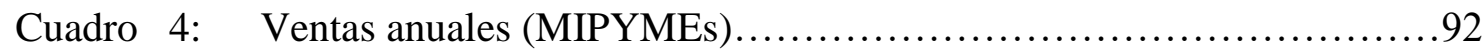

Cuadro 5: Regímenes a los que se pueden acoger las MYPE. Adaptado de sección emprender de SUNAT ......................................... 99

Cuadro 6: Dimensiones de la estrategia organizativa..........................115

Cuadro 7: Actores políticos................................................ 123

Cuadro 8: $\quad$ Intereses de los actores......................................... 125

Cuadro 9: $\quad$ Grado de poder de los actores................................... 127

Cuadro 10: Perú: Empleo informal por tamaño de empresas.......................131

Cuadro 11: Relación Objetivos Estratégicos Sectoriales e Institucionales............135

Cuadro 12: $\quad$ Matriz Estratégica de Gestión......................................158

\section{ÍNDICE DE TABLAS}

Tabla 1: $\quad$ Base Tributaria según tamaño de contribuyentes......................26

Tabla 2: $\quad$ Base Tributaria según tipo de contribuyentes, Mayo 2017.............27

Tabla 3: $\quad$ Estimación del número de micro y pequeñas empresas informales......40

Tabla 4: $\quad$ Acceso al financiamiento por estrato...............................96

Tabla 5: $\quad$ Perú: MYPEs formales según rango de ventas, 2016..................139 
Tabla 6: Perú: MYPES formales según volumen de ventas de subsistencia y acumulación, 2016.

Tabla 7: $\quad$ Mypes informales de acumulación, según volumen de ventas, estrato y tamaño, 2016.

Tabla 8: Distribución de población objetivo según estrategia de formalización...159

Tabla 9: $\quad$ MYPEs de acumulación formales y a formalizar - impacto en la base tributaria.

Tabla 10: $\quad$ MYPEs de acumulación formalizadas, según tamaño y año de formalización (tres primeros años)

Tabla 11: Recaudación MYPE formal (en miles de soles) según tamaño de empresa, 2016 .164

Tabla 12: $\quad$ Recaudación MYPE formal 2015-2016 y proyectada (Año 1 - año 3), según tamaño de empresa a formalizar (en miles de soles) 164

\section{ÍNDICE DE FIGURAS}

Figura 1: Generación de Valor Público......................................56

Figura 2: $\quad$ Estimación de población objetivo................................ 141 



\section{INTRODUCCIÓN}

La Superintendencia Nacional de Aduanas y de Administración Tributaria (SUNAT) desempeña un rol estratégico en la búsqueda del bien común del país, al ser la responsable de gestionar los ingresos fiscales necesarios para financiar el presupuesto público y, con ello, contribuir a la estabilidad fiscal y macroeconómica. Para cumplir esta misión, la administración tributaria debe alcanzar las metas de recaudación fijadas por el gobierno central, enfrentando el problema estructural de la informalidad.

Las estadísticas reflejan que las empresas tanto en el sector formal como informal se mantienen concentradas en unidades productivas pequeñas de bajos niveles de ventas, de hecho, el $99.8 \%$ de la base tributaria de la SUNAT se compone de medianos y pequeños contribuyentes, asimismo, el $40 \%$ de microempresas vende un máximo de 2 UIT al año, lo que revela que la mayoría de empresas en el Perú no tiene el nivel de productividad suficiente para cubrir los múltiples costos de ser formal (salario mínimo y beneficios laborales, impuestos, trámites, etc.), más aún de enfrentar altos costos financieros, entre otros factores que limitan su crecimiento.

A pesar de los diferentes dispositivos legales que ha producido el Estado para incentivar la formalización de las micro y pequeñas empresas, integrados en el Texto Único Ordenado de la Ley de Impulso al Desarrollo Productivo y al Crecimiento Empresarial, aprobado por el Decreto Supremo N 013-2013-PRODUCE, el sector informal permanece arraigado y afectando la vida económica del país; así, en el año 2016 se estimaba que el 53,2\% de las MYPEs era informal, un punto mayor al registrado en el año 2015 (52,3\%). Los avances macroeconómicos registrados en el Perú en la primera década del presente siglo tampoco hicieron retroceder al sector informal, más bien ha ido adoptando nuevas formas y afectando a diversos grupos vulnerables, sumado al efecto externo de que dichas actividades congestionan la infraestructura pública sin contribuir con los ingresos tributarios necesarios para abastecerla. 
La SUNAT en el marco de su misión ha generado estrategias para incrementar la recaudación, las que de cierto modo ha generado en la ciudadanía la percepción desfavorable de una administración tributaria coercitiva, con una cultura predominantemente fiscalizadora e incisiva respecto a una limitada base tributaria, desincentivando la aún temerosa iniciativa de formalización. Con el fin de corregir estas distorsiones y con el objetivo de ampliar la base tributaria y reducir la informalidad, la autoridad tributaria se ha focalizado en los últimos años, en reducir los costos de los contribuyentes y simplificar sus procesos para dar mejores servicios, conjuntamente con la modernización e integración de los canales de atención y programas de educación tributaria, en una búsqueda por priorizar la facilitación más que la sanción. Pero aquello tampoco ha logrado un cambio sustantivo.

Pues la decisión de un individuo o empresario de participar o no en el sector informal obedece a un análisis costo beneficio; en tanto la formalización no ofrezca beneficios palpables para el microempresario, éste no la considera necesaria, sustentándose en que siendo negocios pequeños de bajos volúmenes de ventas, no podrían asumir la carga de impuestos si se registra, sin perjuicio de la situación de inequidad que se genera, pues un alto porcentaje de negocios informales se crean por necesidad económica o como opción de última instancia al no encontrar trabajo, lo que se ve reflejado en el alto porcentaje de MYPEs -más del 75\%- con ingresos de subsistencia que apenas logra cubrir una canasta básica de consumo.

El porcentaje de MYPEs que logra generar ingresos que le permita cubrir los costos de producción o - en un menor porcentaje- que logra generar cierta rentabilidad con excedentes para realizar inversiones en capital, también debe afrontar el mismo dilema, incluyendo probablemente otras variables como el nivel de inversión y desarrollo tecnológico en el sector económico donde se desenvuelve, pues de no ser vital como sucede en los sectores donde mayormente se concentran las unidades productivas informales (Comercio, Transportes y comunicaciones y Otros servicios), optarán por un simple análisis costo beneficio; pues aún siguen siendo pequeñas unidades productivas de baja o mediana productividad, organizadas de manera básica y sin capacidad de acceso al crédito financiero a tasas competitivas. 
En esta situación de inequidad y de importancia sustantiva para la población del país no sólo para los empresarios MYPE- que no ha resuelto ni el crecimiento económico del Perú, es el Estado el responsable de brindar los incentivos necesarios para revertirla. En ese contexto, se propone a la SUNAT como organismo público capaz de generar valor público, impulsar una política que atienda de manera integral las principales necesidades de las MYPE: mejores condiciones financieras, tributarias, simplificación administrativa y de fortalecimiento de capacidades, con el objetivo de incentivar su formalización con incentivos que ayuden a disminuir los costos de formalizarse, pero también a mejorar su productividad y competitividad y con ello alcanzar la rentabilidad que se requiere para una real ampliación de la base tributaria.

El presente proyecto está estructurado en ocho capítulos. El primero refiere los aspectos generales de la informalidad, definiendo entre otros, el problema y los objetivos a alcanzar; en el segundo capítulo se describe y analiza el marco teórico en el que se sustenta la propuesta; el tercero aborda los antecedentes y contexto en el que se genera la política pública; en el cuarto capítulo se formula la política pública bajo el enfoque de gestión estratégica con generación de valor público y enfoque integrado de políticas públicas; en el quinto, se desarrolla la implementación de la política pública y en el sexto la evaluación de la misma; en el sétimo capítulo se analiza brevemente el rol de las organizaciones de la sociedad civil en las políticas públicas y en el octavo se registran las conclusiones y recomendaciones. Finalmente, se señala la bibliografía revisada para el desarrollo del presente trabajo de tesis. 


\section{CAPÍTULO I}

\section{ASPECTOS GENERALES}

\subsection{Antecedentes}

\subsubsection{En el ámbito internacional.}

En el trabajo de investigación, La economía informal: definiciones, teorías y políticas, 2012, realizada por Martha Alter, se menciona algunos puntos importantes:

- El término “sector informal” fue introducido en 1971, por el antropólogo británico Keith Hart en su estudio sobre actividades de bajos ingresos entre personas sin formación que emigraban del norte de Ghana a la capital, Accra, y no encontraban empleo asalariado.

- La Organización Internacional del Trabajo (OIT) organizó una serie de grandes "misiones de empleo" multidisciplinarias a varios países en desarrollo; siendo la primera misión de empleo la desarrollada en Kenia en 1972, de acuerdo a la cual se registraba la existencia de un dinámico "sector informal” que incluía empresas rentables y eficientes, así como actividades marginales.

- La percepción inicial de los estudiosos y de la OIT era que el sector informal al ser fuente de empleo, reduciría la pobreza. Surgiendo dos corrientes de pensamiento respecto a la informalidad en los países en desarrollo; una que proponía que el sector informal no estaba vinculado al sector formal, por tanto, desaparecería cuando el país alcanzara suficiente crecimiento económico y desarrollo industrial; la otra, argumentaba que el sector informal se expandiría, pues el desarrollo industrial podría seguir un patrón distinto en los países en desarrollo. 
- En la década de 1980 se amplían los debates sobre el sector informal a raíz de la reorganización de la producción en Europa y Norteamérica; la producción se estaba reorganizando en unidades económicas de pequeña escala, descentralizadas y más flexibles, lo que daría inicio a la informalización de las relaciones de empleo. Durante los años 1990, la globalización de la economía contribuiría a la informalización de la fuerza laboral en muchos sectores y países.

- En la XV Conferencia Internacional de Estadísticos del Trabajo (CIET) en 1993, se adopta por consenso por primera vez la definición de Sector Informal, la que comprendía el empleo y la producción realizada en empresas pequeñas no constituidas en sociedad o de capital no registrado. En 2003, la CIET amplió la definición estadística internacional de Sector Informal. La economía informal se determinaría en relación a dos universos de la macroeconomía: los establecimientos de las unidades de producción y los empleos de los trabajadores. El sector informal se refería al primer universo; el empleo informal, al segundo.

La Conferencia Internacional del Trabajo (CIT), en su 104.a reunión desarrollada el 12 de junio de 2015 en Ginebra, adopta la Recomendación 204 sobre la transición de la economía informal a la economía formal; en la misma se reconoce que la mayoría de las personas que se incorporan a la economía informal no lo hacen por elección, sino como consecuencia de la falta de oportunidades en la economía formal y por carecer de otros medios de sustento; afirmando que la transición de la economía informal a la economía formal es esencial para alcanzar un desarrollo incluyente y hacer efectivo el trabajo decente para todos.

\subsubsection{En el ámbito nacional.}

En el ámbito nacional identificamos algunos hechos de importancia:

- Con el Decreto Ley N 21435 del 25 de febrero de1976, Ley de la pequeña empresa del sector privado, se aprueba el primer régimen especial de promoción al sector de pequeñas empresas; definiéndola en función de sus montos de ventas anuales por 
actividad económica, con la finalidad de acogerse a un sistema tributario preferencial (impuesto único) y a otros incentivos para su desarrollo. El fin de esta ley era promover y contribuir con la generación de empleo y riqueza para el desarrollo nacional.

Con leyes posteriores se normaron aspectos relativos al funcionamiento y constitución de las micro y pequeñas empresas (MYPEs), tales como el funcionamiento de empresas Unipersonales y Empresas Individuales de Responsabilidad Limitada, estableciendo límites en su ejercicio - que han ido variando en el tiempo-respecto al número de trabajadores contratados y el volumen de ventas anuales.

- En 1986, Hernando de Soto publica un estudio sobre la informalidad en el Perú -El otro sendero- en el que sustenta el papel de la informalidad en la economía, la política y la cultura peruana; esta publicación generó una mayor atención sobre la informalidad en la agenda pública del país. De acuerdo a La economía informal: definiciones, teorías y políticas, 2012, realizada por Martha Alter, "de Soto es catalogado dentro de la escuela de pensamiento "Legalista", cuya teoría causal de la economía informal es que un sistema legal hostil lleva a los trabajadores independientes a operar de manera informal con sus propias normas informales y extrajudiciales".

- El 8 de junio de 1988 se crea la Superintendencia Nacional de Administración Tributaria (SUNAT)1, aprobado con Ley $\mathrm{N}^{\circ} 24829$, con la finalidad de administrar, aplicar, fiscalizar y recaudar los tributos internos con excepción de los municipales, así como proponer y participar en la reglamentación de las normas tributarias. De esta manera, la SUNAT desempeña un rol estratégico en el Estado al ser la institución responsable de gestionar los ingresos fiscales necesarios para financiar el presupuesto público.

- En 1993, el Instituto Nacional de Estadística e Informática INEI, incluyó por primera vez un módulo del sector informal en la Encuesta Nacional de Ingresos y Gastos de los

\footnotetext{
${ }^{1}$ Hoy Superintendencia Nacional de Aduanas y Administración Tributaria (SUNAT).
} 
Hogares de 1993-1994 (ENAPROM), que sirvió de base para que en el año 2001 se implementara el modulo del trabajador independiente en la Encuesta Nacional de Hogares (ENAHO). Esta nueva información debía servir de base para profundizar el conocimiento sobre el sector informal peruano.

Los esfuerzos por tratar de medir la economía informal, en relación a dos universos de la macroeconomía: sector informal y empleo informal, han culminado con un estudio publicado por el INEI en mayo de 2014, que identifica tanto el empleo como el sector informal, como dos caras de la misma moneda. De acuerdo al INEI, dicho documento denominado Producción y Empleo Informal en el Perú - Cuenta Satélite de la Economía Informal 2007 - 2012, marca un hito en la historia estadística del país, pues por primera vez se publica un estudio identificando tanto el empleo como el sector informal, y sus principales agregados económicos, dentro del marco conceptual de las Cuentas Nacionales.

Como parte de la investigación, asimismo se han revisado otros estudios sobre el tema de la informalidad en el contexto nacional, relevándose la siguiente información:

- En el 2007, Marino, en su tesis "Análisis de los factores causantes de la informalidad y evasión tributaria de las MYPEs comercializadores de ropa en Piura", realiza una investigación a fin de conocer las causas asociadas a la evasión tributaria en las empresas formalmente constituidas y la informalidad en las MYPEs del departamento de Piura, para ello entrevistó y encuestó a una muestra conformada por MYPEs comerciantes de Piura, y planteó como hipótesis que la informalidad es producto de la combinación de la carga impositiva elevada, del drástico régimen de sanciones y de la ineficiencia de los trámites burocráticos. Este estudio comprendió a las MYPEs piuranas dedicadas a la comercialización de ropa, registradas en el REMYPE.

Entre las conclusiones más importantes de esta tesis, se señala que las principales causas que dan origen al alto índice de informalidad y evasión tributaria son las siguientes: Complejidad de trámites burocráticos, alto costo de formalización, excesiva carga 
tributaria y complejidad de las obligaciones (relacionado con la magnitud de las sanciones tributarias).

Por otro lado, menciona que las causas de la evasión tributaria, se encuentran relacionadas con la economía informal, corrupción, restricciones de financiamiento de los contribuyentes y la alta concentración del ingreso. Relaciona, además estas altas tasas de evasión, con la cultura de cumplimiento tributario que existe en el país, ello debido a factores que incentivan estas conductas, como la percepción de que la carga tributaria no es justa, la desconfianza respecto al destino de lo recaudado, entre otros.

- En la tesis "Factores que propician la informalidad de las PYMES y su incidencia en el desarrollo de éstas en la provincia de Trujillo, distrito de Victor Larco" (2016), Mendiburu, realiza una investigación que tiene por objetivo identificar y cuantificar los factores que propician la informalidad de las PYMES y como incide la informalidad en el desarrollo de éstas, a fin de medir las consecuencias para el pequeño empresario peruano, para ello utilizó como técnicas: encuestas, entrevistas, análisis de contenido y observación, partiendo de la hipótesis siguiente: La informalidad incide negativamente en el desarrollo de las PYMES informales. A partir de una población de 1,475 comerciantes informales, realizó un muestreo probabilístico al azar para tomar dos muestras: Muestra 1, de 305 pymes con menos de 5 trabajadores; Muestra 2, de 90 pymes con más de 5 trabajadores.

Dentro de sus conclusiones más importantes se puede mencionar que: una de las principales causas que obligan a una empresa a pertenecer en el sector informal es la excesiva carga impositiva, además de la excesiva regulación de la fuerza laboral. Por otro lado, señala que, la informalidad reduce el bienestar de los agentes económicos involucrados, además de limitar el crecimiento del país, debido a la evasión de los impuestos.

Mendiburu, recomienda la generación de políticas públicas, orientadas a dar prioridad a las contrataciones estatales a las MYPEs, la creación de líneas especiales de crédito, acceso a regímenes especiales de impuestos y contribuciones, el desarrollo de un programa de capacitación técnica más profundo, entre otros. Señala finalmente, que el acceso a estos 
beneficios, debe estar sujeto a que el microempresario registre su negocio como persona jurídica.

- Calúa, García, y García, en su tesis "Factores que desalientan la formalización de los empresarios de las micro y pequeñas empresas del sector de manufactura del rubro textil en el Emporio Comercial de Gamarra" (2017), investiga por qué los empresarios en referencia no se formalizan a pesar de los esfuerzos del Estado en ofrecerles mejores incentivos; planteándose la siguiente hipótesis: "El desconocimiento de los beneficios que brinda el Estado y los factores socioculturales son las principales razones por las que los empresarios de las micro y pequeñas empresas del sector manufactura del rubro textil ubicadas en el Emporio Comercial de Gamarra no tienden a formalizarse”.

La investigación señala como razones por las que los referidos empresarios no tienden a formalizarse, las siguientes: los entrevistados no están de acuerdo con la gestión que realiza la SUNAT ni la Municipalidad de la Victoria, desconocen los trámites administrativos, carecen de proyección hacia el futuro, tendencia al facilismo en obtener las cosas y el rechazo a SUNAT, además de la poca familiaridad de los empresarios con la tecnología. Por otro lado, se pueden mencionar que el desconocimiento de los beneficios que brinda el Estado es uno de los factores determinantes para que los empresarios MYPE bajo estudio no se formalicen, lo que está vinculado a la difusión ineficaz por parte del Estado y a la desconfianza que sienten de las entidades del Estado.

\subsubsection{La recaudación tributaria y la base tributaria en el Perú.}

La presión tributaria es un indicador cuantitativo que relaciona los ingresos tributarios de una economía y el Producto Bruto Interno (PBI). Los principales impuestos que componen los ingresos tributarios del Gobierno Central en el Perú son: el Impuesto a la Renta (IR), el Impuesto General a las Ventas (IGV), el Impuesto Selectivo al Consumo (ISC) y el impuesto a la importación (aranceles). 
En el período 2010-2016, la mayor cifra de ingresos tributarios recaudados por la SUNAT fue en el año 2014, con S/ 95,394 millones - excluidas las devoluciones- lo que representó un crecimiento de $6.7 \%$ respecto al 2013 y de $47.9 \%$ respecto a lo recaudado en el año 2010. Sin embargo, en los dos años siguientes el crecimiento de la recaudación disminuyó desde su pico más alto, en $-5.7 \%$ en el 2015 y $-6.7 \%$ en el año 2016.

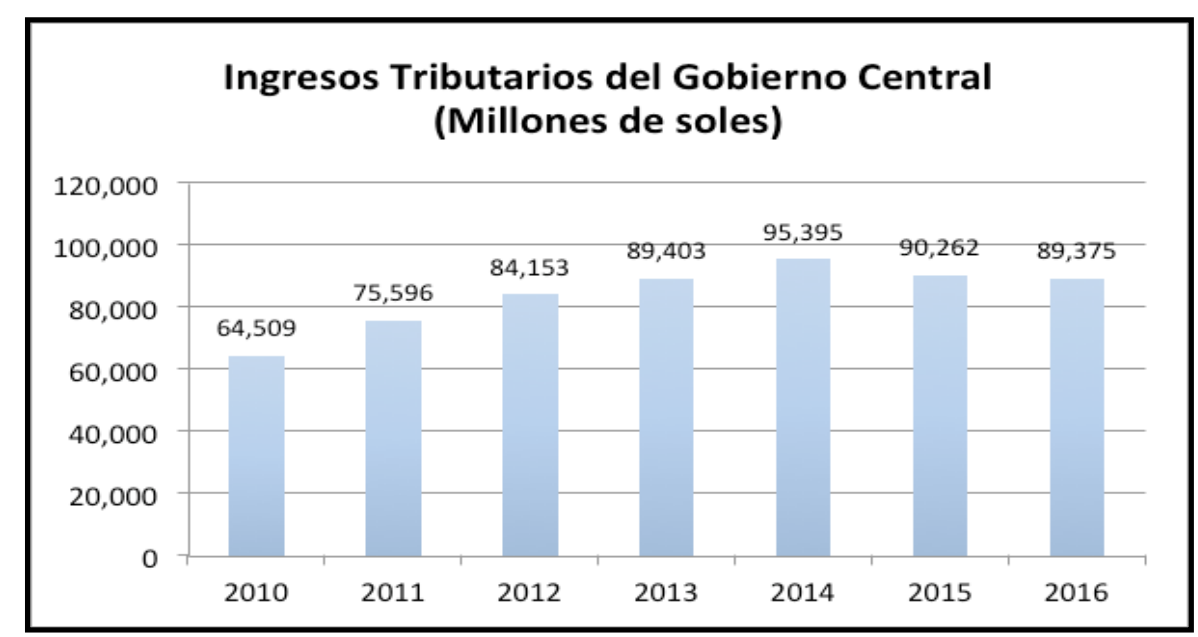

Gráfico 1. Ingresos tributarios del Gobierno Central (millones de soles). Nota: Se excluyen las devoluciones.

Fuente: SUNAT, Estadísticas y estudios, 2016.

En consecuencia, la presión tributaria de $16.6 \%$ alcanzada en el año 2014 cayó a una tasa de $13.6 \%$ en el 2016, la más baja en el período analizado y muy lejana al $18 \%$ que se planteó como meta al 2016, a inicios del gobierno del presidente Ollanta Humala.

El Instituto Peruano de Economía indica: "La presión tributaria es mayor cuando menor son la evasión y la informalidad de una economía” (2017, p. s.p.). Respecto a las cifras mostradas, observamos que ante similares montos recaudados en el 2013 y 2016, la caída en la presión tributarias de 16,6\% a 13,6\% nos indicaría un aumento en la evasión tributaria e informalidad, sin perjuicio de las menores tasas de crecimiento del PBI. 


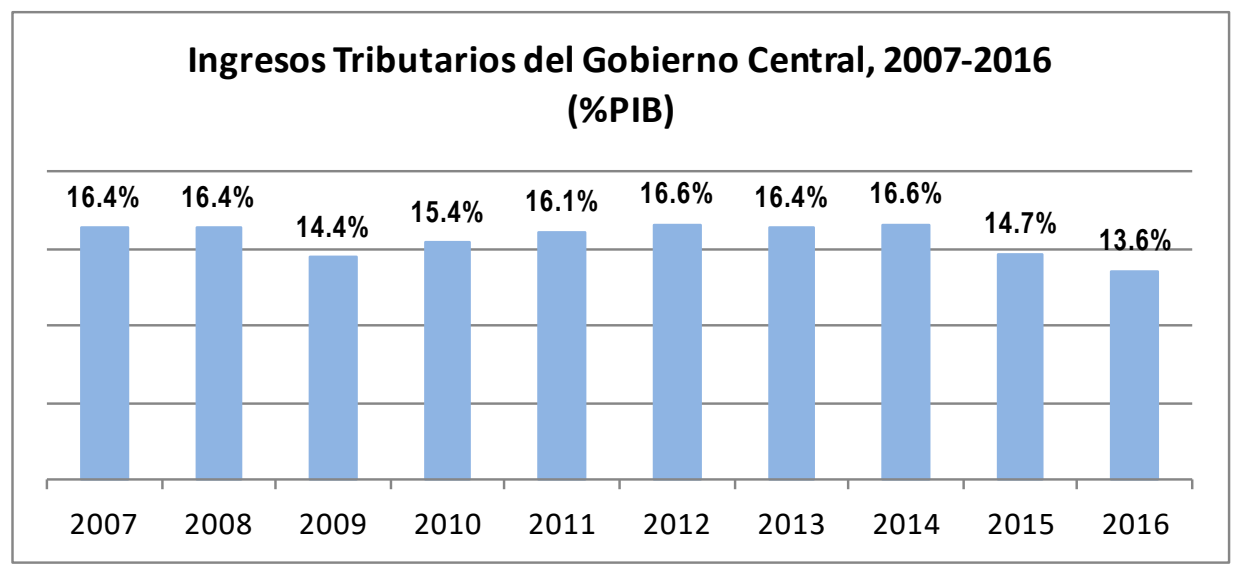

Gráfico 2. Ingresos tributarios del Gobierno Central, 2007-2016.

Fuente: Adaptado de SUNAT, BCRP, 2016.

Entre 12 países de la región (Gráfico 3), en el año 2015 nuestro país fue el sétimo en el orden de mayor presión tributaria, por debajo de Colombia, Chile, Bolivia, Argentina, Uruguay y Brasil. Observándose que aun con una tasa de 16,6\%, la más alta alcanzada hasta la fecha, solo le hubiera permitido subir un puesto respecto al grupo de referencia.

El Instituto Peruano de Economía sostiene: “que las economías industrializadas suelen tener mayor presión tributaria que las economías en desarrollo" (2017, s.p.). En ese sentido, vale resaltar el contradictorio caso que representa México, siendo una economía industrializada respecto al Perú, registre una tasa de presión tributaria inferior de $12.5 \%$, que la ubica en la posición diez (Gráfico 3). Al respecto es preciso señalar que dicho país afronta altas tasas de informalidad, generando que a mediados del 2014 el Gobierno mexicano implemente políticas de incentivos para reducir la informalidad, que comprende entre otros: acceso a servicios médicos, pensión de retiro, acceso a créditos hipotecarios, créditos financieros a tasas preferenciales, así como descuentos en el pago de impuestos (Arellano, S., 2014). 


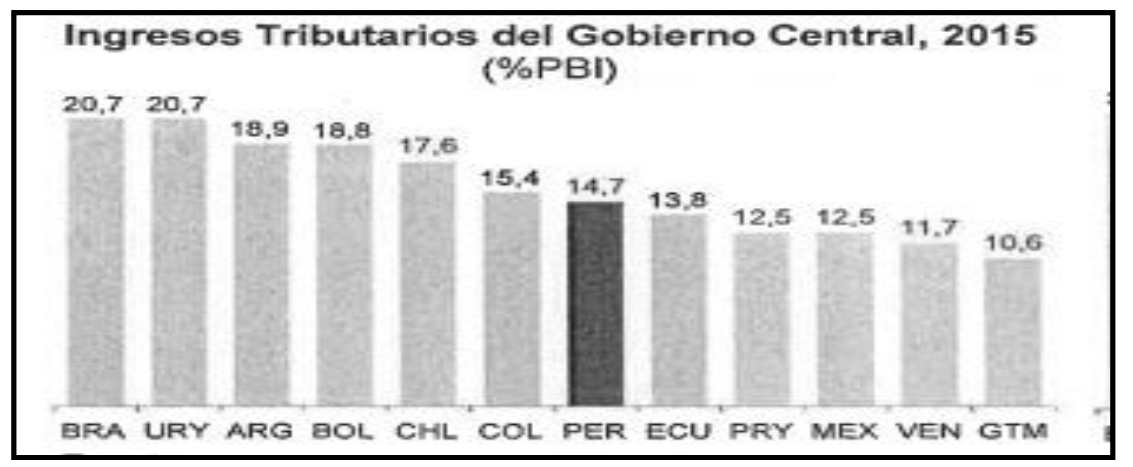

Gráfico 3. Ingresos tributarios del Gobierno Central, 20158 (\%PBI). Fuente: ITGG: WEO, 2016.

Por otra parte, la base tributaria de la SUNAT en el año 2016, según tamaño de empresa, se compone de 8 millones 219 mil ( 99.8\%) Medianos y Pequeños contribuyentes y 12 mil 800 (0.2\%) Principales contribuyentes (ver tabla 1).

Tabla 1.

Base Tributaria según tamaño de contribuyentes (en miles).

\begin{tabular}{|l|r|r|r|r|r|r|r|}
\hline \multicolumn{1}{|c|}{ Concepto } & \multicolumn{1}{c|}{$\mathbf{2 0 1 0}$} & \multicolumn{1}{c|}{$\mathbf{2 0 1 1}$} & \multicolumn{1}{c|}{$\mathbf{2 0 1 2}$} & \multicolumn{1}{c|}{$\mathbf{2 0 1 3}$} & \multicolumn{1}{c|}{$\mathbf{2 0 1 4}$} & \multicolumn{1}{c|}{$\mathbf{2 0 1 5}$} & \multicolumn{1}{c|}{$\mathbf{2 0 1 6}$} \\
\hline Contribuyentes con RUC 1/ & 5116.8 & 5623.4 & 6167 & 6652 & 7112.3 & 7670.5 & 8232 \\
\hline Principales contribuyentes 2/ & 14.2 & 14.3 & 13.9 & 13.6 & 13.7 & 13 & 12.8 \\
\hline Mediano y Pequeños contribuyentes & 5102.6 & 5609.1 & 6153.2 & 6638.4 & 7098.6 & 7657.5 & 8219.1 \\
\hline
\end{tabular}

Nota: 1/ Sólo contribuyentes activos. 2/ La totalidad de los principales contribuyentes pertenecen al Régimen General.

Fuente: SUNAT, Estadísticas y estudios, 2016.

Según tipo de contribuyente, en mayo de 2017, el 74\% de la base tributaria- que asciende a 8 millones 400 mil contribuyentes- son personas naturales sin negocio y $26 \%$ corresponde a personas jurídicas, generadoras de renta empresarial (Tabla 2). 
Tabla 2.

Base Tributaria según tipo de contribuyentes, Mayo 2017 (en miles).

\begin{tabular}{|c|c|c|c|}
\hline & MAYO 2017 & $\%$ & \\
\hline PERSONA NATURAL & $6,262.6$ & $74 \%$ & \\
\hline PERSONA NATURAL SIN NEGOCIO & $6,262.6$ & & \\
\hline PERSONA JURIDICA & $2,146.0$ & $26 \%$ & $100 \%$ \\
\hline PERSONA NATURAL CON NEGOCIO & $1,675.2$ & $20 \%$ & $78 \%$ \\
\hline SOCIEDAD ANONIMA & 258.2 & $3 \%$ & $12 \%$ \\
\hline SOC.RESP.LIMITADA & 56.3 & $1 \%$ & $3 \%$ \\
\hline EMP.INDIVIDUAL RESP.LIMITADA & 156.3 & $2 \%$ & $7 \%$ \\
\hline TOTAL & $8,408.6$ & $100 \%$ & \\
\hline
\end{tabular}

Fuente: SUNAT, 2017.

Del segmento de personas jurídicas, el 78\% corresponde al tipo de contribuyente Persona Natural con Negocio, explicando fundamentalmente la existencia de un alto porcentaje de micro y pequeñas empresas.

\subsection{Definición del problema}

La finalidad primordial de la SUNAT es proporcionar los recursos necesarios para la sostenibilidad fiscal y la estabilidad macroeconómica, recaudando los ingresos necesarios para financiar el gasto público. Para cumplir esta misión, la administración tributaria debe alcanzar las metas de recaudación fijadas por el gobierno central, enfrentando el problema estructural de la informalidad.

En la literatura económica no existe consenso sobre la definición de economía informal. Para entender el accionar de la SUNAT en este contexto nos apoyamos en la clasificación propuesta por Dreyden y College citado por De la Roca y Hernandez (2004), quienes, con una visión legalista de la informalidad, la dividen en tres componentes: (1) evasión tributaria "pura", (2) economía irregular, y (3) actividades ilegales.

La evasión tributaria "pura" la entendemos como aquella que se genera cuando los individuos o empresas registrados en la SUNAT no reportan todos los ingresos generados por la actividad económica registrada. La economía irregular comprendería la producción de bienes 
y servicios legales en establecimientos que no están registrados en la administración tributaria, por tanto, no declaran ni pagan impuestos; las actividades ilegales, son aquellas vinculadas a la producción y comercialización desarrollada fuera del marco legal; en este último caso, la SUNAT tendría intervención cuando por ejemplo realiza el control aduanero y detecta que la mercancía ha sido contaminada con drogas (De la Roca, J., y Hernandez, M., 2004).

Respecto a la reducción de la evasión tributaria "pura”, la SUNAT está implementando nuevos mecanismos que le permitirán un mayor y mejor acceso a la información de los contribuyentes, tales como el uso masivo de comprobantes de pago electrónico y la administración centralizada de las operaciones de los contribuyentes a través de la Cuenta del contribuyente, lo que mejorará la efectividad en los procesos de recaudación y control de la deuda, entre otros mecanismos.

En relación a las empresas de "economía irregular" no registradas en la administración tributaria, siendo un problema multidimensional como se analiza más adelante, son menos eficaces las estrategias de simplificación y facilitación desplegadas por ésta, y sus intervenciones por el contrario, han generado en la ciudadanía la percepción desfavorable de una SUNAT coercitiva, con una cultura predominantemente fiscalizadora, incisiva respecto a una limitada base tributaria, desincentivando la aún temerosa iniciativa de formalización de microempresarios.

En este contexto, el presente proyecto se interesa en el componente de economía irregular o simplemente "economía informal". Para comprender este marco revisamos las estadísticas sobre economía informal elaboradas por el Instituto Nacional de Estadística e Informática (INEI) del Perú. De acuerdo a esta entidad la economía informal tiene dos dimensiones distintas y a la vez complementarias: el sector y el empleo. Por un lado, el sector informal se refiere a las unidades productivas de los hogares que producen bienes y servicios en pequeña escala, no llevan contabilidad, sus gastos productivos no se distinguen de sus gastos familiares, no tienen acceso a créditos formales, tienen una organización rudimentaria y no están registradas en la administración tributaria. 
Por otro lado, el empleo informal hace referencia a aquellos empleos que no gozan de beneficios estipulados por la legislación laboral como seguridad social, gratificaciones, vacaciones pagadas, licencias por maternidad, etc., que se presentan en el sector informal, y en menor medida, en el sector formal (INEI, 2014).

Para efecto del presente proyecto, utilizamos la definición de Sector Informal adoptado por el INEI:

El sector informal se refiere a las empresas de hogares (unidades productivas no constituidas en sociedad, excluyendo las cuasisociedades ${ }^{2}$ ) que no están registradas en la administración tributaria (SUNAT). Para el caso de las unidades productivas del sector primario ${ }^{3}$ no constituidas en sociedad, se considera que todas pertenecen al sector informal. (2014, p. 48).

De acuerdo a la Encuesta Nacional de Hogares (ENAHO) del periodo 2007-2015, realizada por INEI, en el año 2015 el sector informal en el Perú alcanzó el 76.5\% de las unidades productivas del país (ver Gráfico 4), con una producción informal que alcanzó el 19\% del PBI, cifra por encima del promedio de la región de América Latina (13.5\%) y de países como Brasil (12.3\%), México (10.4\%), Argentina (9.2\%) y Chile (4.8\%). Lo que nos grafica la magnitud de las actividades informales en nuestro país.

Asimismo, del 2007 al 2015 el PBI del país creció en 88.5\%; en dicho período la participación del sector informal se mantuvo en promedio en 19\%, con una absorción de mano de obra de $55.9 \%$ de la PEA, es decir, utilizando cerca de las 3/5 partes de la cantidad de trabajo, su valor agregado representa menos de 1/5 del PBI, lo que nos sugiere fundamentalmente la baja productividad del sector informal y una deficiente asignación de recursos. (Ver Gráfico 5).

\footnotetext{
${ }^{2}$ Entiéndase por cuasisociedad toda empresa no constituida en sociedad "que funciona en todo -o en casi todo- como si fuera una sociedad" (cf. ONU et al. 2009, inciso 4.42).

${ }^{3}$ El sector primario incluye las actividades Agricultura, Pesca y Minería.
} 


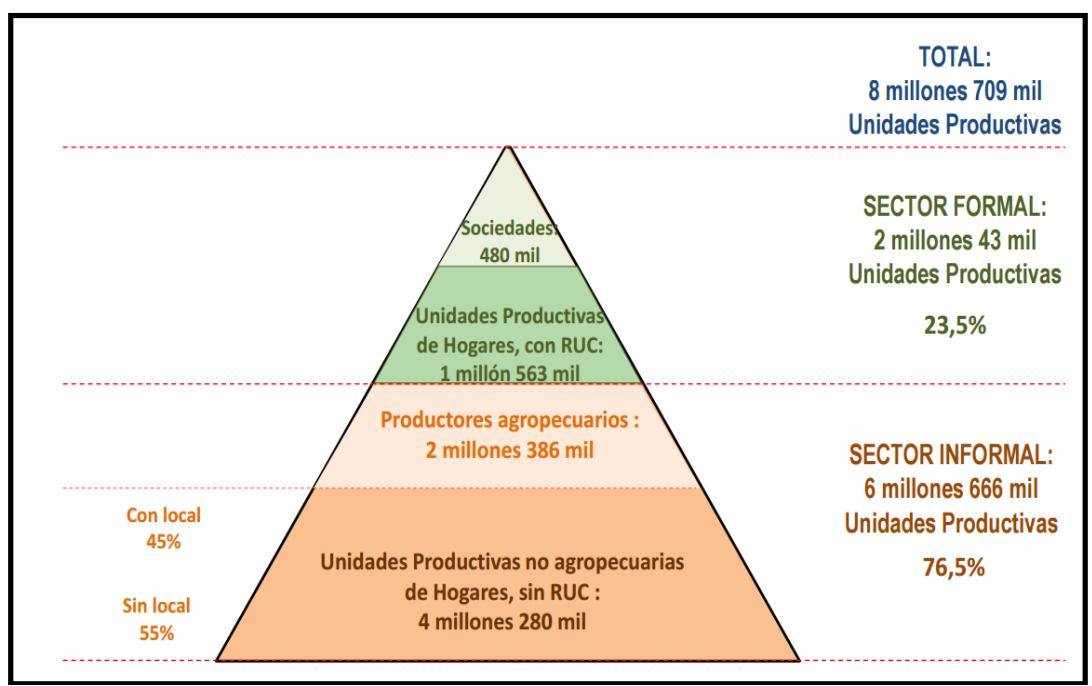

Gráfico 4. Distribución de las unidades productiva de la Economía Peruana.

Fuente: INEI - ENAHO, 2015.

Es de destacar también que el empleo informal ascendería a 73.2\% de la PEA, agregando el empleo informal que se desempeña en el sector formal, de aproximadamente 17.2\%. (Ver Gráfico 6).

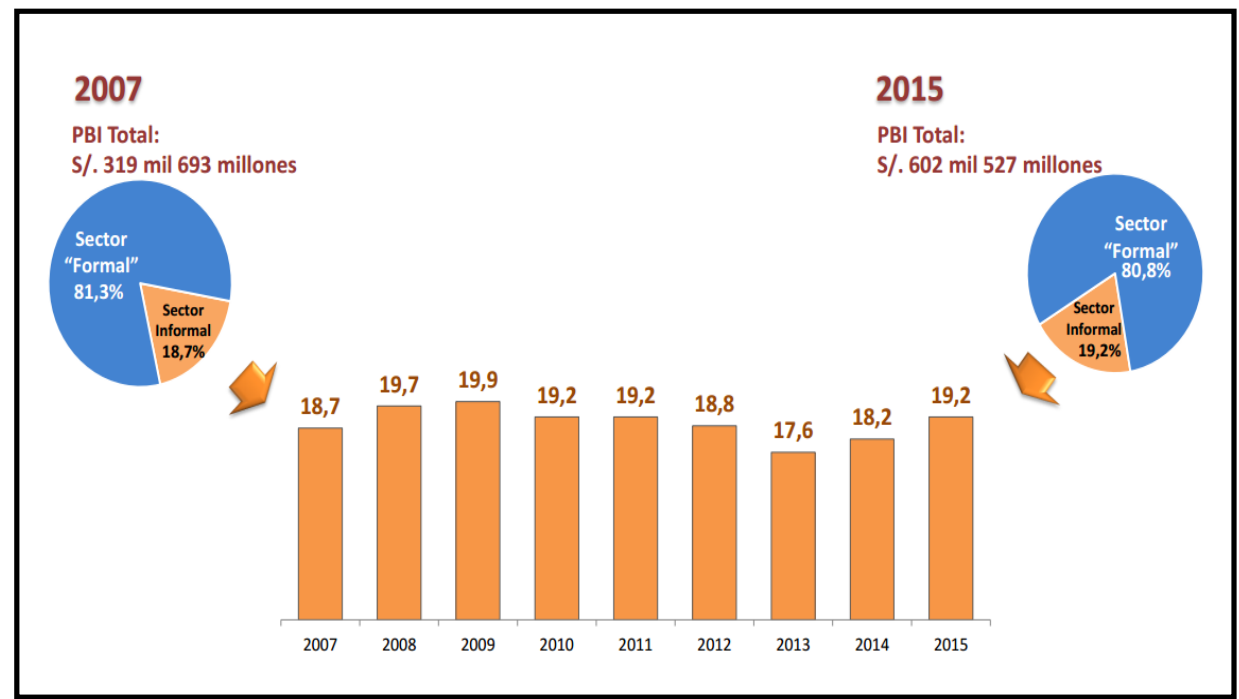

Gráfico 5. Evolución PBI Sector Informal, 2007-2015.

Fuente: INEI , Producción y empleo informal en el PERÚ Cuenta Satélite de la Economía Informal 2007-2015, 2016. 


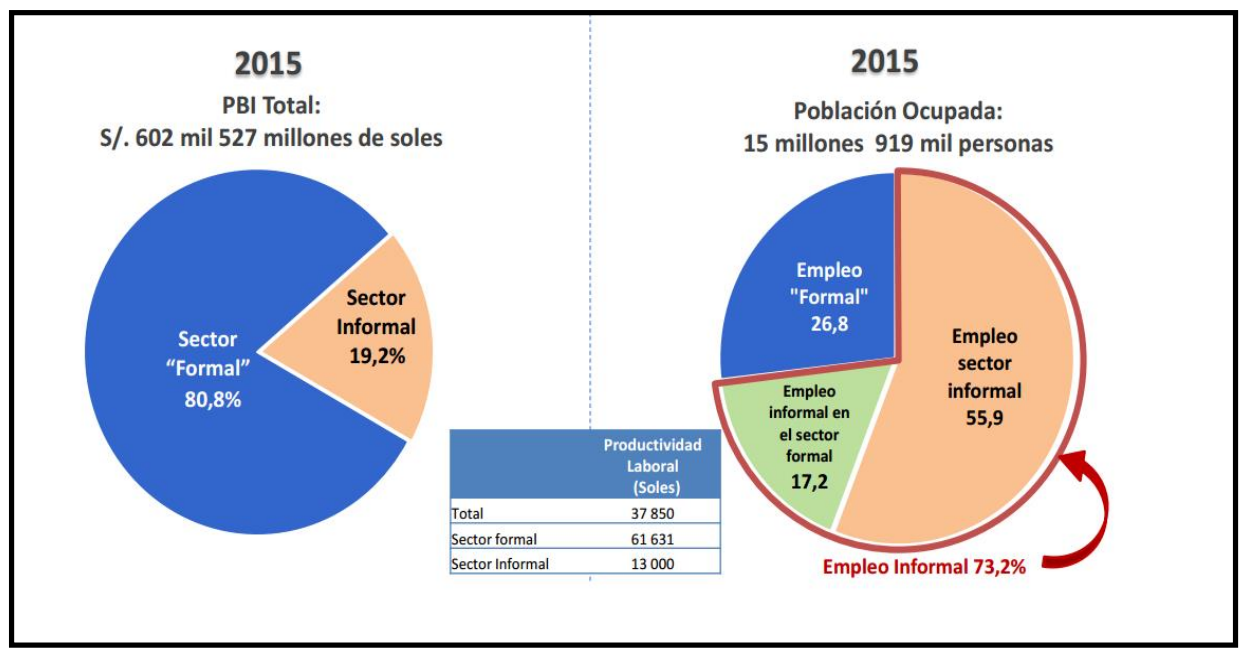

Gráfico 6. Participación del empleo informal por sector.

Fuente: INEI, Producción y empleo informal en el PERÚ Cuenta Satélite de la Economía Informal 2007-2015: Encuesta Nacional de Hogares, 2016.

Respecto a la producción informal según actividad económica, sobresale que la actividad Agropecuario y Pesca es eminentemente informal, con el 91\% del PBI que genera; lo que explicaría los bajos salarios de los trabajadores, mayormente jornaleros, y el alto nivel de pobreza en esta actividad, especialmente en las zonas andinas. Otros sectores con alta participación de PBI informal son: Restaurantes y Alojamiento (40\%), Transportes y Comunicaciones (36\%), Comercio (26\%) y Construcción (19\%).

Asimismo, las unidades productivas informales, excluyendo a las de la actividad Agropecuario y Pesca, se concentran en las actividades de Comercio (22,4\%), Transportes y Comunicaciones $(14,2 \%)$ y Otros servicios $(9,2 \%)$, resaltando que la actividad Restaurantes y Alojamiento que concentra sólo al 7,7\% de las unidades productivas informales, genere el $40 \%$ del PBI de esta actividad, destacándose una mayor productividad respecto a las demás actividades en el sector informal, caracterizándose asimismo por ser de alta absorción de mano de obra. 


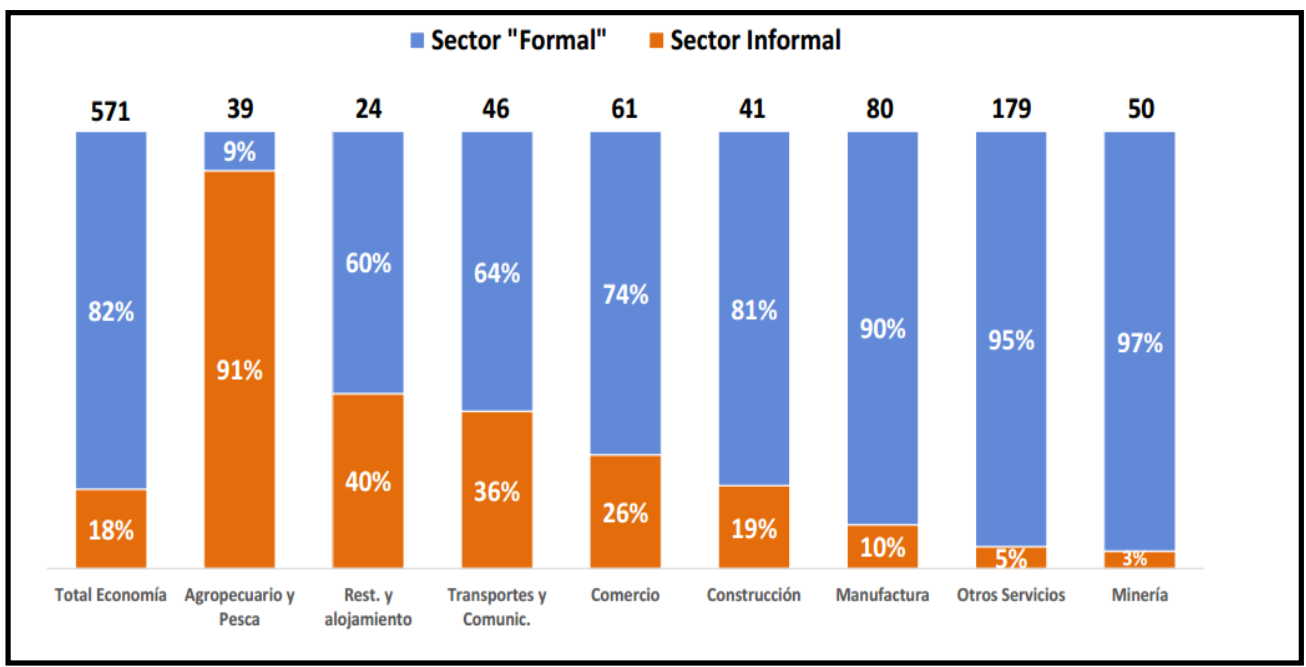

Gráfico 7. Participación del sector informal en el PBI: Actividad económica 2014 (Miles de millones de soles corrientes).

Fuente: INEI, Producción y empleo informal en el PERÚ Cuenta Satélite de la Economía Informal 2007-2015, 2016.
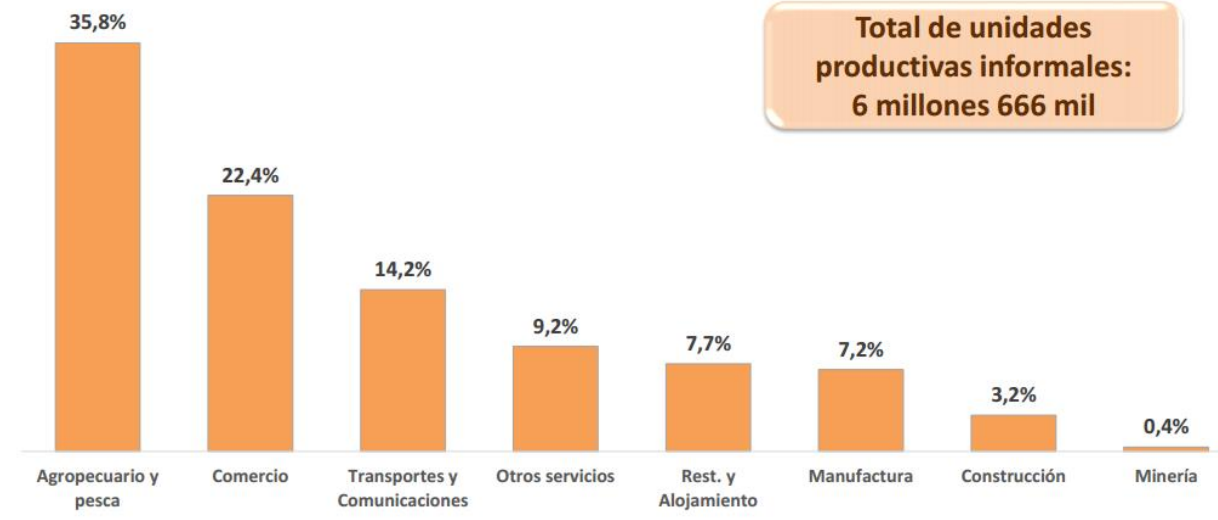

Gráfico 8. Distribución de unidades productivas informales.

Fuente: INEI, Producción y empleo informal en el PERÚ Cuenta

Satélite de la Economía Informal 2007-2015, 2016.

En el Gráfico 9 se aprecia que las empresas en general se mantienen concentradas en unidades productivas pequeñas de bajos niveles de ventas, lo que crea condiciones desfavorables para la generación de empleo formal. En el Gráfico 10 se observa que la empresa de 1 a 5 personas labora con $90 \%$ de empleo informal, las empresas de 6 a 10 personas con el $84.8 \%$, lo que va disminuyendo con el mayor tamaño de la empresa, así, aquellas de 31 a más empleados, solo registra un 23.3 de empleo informal. 
Esto revelaría por una parte, que la mayoría de empresas en el Perú - y en particular las micro y pequeñas empresas- no tiene el nivel de productividad suficiente para cubrir los múltiples costos de ser formal (salario mínimo y beneficios laborales, impuestos, trámites, etc.), además de tener que enfrentar los altos costos financieros; por otra, que las medidas que se implementen para incentivar la formalización de las MYPE requerirá identificar el nivel de desarrollo de éstas, pues aquellas con ingresos de subsistencia estarán más alejadas de la posibilidad de cumplir con los costos de la formalidad.

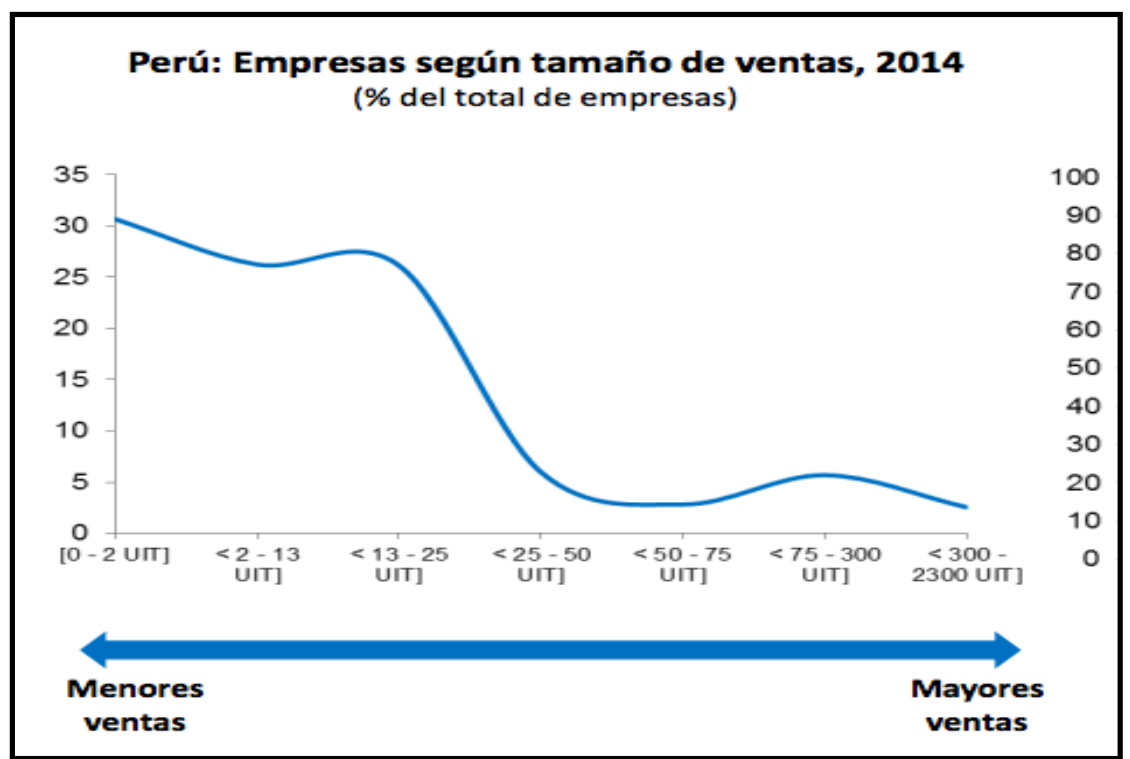

Gráfico 9. Perú: Empresas según tamaño de ventas, 2014 (\% del total de empresas).

Fuente: Produce, INEI. 


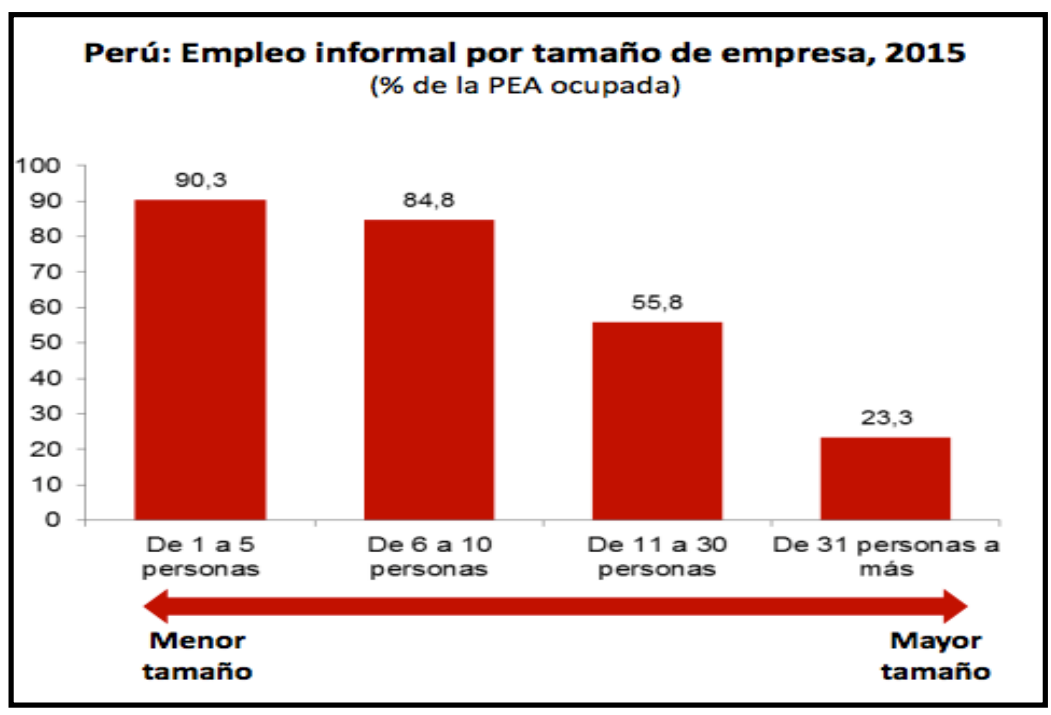

Gráfico 10. Perú: Empleo informal por tamaño de empresas, 2015 (\% de la PEA ocupada).

Fuente: PRODUCE - INEI.

Al respecto, el Sistema Integrado de Apoyo a la Pequeña Empresa BMI \& Banco Multisectorial de Inversiones (1997), realiza la siguiente clasificación de microempresas, la cual nos ayudará a plantear la propuesta de política pública:

\section{a. Microempresa de subsistencia}

Se caracterizan por tener una muy baja productividad que sólo les permite obtener ingresos de subsistencia; para cubrir por lo general necesidades básicas, como alimentación, vivienda y educación. Generalmente conducida por mujeres, es el segmento de mayor concentración con alrededor del $70 \%$ de las microempresas, principalmente ubicadas en el sector de comercio minorista y servicios. En este segmento no existe un límite claro entre los ingresos de la unidad económica y los gastos del hogar. 


\section{b. Microempresa de acumulación simple}

Son aquellas con ingresos que alcanzan a cubrir los costos de producción, pero sin otorgar al empresario una rentabilidad suficiente para realizar inversiones en capital; comprendería a alrededor del $26 \%$ de microempresas y representaría la fase de tránsito hacia una microempresa de acumulación ampliada, sin embargo, también podría representar una declinación hacia el segmento anterior.

\section{c. Microempresa de acumulación ampliada}

Son microempresas con una productividad elevada que les permite generar excedente para invertir en el crecimiento de la empresa. Sólo representan aproximadamente al 4\%; caracterizándose por desempeñarse en sectores más competitivos como el de manufactura, donde se le exige mayor productividad y calidad, con una mayor inversión en tecnología. (1997, p. 2-3).

En este contexto, es imprescindible que los estímulos ofrecidos para incentivar la formalización deben ser percibidos como superiores a los costos de acceso y permanencia en el sector formal, sabiendo que los servicios ofrecidos por el gobierno son deficientes y cuando, además, la presencia y control del estado son débiles.

De conformidad al artículo 59 $9^{\circ}$ de la Constitución Política del Perú, el Estado estimula la creación de riqueza y garantiza la libertad de trabajo, la libertad de empresa, comercio e industria y promueve las pequeñas empresas en todas sus modalidades. En ese marco, se han desarrollado varios intentos de establecer un tratamiento preferencial a la creación de la micro y pequeñas empresas, mediante normas específicas promulgadas desde los años setenta.

Pero recién con la promulgación de la Ley $\mathrm{N}^{\circ} 28015$ "Ley de Promoción y Formalización de la Micro y Pequeña Empresa" en Julio de 2003, se dispone entre otras cosas, la implementación de un Plan Nacional MYPE. Así, con Decreto Supremo Nº 009-2006-TR del 
8 de mayo del 2006 se aprueba el Plan Nacional de Promoción y Formalización para la Competitividad y Desarrollo de las MYPEs 2005 - 2009; convirtiéndose en el primer instrumento orientador de las acciones que deben desarrollar las diversas instancias públicas y privadas (Ministerio de Trabajo Promoción y Empleo, 2005) que promueven a las micro y pequeñas empresas en un contexto de economía globalizada.

El Plan MYPE correspondiente al período 2005-2009 incluyó como uno de los puntos centrales de análisis a la informalidad, la cual en el año 2004 se estimaba en un $75 \%$ de las MYPEs a nivel nacional; asimismo, estableció sus líneas de acción en función a tres ejes de desarrollo y tres estratos empresariales identificados. Los ejes estratégicos fueron los siguientes:

1. Fomento de la competitividad y productividad de las MYPEs.

2. Entorno favorable para la formalización y calidad del empleo.

3. Institucionalidad público-privada de promoción de la MYPEs y los nuevos emprendimientos.

El Consejo Nacional para el Desarrollo de la Micro y Pequeña empresa (2009) indica los estratos empresariales del Plan MYPE 2005-2009, en función a la capacidad de autofinanciamiento para su crecimiento y generación de valor económico, productividad y capacidad de innovación y diferenciación, como sigue:

\section{a) MYPE de Acumulación}

Las micro y pequeñas empresas de acumulación, tienen la capacidad de generar utilidades para mantener su capital original e invertir en el crecimiento de la empresa, tienen mayor cantidad de activos y se evidencia una mayor capacidad de generación de empleo remunerado. 


\section{b) MYPE de Subsistencia}

Las micro empresas de subsistencia son aquellas unidades económicas sin capacidad de generar utilidades, en detrimento de su capital, dedicándose a actividades que no requieren de transformación substancial de materiales o deben realizar dicha transformación con tecnología rudimentaria. Estas empresas proveen un "flujo de caja vital", pero no inciden de modo significativo en la creación de empleo adicional remunerado.

\section{c) Nuevos Emprendimientos}

Los nuevos emprendimientos se entienden como aquellas iniciativas empresariales concebidas desde un enfoque de oportunidad, es decir como una opción superior de autorrealización y de generación de ingresos. El plan nacional enfatiza el hecho que los emprendimientos apuntan a la innovación, creatividad y cambio hacia una situación económica mejor y más deseable ya sea para iniciar un negocio como para mejorar y hacer más competitivas las empresas. (2005, p. 19).

Cada eje estratégico se estructuró en líneas de acción para cada uno de los estratos MYPE, sustentado en las necesidades y demandas particulares de cada estrato, sin embargo observamos que ciertas líneas de acción, como la referente a Promoción y Acceso a Servicios Financieros (Cuadro 1), fueron generalizadas para los tres segmentos, sin observar que un microempresa de subsistencia tiene una baja probabilidad de cumplir con los altos costos de financiamiento; pues si bien se promueve disminuir los costos de transacción y brindar seguridad jurídica para los contratos y garantías, así como ampliar la cobertura de créditos, no se menciona ninguna acción encaminada a disminuir las altas tasas de interés que deben afrontar las MYPEs. 
Así también, de las Matrices por Eje de Intervención y Estrato que componen el Plan, en las cuales se señalan los objetivos, metas, acciones y las instituciones responsables de darles viabilidad; observamos que la implementación puede haberse visto afectada por la numerosa cantidad de responsables por cada objetivo y una falta de precisión en los indicadores para el monitoreo respectivo (ver cuadro 1 y 2 ).

\begin{tabular}{|c|c|c|c|c|c|}
\hline ESTRATOS & OBJETIVOS & METAS & ESIRAIEGIAS & ACCIONES & RESPONSABLES \\
\hline \multirow{6}{*}{ 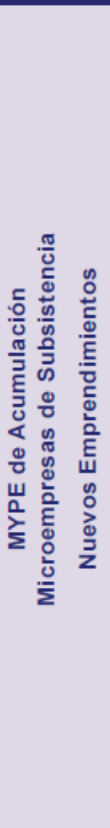 } & \multirow{3}{*}{$\begin{array}{l}\text { a. Disminuir las } \\
\text { asimetrias de } \\
\text { información } \\
\text { relacionado a la } \\
\text { oferta de servicios } \\
\text { financieros en un } \\
\text { mercado imperfecto. }\end{array}$} & $\begin{array}{l}\text { a.1. A fines del } 2008 \text { todas las } \\
\text { regiones del pais disponen de } \\
\text { información financiera de su } \\
\text { región adecuada para su } \\
\text { difusión. }\end{array}$ & \multirow{3}{*}{$\begin{array}{l}\text { Concertación a través del } \\
\text { CODEMYYE y los } \\
\text { COREMYPE. }\end{array}$} & $\begin{array}{l}\text { a.3.1.1. Promover reuniones de coordinación } \\
\text { con los agentes económicos del sector püblico y } \\
\text { privado que manejen información para } \\
\text { compartirla. }\end{array}$ & \multirow{3}{*}{$\begin{array}{l}\text { SBS IMTPE I } \\
\text { COFIDE I } \\
\text { COREMYPE I } \\
\text { CODEMYPE }\end{array}$} \\
\hline & & $\begin{array}{l}\text { a.2. Un } 50 \% \text { de las } \\
\text { Instituciones no reguladas } \\
\text { proporcione hasta el } 2008 \\
\text { información de prestatarios al } \\
\text { sistema de información en las } \\
\text { centrales de riesgo. }\end{array}$ & & \multirow[t]{2}{*}{$\begin{array}{l}\text { a.3.2.1. Difusión de la información financiera a } \\
\text { traves de las diferentes instituciones públicas y } \\
\text { privadas. }\end{array}$} & \\
\hline & & $\begin{array}{l}\text { a.3. Un } 30 \% \text { de las MYPE } \\
\text { puedan acceder a la } \\
\text { información al final del } 2008 .\end{array}$ & & & \\
\hline & \multirow{2}{*}{$\begin{array}{l}\text { b. Disminuir los } \\
\text { costos de transacción } \\
\text { y brindar seguridad } \\
\text { jurídica para la } \\
\text { contratos y garantias. }\end{array}$} & $\begin{array}{l}\text { b.1. A fines del } 2008 \text { se ha } \\
\text { desarrollado en las } \\
\text { principales regiones } \\
\text { sistemas de garantia } \\
\text { regional. }\end{array}$ & \multirow{2}{*}{$\begin{array}{l}\text { Difusión y debate del } \\
\text { proyecto de norma de } \\
\text { garantias. }\end{array}$} & $\begin{array}{l}\text { b.1.1.1. Concluir con la aprobación de las Ley y } \\
\text { el reglamento por el Congreso de la Repüblica e } \\
\text { implementar su ejecución. }\end{array}$ & \multirow{2}{*}{$\begin{array}{l}\text { SBS / COFIDE I } \\
\text { MTPE / GREMIOS } \\
\text { EMPRESARIALES }\end{array}$} \\
\hline & & $\begin{array}{l}\text { b.2. Al } 2008 \text { se han } \\
\text { incrementado en un } 30 \% \\
\text { las MYPE que atienden las } \\
\text { IMF con otros tipos de } \\
\text { garantias. }\end{array}$ & & $\begin{array}{l}\text { b.2.1.1. Promulgación del } \\
\text { reglamento.Promoción y difusión en MYPE e } \\
\text { IMF. }\end{array}$ & \\
\hline & $\begin{array}{l}\text { c. Ampliación de la } \\
\text { cobertura de créditos } \\
\text { dirigidos a las } \\
\text { MYPE. }\end{array}$ & $\begin{array}{l}\text { c.1. Al } 2006 \text { haber } \\
\text { implementado un } 10 \% \text { de } \\
\text { nuevos productos financieros } \\
\text { para la MYPE. }\end{array}$ & & $\begin{array}{l}\text { COFIDE en coordinación con las IFIs diseñarán } \\
\text { tecnología crediticia adecuada a la MYPE. }\end{array}$ & $\begin{array}{l}\text { COFIDE I } \\
\text { INSTITUCIONES } \\
\text { REGULADAS Y NO } \\
\text { REGULADAS I } \\
\text { CODEMYPE } \\
\end{array}$ \\
\hline
\end{tabular}

Cuadro 1. Primera lámina de la Línea de Acción No 1.4. : Promoción y Acceso a Servicios Financieros del Plan MYPE 2005-2009.

Fuente: PRODUCE, Matriz del Plan MYPE 2005-2009, p. 59. 


\begin{tabular}{|c|c|c|c|c|c|}
\hline ESTRATOS & OBJETIVOS & METAS & ESIRAIEGIAS & ACCIONES & RESPONSABLES \\
\hline 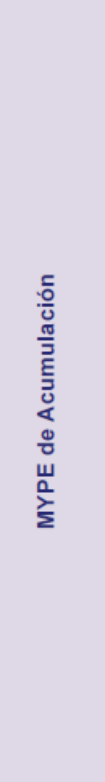 & $\begin{array}{l}\text { a. Contribuir a la } \\
\text { competitividad y } \\
\text { sostenibilidad de } \\
\text { las MYPE } \\
\text { en el mercado. }\end{array}$ & $\begin{array}{l}\text { a.2. Un } 50 \% \text { de las } \\
\text { MYPE atendidas con } \\
\text { algün SDE, aumentan } \\
\text { su productividad, en } \\
\text { por lo menos un } 20 \% \text {. } \\
\text { a.3. Un } 20 \% \text { de las } \\
\text { MYPE atendidas con } \\
\text { algün SDE mejoran su } \\
\text { ambiente y condiciones } \\
\text { de trabajo. }\end{array}$ & $\begin{array}{l}\text { a.1.1. Identificación y } \\
\text { focalización sectorial, por } \\
\text { regiones y cadenas } \\
\text { productivas, de las demanda } \\
\text { de SDE. } \\
\text { a.1.2. Promoción y desarrollo } \\
\text { de la demanda en los } \\
\text { empresarios de MYPE } \\
\text { facilitando su acceso a los } \\
\text { diversos tipos de SDE. } \\
\text { a.2.1. Fortalecimiento de los } \\
\text { proveedores, desarrollando sus } \\
\text { capacidades metodológicas, } \\
\text { técnicas y de gestión, y mejora } \\
\text { en la calidad de sus SDE } \\
\text { orientados a satisfacer la } \\
\text { demanda de las MYPE. } \\
\text { a.3.1. Coordinación y } \\
\text { concertación publico privado y } \\
\text { con la Cooperación } \\
\text { Internacional en el desarrollo } \\
\text { de los programas de SDE } \\
\text { orientados a las MYPE. } \\
\text { a.3.2. Incorporación dentro de } \\
\text { los programas de SDE a las } \\
\text { MYPE la evaluación y mejora } \\
\text { en las condiciones de trabajo } \\
\text { como un aspecto sustancial de } \\
\text { competitividad. }\end{array}$ & $\begin{array}{l}\text { a.1.1.1. Realizar estudios de mercado de SDE } \\
\text { analizando, monitoreando y evaluando } \\
\text { regularmente el desarrollo de la demanda y de la } \\
\text { oferta. } \\
\text { a.1.2.1. Afianzar, desarrollar y generar } \\
\text { mecanismos e instrumentos que faciliten su } \\
\text { acceso a los SDE. } \\
\text { a.1.2.2. Implementar sistemas de co-financiamiento } \\
\text { (Publico-empresario) de los SDE. } \\
\text { a.2.1.1. Generar mecanismos de trabajo conjunto } \\
\text { entre las empresas privadas, la Cooperación } \\
\text { Internacional y las entidades publicar en la } \\
\text { promoción y monitoreo de los SDE. } \\
\text { a.2.1.2. Apoyar el desarrollo y consolidación de } \\
\text { los sistemas de certificación y acreditación de la } \\
\text { calidad de los SDE de los proveedores. } \\
\text { a.3.1.1. Difundir y explicar el régimen laboral } \\
\text { especial para la MYPE dentro del conjunto de los } \\
\text { SDE. }\end{array}$ & $\begin{array}{l}\text { MTPE (DNMYPE- } \\
\text { PROMPYME) } \\
\text { PRODUCE, } \\
\text { PROMPEX, } \\
\text { MINAG } \\
\text { PCM } \\
\text { Consejo de } \\
\text { Competitividad } \\
\text { MED } \\
\text { UNIVERSIDADES } \\
\text { (públicas y } \\
\text { privadas) } \\
\text { Institutos superiores. } \\
\text { (püblicas y } \\
\text { privadas) } \\
\text { Gobiernos Regionales } \\
\text { Gobiernos Locales } \\
\text { Gremios empresariales } \\
\text { Proveedores de } \\
\text { SDE ONG, } \\
\text { COPEME } \\
\text { Empresas. }\end{array}$ \\
\hline
\end{tabular}

Cuadro 2. Primera lámina de la Línea de Acción $\mathrm{N}^{\mathrm{o}}$ 1.3.1.: Servicios de Desarrollo Empresarial del Plan MYPE 2005-2009.

Fuente: Matriz del Plan MYPE 2005-2009, p. 53.

Con modificaciones posteriores a la Ley MYPE, en el año 2008 se incorporó el régimen laboral especial para las MYPE y amplió el parámetro de volumen de ventas y cantidad de trabajadores para las pequeñas empresas, con el objetivo de incentivar la formalización. No obstante, estimaciones de PRODUCE para el año 2010 calculaban un 69,6\% de MYPEs informales (tabla 3), con sólo una reducción de casi un punto porcentual por año desde el 2004.

Recién en el año 2013 se aprecia un fuerte descenso de MYPEs informales (58,5\%), lo que coincide con la promulgación de la Ley $\mathrm{N}^{\circ} 30056^{4}$, publicada el 02 de julio de 2013. Esta Ley modifica diversas leyes para facilitar la inversión, impulsar el desarrollo productivo y el crecimiento empresarial; asimismo se ajustaron las características que debían reunir las micro, pequeñas y medianas empresas (MIPYMES), estableciendo parámetros para las medianas empresas:

\footnotetext{
${ }^{4}$ La Novena Disposición Complementaria Final de la Ley No 30056, Ley que modifica diversas leyes para facilitar la inversión, impulsar el desarrollo productivo y el crecimiento empresarial, dispone que mediante decreto supremo refrendado por el Ministro de la Producción, se promulgue el Texto Único Ordenado de la Ley de Impulso al Desarrollo Productivo y al Crecimiento Empresarial y sus modificatorias; el mismo que fue aprobado por el Decreto Supremo № 013-2013-PRODUCE, texto que integra lo dispuesto en la Ley No 28015 , Ley de Promoción y Formalización de la Micro y Pequeña Empresa, el Decreto Legislativo No 1086 y las Leyes No 29034, № 29566, № 29903 y Nº 30056.
} 


\begin{tabular}{|l|l|}
\hline Categoria & Ventas anuales \\
\hline Microempresa & Hasta 150 UIT \\
\hline Pequeña empresa & Más de 150 y hasta 1,700 UIT \\
\hline Mediana empresa & Más de 1,700 y hasta 2,300 UIT \\
\hline
\end{tabular}

Cuadro 3. Características Mipymes.

Fuente: Adaptado de Art. 10 de la ley 30056, 2013.

Aun con los beneficios para impulsar la formalización, actualizados en el Texto Único Ordenado de la Ley de Impulso al Desarrollo Productivo y al Crecimiento Empresarial y sus modificatorias, aprobado por el Decreto Supremo N ${ }^{\circ}$ 013-2013-PRODUCE, publicado el 28 de diciembre de 2013, la presencia de MYPEs informales sigue siendo alta, las cuales según estimaciones de PRODUCE, en el año 2016 ascendían a 1 millón 973 mil 888.

Tabla 3.

Estimación del número de micro y pequeñas empresas informales, 2010-2016.

\begin{tabular}{|c|c|c|c|c|c|c|c|c|c|c|}
\hline \multirow{2}{*}{$\begin{array}{c}\text { Estrato } \\
\text { empresarial }\end{array}$} & \multicolumn{2}{|c|}{$\begin{array}{l}\text { Número total estimado de } \\
\text { micro y pequeñas } \\
\text { empresas }^{1 /}\end{array}$} & \multirow{2}{*}{ Total } & \multirow{2}{*}{$\begin{array}{c}\text { Estrato } \\
\text { empresarial }\end{array}$} & \multicolumn{2}{|c|}{$\begin{array}{l}\text { Micro y pequeñas empresas } \\
\text { formales }\end{array}$} & \multirow{2}{*}{ Total } & \multirow{2}{*}{$\begin{array}{c}\text { MYPE } \\
\text { informales } \\
\text { (estimado } \\
\text { por } \\
\text { diferencias) }\end{array}$} & \multicolumn{2}{|c|}{ Porcentaje } \\
\hline & $\begin{array}{c}\text { De } 2 \text { a } 10 \\
\text { trabajadores }\end{array}$ & $\begin{array}{c}\text { De } 11 \text { a } 100 \\
\text { trabajadores }\end{array}$ & & & $\begin{array}{c}\text { De } 2 \text { a } 10 \\
\text { trabajadores }\end{array}$ & $\begin{array}{l}\text { De } 11 \text { a } 100 \\
\text { trabajadores }\end{array}$ & & & Formales & Informales \\
\hline 2010 & $3,889,789$ & 49,984 & $3,939,774$ & 2010 & $1,179,274$ & 20,072 & $1,199,346$ & $2,740,428$ & $30.4 \%$ & $69.6 \%$ \\
\hline 2011 & $3,807,708$ & 51,266 & $3,858,975$ & 2011 & $1,267,060$ & 22,047 & $1,289,107$ & $2,569,868$ & $33.4 \%$ & $66.6 \%$ \\
\hline 2012 & $3,791,973$ & 50,142 & $3,842,115$ & 2012 & $1,321,992$ & 23,398 & $1,345,390$ & $2,496,725$ & $35.0 \%$ & $65.0 \%$ \\
\hline 2013 & $3,618,305$ & 40,503 & $3,658,808$ & 2013 & $1,496,320$ & 22,149 & $1,518,469$ & $2,140,339$ & $41.5 \%$ & $58.5 \%$ \\
\hline 2014 & $3,600,543$ & 37,177 & $3,637,720$ & 2014 & $1,571,121$ & 25,940 & $1,597,061$ & $2,040,659$ & $43.9 \%$ & $56.1 \%$ \\
\hline 2015 & $3,512,575$ & 27,600 & $3,540,174$ & 2015 & $1,660,224$ & 27,574 & $1,687,798$ & $1,852,376$ & $47.7 \%$ & $52.3 \%$ \\
\hline 2016 & $3,676,243$ & 31,758 & $3,708,001$ & 2016 & $1,706,655$ & 27,458 & $1,734,113$ & $1,973,888$ & $46.8 \%$ & $53.2 \%$ \\
\hline
\end{tabular}

Nota: el número total de micro y pequeñas empresas se estima con información de la ENAHO y el método de conductores. En tanto, el número de micro y pequeñas empresas formales provienen del padrón de contribuyente de la Sunat 1/ Incluye actividad principal y secundaria.

Fuente: PRODUCE-OEE.

Asimismo, es preciso resaltar la dominancia de microempresas en el universo MYPE, con una presencia de $99 \%$ en promedio anual respecto a las pequeñas empresas; estimándose en ese sentido el fuerte impacto que ejercería una política de incentivos para la formalización, en el segmento de microempresas. 
Por otra parte, la Encuesta Nacional de Empresas $2015^{5}$ ejecutada a nivel nacional sobre 19,204 unidades empresariales con ventas mayores a 20 Unidades Impositiva Tributarias (UIT) durante el año 2014 (INEI, 2016), si bien no ofrece en todos los casos la información segmentada por tamaño de empresa, nos acerca al conocimiento sobre la realidad empresarial peruana y nos permite inferir sobre las necesidades de las micro y pequeñas empresas del país.

Así, de una lista de 22 opciones sobre los factores que restringieron el crecimiento empresarial, las empresas respondieron que en el año 2014 los tres principales factores fueron: la informalidad (39.5\%), la demanda limitada (36.7\%) y la dificultad de financiamiento (34.8\%). Esta pregunta al no discriminar las respuestas por tamaño de empresa, probablemente está promediando a la baja las mayores restricciones que enfrentan las micro y pequeñas empresas. Así, por ejemplo, el 81,2\% de las empresas considera que existe competencia informal para su principal producto. A nivel de segmento empresarial, el mayor porcentaje se presenta en la microempresa $(84,2 \%)$, mientras que la competencia informal es menor en la mediana y gran empresa $(65,3 \%)$.

Consideramos que los factores "dificultad para el financiamiento" y "demanda limitada" tienen más importancia de la que se señala para las MYPE respecto a la mediana y gran empresa; aunque en general para el 90,2\% de empresas, el criterio más importante para tomar un crédito es la tasa de interés; las altas tasas de interés que afrontan las microempresas, del orden de $43,1 \%{ }^{6}$ en promedio anual, respecto al $6,9 \%$ de la gran empresa, limita decididamente su acceso al crédito. Así, de acuerdo a la Encuesta Nacional de Empresas, en el año 2014, solo el 28.0\% de microempresas utilizó algún tipo de crédito del sistema financiero para capital de trabajo o inversión en activo fijo; en tanto, las grandes empresas los utilizaron en 42,7\%. A lo que hay que agregar que, en el sector informal, las microempresas estarían más limitadas para acceder a este tipo de financiamiento.

\footnotetext{
${ }^{5}$ La Encuesta Nacional de Empresas 2015 es una investigación estadística destinada a recoger información de las empresas formales para la medición anual de los indicadores de desempeño del Programa Presupuestal "Desarrollo Productivo de las Empresas" en el marco del Seguimiento del Presupuesto por Resultados (PPR). El objetivo de la encuesta es contar con información sobre productividad, indicadores de desempeño, información de ingresos y gastos; situación tecnológica, percepción sobre regulaciones, conocimiento sobre productos financieros, capacitación, problemas de provisión de insumos e infraestructura complementaria (INEI, 2015).

${ }^{6}$ Tasa de Interés Promedio del Sistema Financiero para Créditos a la Microempresa al 31/08/2017.
} 
Por otro lado, la disponibilidad de información, las habilidades y capacidades de quien gestiona una empresa son aspectos que influyen en el posicionamiento de ésta y en su participación en el mercado. Al respecto, la referida encuesta revela ciertas carencias y necesidades de las microempresas, como por ejemplo que el 56.9\% no contaba con un plan de negocios al iniciar sus operaciones y solo el $16.6 \%$ contaba con uno de forma posterior al inicio de sus operaciones (INEI, 2015).

Así también, la capacitación como una estrategia para el desarrollo del capital humano es más esquiva para las MYPEs, donde la capacitación alcanzó al 35.4\% de colaboradores en microempresas, $51.9 \%$ en pequeñas empresas, $47.3 \%$ en medianas empresas y $79.5 \%$ en el caso de las grandes empresas.

Otro factor de importancia, que ocupa el cuarto lugar con el 30,6\% de empresas que lo mencionan como limitante para su crecimiento es la excesiva regulación tributaria; si bien sólo el $28,3 \%$ señala tener dificultades en el pago de impuestos, el $42 \%$ indica que es porque no contaba con los recursos o, porque no pudo pagar a tiempo (41\%).

Por otra parte, sobre el aspecto tributario, uno de los últimos dispositivos legales para incentivar el crecimiento empresarial y la formalización es el Decreto Legislativo $\mathrm{N}^{\circ} 1269$ que establece el Régimen MYPE Tributario del impuesto a la renta (RMT), vigente desde el 01 de enero de 2017. Bajo este régimen, las empresas cuyos ingresos netos no superen las 1700 UIT, pagará una tasa de cobro de impuesto a la renta de 10\% para las "primeras utilidades" -hasta 15 UIT de la renta anual- y para el remanente -más de 15 UIT- la tasa de $29.5 \%$ de la renta anual.

Los primeros resultados, del período enero-abril de 2017, señalan que el $96 \%$ de los contribuyentes de este nuevo régimen $(377,228)$ son contribuyentes que provienen de otros regímenes, principalmente del régimen general $(88,9 \%)$, en tanto sólo el $4 \%$ son nuevos contribuyentes (ver Gráfico 11). 
Si bien, el período aun es corto para evaluar su impacto en la formalización de las MYPEs, es preciso que además de un tratamiento tributario especial para las ganancias, el Estado evalúe otras variables que de manera integral se orienten a mejorar la rentabilidad de las MYPEs, a fin de que los beneficios se perciban como mayores a los costos de formalizarse.

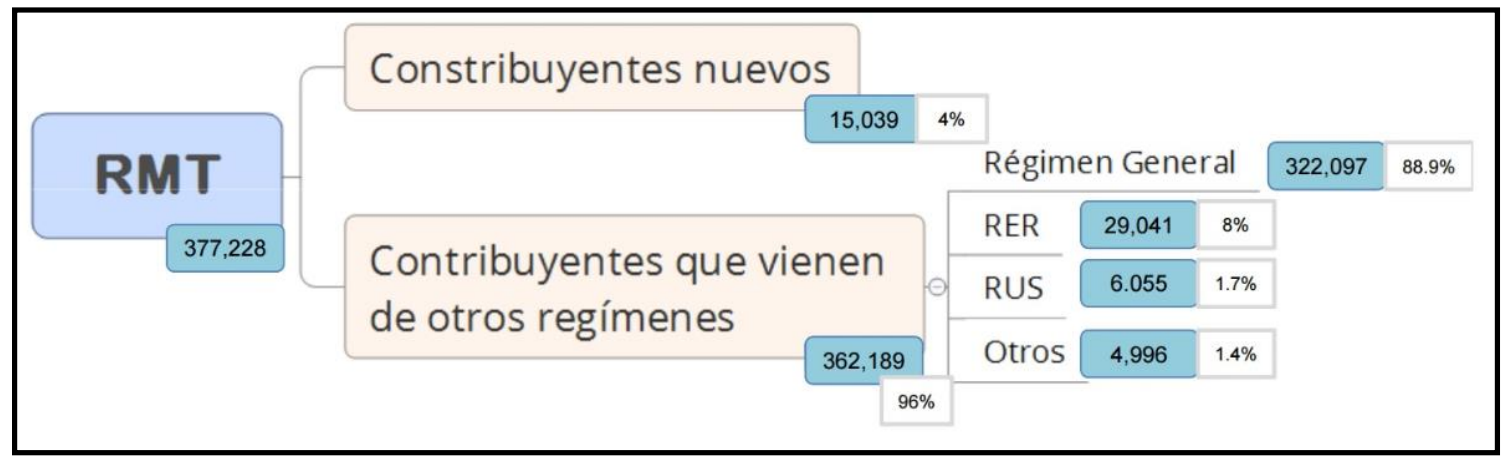

Gráfico 11. Régimen MYPEs Tributario, enero- abril de 2017. Fuente: Gestión, 2017.

Dado lo expuesto, podemos identificar el problema como sigue:

"Las intervenciones de política para promover la formalización de las micro y pequeñas empresas en los últimos años no han tenido el impacto esperado, debido a que no se adecuan mayormente a las limitaciones, necesidades y riesgos específicos de estas unidades económicas, además de carecer de un monitoreo adecuado, que impide ampliar la base tributaria".

En base a lo cual el presente proyecto se propone elaborar una propuesta de política pública que fomente la formalización de las micro y pequeñas empresas, a través de un programa de incentivos que ayude a mejorar su competitividad y rentabilidad como base primordial para asegurar su acceso y permanencia en la formalidad, contribuyendo equitativamente con el país. 


\subsubsection{Objetivo General del Proyecto.}

Incentivar la formalización de las Micro y Pequeñas empresas en el país.

\subsubsection{Objetivos Específicos del Proyecto.}

1. Promover el acceso a crédito financiero a tasas de interés competitivas en el mercado.

2. Proponer la exoneración del pago de impuestos a las microempresas que se formalicen con el programa, por un período de dos años.

3. Simplificar el trámite de formalización y constitución de empresas a un costo cero.

4. Diseñar un programa de capacitación orientado a mejorar la competitividad, con énfasis en tres aspectos: Gestión de la excelencia, apertura de mercados y administración de recurso humanos.

\subsection{Justificación del tema}

A pesar de los diferentes dispositivos legales que ha producido el Estado para incentivar la formalización de las micro y pequeñas empresas, el sector informal se mantiene resistente y afectando la vida económica del país; pues si bien es la mayor fuente generadora de empleo y un importante agente dinamizador del mercado, CEPLAN indica que esta problemática "posee grandes costos para los trabajadores informales, las microempresas y la sociedad en su conjunto" (2016, p. 5).

Para los trabajadores informales, CEPLAN menciona, que "estos costos incluyen los bajos salarios y la falta de protección social en salud, seguridad laboral y pensiones" (2016, p. 5), estrechando su relación con la pobreza ${ }^{7}$. Las estadísticas demuestran que los pobres se concentran en los hogares que perciben ingresos exclusivamente del sector informal, donde

\footnotetext{
${ }^{7}$ En la metodología de la medición de la pobreza monetaria absoluta utilizada por el INEI "se considera pobre a todas las personas residentes en hogares particulares, cuyo gasto per cápita valorizado monetariamente, no supera el umbral de la línea de pobreza. (...) Se utilizan dos tipos de líneas: de Pobreza Extrema y de Pobreza. La línea de Pobreza Extrema es un valor monetario necesario para la adquisición de una canasta de alimentos capaz de satisfacer un mínimo de necesidades nutricionales de las personas. La línea de Pobreza es el valor de la línea de Pobreza Extrema más el valor monetario necesario para satisfacer un conjunto de necesidades no alimentarias consideradas esenciales (transporte, vestimenta, vivienda, educación y salud)" (INEI 2013, p. 91).
} 
alcanzan al 38\% de los hogares, frente al 3\% de hogares pobres entre aquellos con ingresos exclusivamente del sector formal. Además, que los pobres extremos sólo se encuentran en el primer grupo (INEI, 2014).

Un hecho a resaltar es que el trabajador informal del sector formal finalmente termina desplazándose al sector informal como trabajador independiente ${ }^{8}$, engrosando el porcentaje de MYPEs informales. Para las microempresas o negocios de trabajadores independientes son costos la baja productividad y los ingresos de subsistencia que sólo logran cubrir las necesidades básicas del hogar del microempresario, limitando sus posibilidades de generar utilidades, de asociarse e incrementar su productividad.

Para la sociedad, existen costos sociales pues tanto trabajadores como empresas de la economía informal, evaden impuestos, a menudo violan los derechos de propiedad intelectual, no cumplen con las normas laborales, de seguridad y medioambiente, entre otros.

\section{Adicionalmente, de acuerdo a Loayza:}

El sector informal genera un factor externo negativo que se agrega a su efecto adverso sobre la eficiencia: las actividades informales utilizan y congestionan la infraestructura pública sin contribuir con los ingresos tributarios necesarios para abastecerla. Considerando que la infraestructura pública complementa el aporte del capital privado en el proceso de producción, la existencia de un sector informal de gran tamaño implica un menor crecimiento de la productividad, poniendo en riesgo las perspectivas de crecimiento del país. (2008, p. 46).

\footnotetext{
${ }^{8}$ De los 15 millones 919 mil empleos generados en el año 20015 (INEI, 2015), se observa que en el grupo etario de 45 a 64 años (27,5\% de empleos), el empleo formal crece muy ligeramente al del grupo de 25 a 44 años (de 31,3\% a 31.5\%), pero el empleo informal se reacomoda entre el sector formal e informal: disminuye en el sector formal de $17,6 \%$ a 10,4\% y aumenta en el sector informal de $51,1 \%$ a $58,1 \%$.
} 
Dada la complejidad y el impacto multidimensional de esta problemática pública, el Estado debe implementar una política integral sobre la base de las necesidades del micro y pequeño empresario informal; se debe considerar que este empresario, antes de comprometerse con sus obligaciones tributarias y laborales quiere asegurar su sobrevivencia en el mercado, objetivo que, de acuerdo a las estadísticas oficiales, tiene una baja tasa de éxito.

El microempresario informal, y en menor medida el pequeño empresario, debe afrontar dificultades para acceder a financiamiento y capital de trabajo, con desconocimiento de mercadeo, sin acceso a una asesoría profesional, desconocimiento de información sobre su sector o los mercados en los que compite. En este contexto, el Estado debe ofrecer las condiciones para fortalecer su productividad y rentabilidad.

De acuerdo al Estudio multidimensional del Perú: Volumen 2, Análisis detallado y Recomendaciones de la OCDE, el Perú debe incluir en su agenda tres aspectos cruciales para su crecimiento inclusivo: "Diversificar la economía, mejorar la conectividad en el transporte y hacer frente a la informalidad" (2016, p. 4).

OCDE en relación al fomento de la formalización de las empresas, señala que el Perú “debe reducir los incentivos a permanecer pequeñas simplificando los regímenes tributarios y reduciendo los costos administrativos y los costos fijos vinculados a la formalidad" (2016, p. 5).

Si bien Perú ya tiene un régimen tributario MYPE, no sólo se trata de reducir costos administrativos, si no también costos financieros, que coadyuven a mejorar la rentabilidad de las micro y pequeñas empresas que les permita afrontar los costos de la formalidad.

Por otra parte, la Recomendación sobre la transición de la economía informal a la economía formal de la OIT - la primera norma internacional del trabajo dirigida específicamente a luchar contra la economía informal- reconoce que "la mayoría de las personas que entran en la economía informal no lo hace por elección sino por falta de oportunidades en la economía formal, y por no disponer de otros medios de subsistencia” (2017, s.p.). 
La OIT (2017), también señala entre sus principios rectores que los países miembros deben tener en cuenta, entre otros, la aplicación de diversas y múltiples estrategias, así como la coherencia y coordinación entre un amplio rango de áreas de políticas, para facilitar la transición a la economía formal. Lo que está alineado a la presente propuesta.

Por tanto, para incentivar la formalización de las micro y pequeñas empresas con una efectiva ampliación de la base tributaria, la SUNAT debe impulsar la implementación de una política pública con los objetivos específicos planteados, relacionados a los aspectos financiero, tributario, administrativo y de fortalecimiento de capacidades, para mejorar la productividad y competitividad de las MYPEs, pues sin empresas rentables, no mejorarán las condiciones de la recaudación tributaria.

\title{
$1.4 \quad$ Alcances y limitaciones
}

\begin{abstract}
Alcance:
Este trabajo corresponde a la elaboración de una política pública, como primera etapa del ciclo de políticas públicas, la misma que ha considerado elementos válidos de otras políticas públicas y proyectos relacionados con el tema.

Partiendo de la base que las politicas y proyectos previos no han logrado los resultados esperados, se plantea una nueva propuesta con viabilidad sostenible, evaluada en el marco del modelo de Gestión estratégica y creación de valor en el sector público, de Mark Moore; encontrándose que es viable en la dimensión sustantiva, política y operativa.

Con base en lo señalado, como una etapa posterior a la elaboración de la Política Pública propuesta, se la incorporará dentro de la Planificación Estratégica de la Institución que la promueve; plantéandose para su implementación, las estrategias, actividades, resultados e indicadores de impacto, los que se especificarán en la Matriz estratégica de gestión de la política pública, en el capítulo $\mathrm{V}$ del documento.
\end{abstract}




\section{Limitaciones:}

- Limitada disponibilidad de datos del sector informal. Se dispone de estadísticas de economía informal a nivel agregado (INEI, 2015). Las estimaciones necesarias se realizarán tomando como base las estadísticas (volumen de ventas, recaudación, etc.) de las micro y pequeñas empresas formales, generadas por PRODUCE y SUNAT.

- La información estadística de empresas formales, no siempre dispone de datos publicados por segmento empresarial (micro, pequeño, mediano y grande), como la Encuesta Nacional de Empresas 2015.

- La segmentación vigente de las MYPEs (Ley $N^{\circ}$ 30056) sólo se sujeta a su volumen de ventas anuales; antes de la Ley se consideraba simultáneamente volumen de ventas y número de trabajadores, según detalle:

a) Microempresas: con ventas hasta 150 UIT y hasta 10 trabajadores

b) Pequeñas: con ventas mayores a 150 UIT hasta 1700 UIT y, hasta 100 trabajadores.

La estimación de micro y pequeñas empresas realizada por PRODUCE a efecto de estimar las MYPEs informales, se realiza utilizando la cantidad de trabajadores (Microempresas: de 2 a 10 trabajadores y pequeñas empresas: de 11 a 100 trabajadores). 


\section{CAPÍTULO II}

\section{MARCO TEÓRICO}

\subsection{Creación de valor público en la gestión pública}

La primera definición que la Real Academia de la Lengua Española otorga a la palabra "valor" es el grado de utilidad o aptitud de las cosas para satisfacer las necesidades o proporcionar bienestar o deleite. En ese contexto, el valor público sería el grado de utilidad que genera (o deberían generar) las acciones del Estado para satisfacer las necesidades de sus ciudadanos.

Si bien el enfoque de valor público introducido por Moore, en su obra Gestión Estratégica y Creación de Valor en el Sector Público, no tiene una definición de valor en estricto, intenta explicarlo a través de una idea muy simple: "el objeto del trabajo directivo en el sector público es crear valor público, así como el del trabajo directivo del sector privado es crear valor privado" (1998, p. 60).

La idea queda muy clara respecto al sector privado porque sabemos que si una empresa logra producir bienes o servicios que la gente demanda y paga por ellos un precio que permite obtener un cierto margen de ganancias, la empresa, vale decir los directivos que la gestionan están generando valor para sus dueños o accionistas. En el caso del sector público, el concepto de valor es más abstracto. Si bien el gobierno también nombra directivos que se ocupan de la "producción" en los diferentes sectores - solventada con los tributos recaudados- como en educación (que los niños se eduquen), salud (los ciudadanos reciban atención médica), seguridad (transitar sin temor de ser asaltado), los cuales también crean valor para la sociedad, no se mide si los ciudadanos realmente demandarían estos servicios si tuvieran la opción de decidir si gastan o no su propio dinero. 
Considerando que los recursos monetarios que los ciudadanos proporcionan a los directivos públicos para sus actividades tienen un alto costo de oportunidad - al dejar de destinar parte de sus ingresos a otros usos, principalmente al consumo privado- no es suficiente decir que los directivos generan resultados valiosos, sino que debe demostrarse que los resultados obtenidos son comparables a la satisfacción que obtiene un consumidor cuando elige libremente un bien y está dispuesto a pagar por éste, un precio superior a su costo; solo entonces se habría producido valor público (Moore, M., 1998).

Ahora bien, para tener un ciudadano satisfecho primero se debe conocer cuáles son las necesidades que requiere satisfacer y en consecuencia decidir qué se debe producir; es decir, más allá del poder coercitivo de la tributación, el Estado no debería cuestionar la soberanía del consumidor decidiendo unilateralmente las acciones y servicios que debe ofrecer, sino que debe impulsar la representación democrática como un factor clave para generar valor público.

Si bien un ciudadano no podría decidir individualmente, si lo puede hacer a través de decisiones colectivas mediante el proceso de los gobiernos representativos. En la práctica, según Moore, se trata del "reconocimiento explícito del poder de la política para establecer normativamente los propósitos públicos” (1998, p. 63). De esta manera se espera que las aspiraciones colectivas se materialicen en el mandato legislativo o ejecutivo del representante elegido; sin perjuicio de la vulnerabilidad del juego democrático a diferentes tipos de corrupción, lo que le resta garantías al proceso de decisión.

Moore recurre a diversos casos o experiencias de directivos públicos de la administración norteamericana para explicar la estructura de razonamiento que debe seguir un directivo público para generar valor público, quien más que un administrador o técnico, debe ser un estratega; en dicho contexto debe ser capaz de integrar:

a) La reflexión sustantiva sobre lo que es valioso y eficaz; b) un diagnóstico de las expectativas políticas; y c) análisis detallados de lo que es viable 
operativamente. En resumen, al concebir el valor público, los directivos deben encontrar una manera de integrar la dimensión política, la dimensión sustantiva y la dimensión administrativa. (1998, p. 47).

A través de un caso sobre la actividad de recogida de basura por parte de un municipio, Moore explica la definición de valor público y la importancia del proceso de autorización de las actividades del sector público. La cuestión era porqué esta actividad debía realizarla el municipio y no ser privatizada. Si bien de la simple inspección se revelaba el valor que se estaba produciendo al mantenerse las calles limpias respecto a que no lucirían así ante una ausencia del servicio, nada aseguraba que los ciudadanos valoran esta consecuencia. Si el servicio de recogida de basura se ofertara y comprara en el mercado, se sabría el valor que le otorga el ciudadano a través de su voluntad de comprar dicho servicio. Pero cuando se utiliza el financiamiento público ya no se trata de satisfacer deseos individuales si no que es necesario explicar el valor de la actividad en términos que satisfaga a toda la comunidad.

De acuerdo a Moore, "La necesidad de dar una respuesta genérica y políticamente aceptable", constituye el problema central en la definición del valor de las actividades públicas" (1998, p. 72).

Es importante entonces cómo se enuncia el valor de la actividad a fin de convencer no sólo a los individuos como clientes sino a la comunidad en su conjunto, a manera de consumidor colectivo. Así por ejemplo, siguiendo el caso de recogida de basura, si el valor de la actividad limpieza pública se centrara sólo en la mejora del aspecto estético que genera la limpieza, no parecería una buena justificación para gastar los recursos públicos, en tanto que si la actividad transmite un valor público más poderoso, como el de protección de la salud pública, será justificable para el consumidor colectivo, el gastar los recursos en limpieza pública, generando la percepción de que la recogida de basura permite reducir o eliminar el riesgo de enfermedades e insalubridad. 
A partir del análisis de este caso, Moore plantea seis cuestiones básicas sobre la visión gerencial del valor público, que resumimos a continuación:

1. El valor se encuentra en los deseos y las percepciones de las personas. Los directivos públicos deben satisfacer diferentes tipos de deseos y actuar de acuerdo con determinadas percepciones.

2. Los deseos que deben satisfacer las organizaciones públicas son los que los ciudadanos expresan a través de las instituciones del gobierno representativo.

3. Los directivos del sector público pueden satisfacer los deseos de los ciudadanos y clientes a través de dos actividades diferentes para dos mercados distintos: la primera relacionada a producir cosas de valor para determinados clientes y beneficiarios, como becas para alumnos destacados de bajos recursos, desayunos para los infantes de colegios públicos, parques para las familias, incrementar la fuerza policial en las calles. Son actividades que generan valor aun cuando no siempre sean un producto físico o consumible individualmente. La segunda, organizando y gestionando una institución que satisfaga los deseos de los ciudadanos y sus representantes, de una sociedad en orden, con organizaciones públicas eficientes y responsables con la rendición de cuentas.

4. Dado que la actividad pública implica siempre usar la autoridad política; es más importante, que la satisfacción que puedan recibir de una actividad pública, asegurar a los ciudadanos que su dinero se está utilizando 
correctamente, así como garantizar los criterios de equidad y eficiencia en la producción y distribución de los productos.

5. La política, concebida a partir del acuerdo político que refleja la voluntad popular, aún con las imperfecciones del mercado político, es lo que da respuesta a la pregunta de qué bienes producir con recursos públicos. Por ello, una parte fundamental del trabajo de los directivos públicos es fortalecer las políticas que venden a sus autorizadores.

6. En un mundo cambiante, las aspiraciones de los ciudadanos también cambiarán y los métodos de producción quedarán obsoletos; en ese contexto, los directivos públicos deben estar abiertos y preparados para reposicionar a la organización y adaptarla a las nuevas demandas, de manera innovadora y abierta a la experimentación. (1998, p. 87-90).

Para desarrollar la estrategia de ejecución de las actividades públicas generando valor público, Moore recurre a diversos conceptos utilizados en el sector privado, tales como el de "estrategia organizativa"; a través de este concepto se anima a los ejecutivos a visualizar a su empresa en el entorno externo, para posicionarla en relación a sus competidores, para ello debían ser capaces de identificar nuevas oportunidades en el mercado, en las que podrían adelantarse a la competencia; requiriéndose por ello no solo "mirar hacia afuera" sino pensar dinámica y estratégicamente.

Así también con el concepto de "capacidad distintiva", entendida como aquel conjunto de capacidades generales que poseía la empresa que le permitían no solo producir lo que actualmente hacía, sino que, en un contexto más amplio, le permitiría elaborar los productos nuevos por crear. En este ejercicio, los ejecutivos aprendieron a identificar amenazas y oportunidades, así como ser más imaginativos para posicionar su empresa en un mercado competitivo y cambiante. 
Es un resumen del caso:

Este concepto puede ser explicado con el caso de una biblioteca pública, según relata Moore; a esta biblioteca empezaron a llegar en una determinada hora de la tarde un número amplio de escolares, los cuales eran recogidos unas horas después por sus madres. La razón que se descubrió informalmente era que las madres trabajadoras estaban utilizando la biblioteca como guardería. En términos prácticos, la biblioteca se estaba "perjudicando" con un público infantil que incrementaba el trabajo de ordenar y limpiar, además de incomodar a los usuarios habituales de la misma.

La directora tuvo diversas ideas para solucionar el problema antes de tomar una decisión final; desde prohibir la entrada de los niños o solicitar un aumento en el presupuesto, hasta resolver el problema dentro de su propia organización; reorganizando los recursos disponibles para garantizar el personal adecuado para vigilar a los niños, impartir algún programa apropiado para los escolares y adecuar un ambiente propicio para éstos. Es decir, pudo establecer sus capacidades distintivas y adecuarse al cambio operativo, reposicionar su organización creando más valor público (Moore, M., 1998).

Se resaltan dos cambios importantes en la definición de estrategia, a partir de la diversificación de la producción de las empresas y los mayores beneficios de sus carteras financieras. El primero, es la identificación de otros elementos con valor estratégico en la empresa, como por ejemplo: personal clave, una relación de confianza con los proveedores, ubicación geográfica con beneficios fiscales o ventajas logísticas, es decir, un recurso estratégico no necesariamente es un producto o una tecnología (Moore, M., 1998).

El segundo, los directivos ya no visualizan a la empresa como un único negocio sino como una cartera de diferentes negocios. Esto permitiría generar una suerte de complementariedades en los costos de producción, el financiamiento, la distribución o el marketing entre los diferentes negocios, pero además genera la ventaja de diversificar el riesgo con diferentes productos en diferentes sectores (Moore, M., 1998). 
En ese contexto, las organizaciones públicas deben empezar a valorar mejor su principal recurso, el recurso humano, el que le permitirá lograr su misión en la medida de cuan preparado y valorado se encuentre para hacer realidad la estrategia planteada por sus directivos. Al igual que en el sector privado, las instituciones públicas deben abrirse a la posibilidad de complementar sus servicios aprovechando sus capacidades distintivas, para crear nuevas líneas de producción acorde a las necesidades cambiantes de sus ciudadanos, flexibilizando el entorno de trabajo en el que enmarcan su misión, para lo cual deben disponer de recursos estratégicos, entre éstos, empleados preparados y decididos a darle valor a los servicios que ofrecen.

Otro aspecto que destaca Moore de la estrategia corporativa exitosa es la gobernabilidad en la gestión de la empresa, expresada en el "acuerdo sostenible" entre una variedad de actores. Tradicionalmente la empresa negociaba por alguna demanda sólo con sus trabajadores; actualmente han aparecido otros actores y nuevas demandas; el gobierno, por ejemplo, puede exigir acciones de responsabilidad social, además del cumplimiento tributario; las comunidades locales pueden establecer demandas que si no son cumplidas podrían afectar la imagen de la empresa. Estas restricciones han hecho que los directivos gradualmente varíen su foco de atención, antes solo en maximizar el valor de las acciones, a generar valor considerando también los intereses de otros grupos (Moore, M., 1998)

Este aspecto también es adaptable a las instituciones públicas, pues los directivos deben adecuar su actuación a los deseos y las percepciones de los ciudadanos en los diferentes grupos de interés, tales como gremios sindicales, agrupaciones de comerciantes, gremios empresariales, entre otras agrupaciones de la sociedad civil, que si bien en todos los casos no se puede tratar de sus "clientes", si son parte de la comunidad. Así por ejemplo, la administración tributaria nacional, si bien tiene como parte de su misión la recaudación de impuestos y la facultad de aplicar sanciones ante el incumplimiento, no ha logrado analizar y determinar una estrategia para incentivar el cumplimiento entre los contribuyentes con disponibilidad de ingresos en un período mayor al que los declaran, motivado por cuestiones del mercado. Sin embargo, tiene las capacidades distintivas para generar acuerdos sostenibles que debe aprovechar en el futuro inmediato. 
Finalmente, los conceptos explicados por Moore confluyen en un método que es la adaptación del concepto de estrategia corporativa del sector privado a la realidad del sector público, conceptualizada en tres argumentos claves que dan lugar al denominado triángulo estratégico; la que simultáneamente: a) declara la misión o propósito general de la organización (construido en base a valores públicos importantes); b) explica las fuentes de apoyo y legitimidad que se utilizarán para satisfacer el compromiso de la sociedad en dicha tarea; y c) explica como la tarea se organizará y gestionará para conseguir los objetivos (Moore, M., 1998).

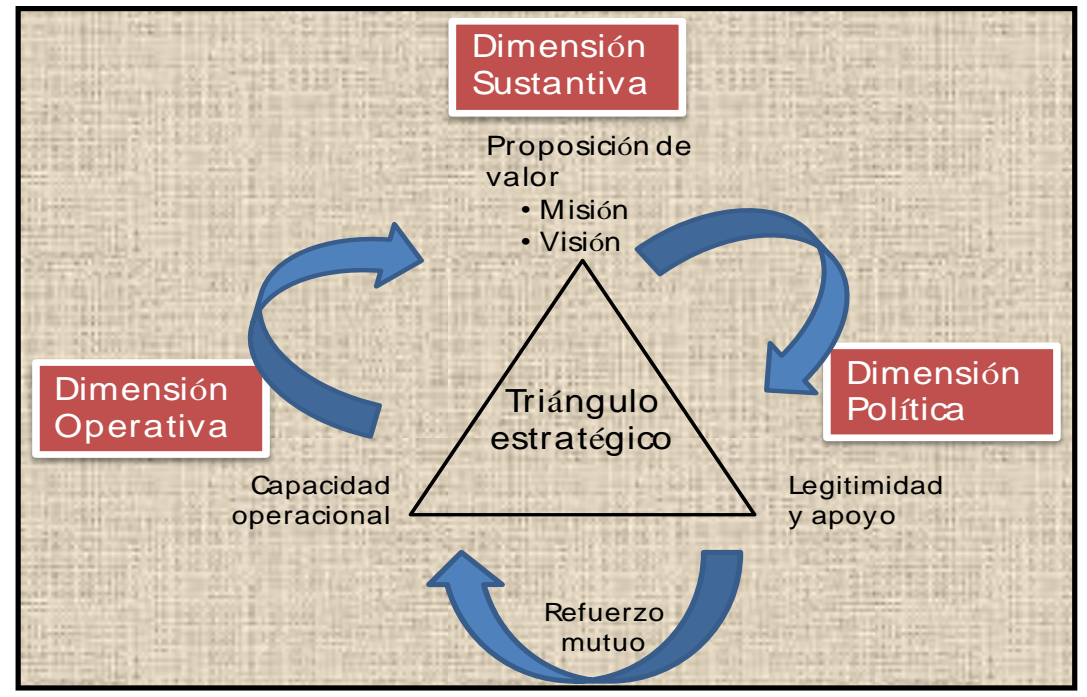

Figura 1. Generación de Valor Público.

Un directivo público se asegurará de que la estrategia genera valor público, cuando logra alinear los tres factores, satisfaciendo tres pruebas:

a) La estrategia debe ser valiosa en términos sustantivos. Se debe generar valor con un costo bajo en dinero y autoridad.

b) Ser capaz de atraer constantemente la autoridad y dinero del entorno político autorizador, a quien se le rendirá cuentas.

c) Ser operativa y administrativamente viable, a través de la misma organización o con la ayuda de otras que pueden ser inducidas en el propósito. 
El triángulo estratégico impulsará al directivo público a tener una mirada hacia fuera, que le permitirá concebir la producción que satisface los deseos y percepciones del ciudadano. En este objetivo no debe perder de vista que la satisfacción que debe brindarse debe ser similar al que obtiene un consumidor cuando elige libremente pagar por un bien; y más importante aún, que perciba que su dinero se gasta correctamente bajo criterios de equidad y eficiencia. Bajo este método, el directivo tenderá a mirar hacia arriba para identificar y analizar su entorno político autorizador; que le garantizará la autorización para gastar los recursos; y hacia abajo y hacia adentro para identificar y gestionar los recursos operativos que requiere para implementar el plan, en el que puede convocar el apoyo de otras instituciones públicas.

\subsection{Políticas públicas}

La palabra "política" tiene al menos tres acepciones en el idioma español, las que en el idioma inglés si se distinguen, según veremos. La primera, la política en términos del juego político, a través de alianzas, negociaciones o conflictos en la lucha por el control del poder, en inglés es politics. La segunda, la política referida a la arquitectura institucional, al ámbito de las organizaciones de Estado, en inglés polity. La última, política como acciones o decisiones de las autoridades públicas, policy en inglés. Es en este último concepto en el que nos centraremos principalmente, como public policy o políticas públicas.

\subsubsection{Definición de políticas públicas.}

En la literatura especializada existe una amplia gama de definiciones del concepto de política pública. En todas las definiciones revisadas se observa que el Estado cumple un rol activo de generador de acciones conducentes a solucionar determinado problema $o$ insatisfacción pública. Sin embargo, en su elaboración pueden intervenir tanto actores gubernamentales como no gubernamentales.

Los actores gubernamentales pueden pertenecer a diferentes niveles del gobierno: nacional, regional o local; los actores no gubernamentales pueden ser: sindicatos, gremios, iglesia, asociaciones, organismos no gubernamentales, entre otros. 
En ese contexto entendemos que son los actores no gubernamentales los demandantes de la política pública, es decir de activar en la agenda del gobierno la solución de la problemática que los aqueja; para lo cual tendrán que recurrir al marco de procedimientos y de influencias dentro de las organizaciones gubernamentales en alguno de los tres niveles de gobierno.

No obstante, como parte de su plan de gobierno, también el Gobierno toma la iniciativa para solucionar aspectos prioritarios para la población. Lo explica Tamayo, cuando señala que "Las políticas públicas son el conjunto de objetivos, decisiones y acciones que lleva a cabo un gobierno para solucionar los problemas que en un momento determinado los ciudadanos y el propio gobierno consideran prioritarios" (1997, p. 2).

Sin embargo, dado que una política pública afecta a una variedad de personas e intereses, los beneficios que pueda generar para un grupo, puede resultar frustrante para aquellos cuyos intereses son perjudicados por ésta. Esta controversia es lo que generará una lucha de poderes y la influencia del poder económico sobre el político.

Al respecto, Olavarría, nos deja una definición de política pública más ajustada a lo antes señalado, como:

Una intervención del Estado, expresada en una decisión o conjunto de decisiones de una autoridad pública, que considera un análisis técnico - racional para un tema determinado y una finalidad específica, que sigue un procedimiento formal, todo lo cual se da en el contexto de un intenso proceso político de confrontación y articulación de intereses. (2007, p. 23).

Esta definición incorpora un nuevo aspecto, el análisis técnico - racional; de acuerdo a Olavarría, este análisis sirve para identificar aquella alternativa que maximice el bienestar social, incorporando la racionalidad económica como factor de decisión. Al respecto, la teoría de la elección pública (Public Choice) y la teoría de juegos serían las expresiones conceptuales 
que más se aproximan a este análisis. Por una parte, la teoría de la elección pública ("Public Choice") ve a las políticas públicas como decisiones colectivas de individuos egoístas y, desde la teoría de juegos las políticas públicas son vistas como una decisión racional en situaciones competitivas (Olavarría, M., 2007).

Debemos precisar asimismo que una política pública se centra en aspectos institucionales, toda vez que los actores que participan en el proceso de política pública desempeñan sus roles dentro de un contexto institucional y quien toma la decisión es una autoridad legítima, es decir cumpliendo con los requisitos establecidos por la institucionalidad vigente.

\subsection{Ciclo de las políticas públicas}

El ciclo de las políticas públicas ha tenido diversos enfoques, la mayoría de autores coincide en señalar 04 etapas: la gestación, el diseño o formulación, la implementación o ejecución y la evaluación del impacto.

\subsubsection{Etapa de gestación.}

En esta etapa el Estado decide intervenir ante la existencia de una demanda social que es de interés público. Comprende dos aspectos:

\subsubsection{El surgimiento e identificación del problema público.}

De acuerdo a lo señalado por Olavarría, para que un problema se vuelva "problema público", debe presentarse una situación de carencias que afecta negativamente a un segmento de la población o ciudadanía, la cual se considera inaceptable para un grupo de actores con influencia y poder, quienes le dan esta categoría, pues consideran que es necesaria la intervención del Estado para solucionarla, mediante la generación de una política pública. Cabe señalar que el problema público, no solo se refiere a situaciones donde el Estado interviene de modo reactivo, sino 
también pueden ser intervenciones proactivas, en las que el Estado ha identificado la necesidad de la población. Los actores con influencia pueden tomar la decisión de intervenir frente a una determinada situación por diversas razones: éticas y morales, porque tienen cierto conocimiento del tema que le permite ver la necesidad, y hasta por razones de distribución de poder (Olavarría, M., 2007).

\subsubsection{La inclusión en la agenda de gobierno.}

Identificado el problema público, a través de la acción de los actores de poder, el gobierno decide intervenir y se instala en la agenda. Los gobiernos atienden los problemas públicos de acuerdo a su agenda.

Franco Corzo, distingue tres tipos de agenda, que es importante señalar:

- La agenda pública, son los temas que la ciudadanía identifica como situaciones que deben ser resueltas, por lo que busca que sean atendidas por parte de sus representantes.

- La agenda política, son los temas que alcanzan prioridad en el debate y la atención de los actores de poder, que los impulsan.

- La agenda de gobierno, es el conjunto de prioridades que un gobierno tiene planeado realizar y busca materializar a lo largo de su período de mandato.

Para que un problema público sea atendido, debe pasar primero por la agenda pública, ya que es lo que ciudadanía demanda y considera que el gobierno debe resolver. Luego debe pasar por la agenda política, en la que, de acuerdo a la capacidad de los actores políticos, debe ser impulsado.

Finalmente, debe incluirse en la agenda del gobierno, como parte de sus acciones gubernamentales que se deben realizar para para solucionarlo (Corso, J., 2014). 
No todos los problemas públicos ingresan en las agendas. André - Noel señala que los problemas públicos y sus soluciones luchan para entrar en las agendas, por lo que un problema que parece importante en momento dado, puede dejar de parecerlo en otro momento, y dejarse de lado, sin haberse resuelto. Además, se pueden presentar ciertas circunstancias, que dificultan que un problema se incluya en la agenda política, antes que en la agenda de gobierno, por ejemplo: la ausencia de sensibilidad política de un problema en un momento dado, la falta de información, la inexistencia de soluciones políticamente interesantes, entre otros (Roth, A., 2002).

\subsubsection{Etapa de análisis y diseño o formulación.}

\subsubsection{Análisis de políticas públicas.}

El análisis de políticas públicas es un trabajo profesional orientado a la solución de problemas, para lo cual utiliza una serie de métodos, herramientas y técnicas profesionales para comprender un problema público, identificar cuáles podrían ser las causas que lo originan y su posible interdependencia con otros problemas, lo que permitirá buscar la mejor alternativa de solución y evaluar los resultados obtenidos. Esta característica de evaluación de resultados permitirá conocer las consecuencias de la implementación de la política pública, si se lograron los resultados, es decir si fue eficiente y efectiva (Olavarria, M., 2007).

Como se ha mencionado las políticas públicas se deciden en el ámbito político, es decir que no es suficiente conocer el problema y plantear alternativas de solución a través de las políticas públicas, sino que es necesario abordar la dimensión política, para involucrar interés y movilizar actores de poder. En ese sentido, Olavarria indica, “convergen los analistas (técnicos) y los políticos. Los primeros aportan los elementos sustantivos y técnicos de la política pública, los segundos desarrollan su labor en las redes de poder con la finalidad de lograr los apoyos necesarios y neutralizar las oposiciones a la política pública" (2007, p. 27). 


\subsubsection{Diseño o formulación.}

Birkland citado por Olavarría, define el diseño de la política pública como "el proceso por el cual las políticas son delineadas, a través de un análisis técnico y de un proceso político, con la finalidad de alcanzar una cierta meta" (2007, p. 32). Reconociendo, por un lado, un proceso técnico - racional y, por otro, un proceso político.

Al respecto, por el lado del análisis técnico, se delinea, se diseña la intervención para resolver el problema. En este proceso se descompone el problema, se identifican sus características, causas, interconexiones, consecuencias. Por el lado del proceso político, expresado en la confrontación de intereses por parte de los actores de poder (dimensión política) frente al reconocimiento de un problema público (Olavarria, M., 2007).

Corzo (2007), señala que, en esta etapa, el problema público es analizado en detalle para buscar posibles soluciones y elegir la más creativa y viable para resolverlo, para lo cual se debe evaluar los aspectos positivos y negativos de cada decisión y elegir la mejor. Señala también, que el especialista en política pública debe brindar una recomendación de política pública inteligente, presupuestal y económicamente viable, legalmente permisible y administrativa y políticamente posible, a uno o varios decisores que ostentan el poder público para poder llevarla a cabo. Debe responder a las preguntas: ¿Cuál es el mejor resultado que se puede lograr?, ¿Qué solución genera mayores beneficios a la sociedad?.

Es importante mencionar el esquema de trabajo del proceso de construcción de una propuesta de política pública que señala Bardach citado por Olavarría, comprende las siguientes actividades:

- Definir el problema

- Recolectar evidencia 
- Construir alternativas

- Seleccionar criterios

- Proyectar resultados

- Analizar pros y contras

- Decidir

- Presentar el caso (2007, p. 33)

En el que estos ocho pasos no necesariamente se dan en el orden presentado y que tampoco todos están necesariamente en todos los casos, excepto el primero y último.

La propuesta de Olavarría (2007), reordena el proceso de diseño en tres grandes etapas:

a) Comprensión y caracterización del problema.

Identificado el problema, en esta etapa se busca comprenderlo para generar propuestas orientadas a resolverlo. El comprender el problema, permitirá el diseño efectivo de la política pública. En ese sentido, el analista de la política pública, debe hacerse las siguientes preguntas: ¿Cuál es el problema?, ¿Por qué esa situación es un problema?, ¿Qué consecuencias negativas genera?, ¿A quién y cuántos afecta (tamaño del problema) ?, ¿Cómo ha evolucionado el problema?, ¿Cuál es su estado actual?, ¿Qué ocurriría si no se interviene?.

Además, se debe indagar si hay otras políticas que hayan abordado el problema, y el contexto institucional, político, económico y/o social en el cual se desenvuelve.

b) Definición de la propuesta de intervención.

El analista de política pública buscará y evaluará alternativas de solución al problema, que pondrá a disposición de los actores de poder, para que tomen una decisión sobre cual implementar. 
Lo esencial del planteamiento de soluciones, no solo se centra en las opciones que podrían resolver el problema, sino en las que son posibles de implementar, teniendo en cuenta consideraciones políticas, económicas, de oportunidad y otros.

c) Instrumentos de Intervención.

Son los instrumentos que están disponibles para implementar una política pública. Entre los que se puede mencionar:

- Gestión Directa del Gobierno. El gobierno puede utilizar su propia estructura o aparato administrativo, para proveer el bien o servicio que atenderá el problema público.

- Privatización: El gobierno transfiere al sector privado las actividades que realizaba directamente para proveer del bien o servicio, las cuales estarán bajo su responsabilidad por la implementación de la política.

- Regulaciones. Estas pueden ser establecidas a través de leyes y actos del gobierno, ejercida a través de organismos públicos para hacer seguimiento a las actividades de un sector y asegurarse que estas leyes y normas se cumplan.

- Mecanismos de Mercado. Son las intervenciones del Estado para asegurar el correcto funcionamiento de los mercados.

- Impuestos. Las prestaciones de dinero que el Estado exige para tener recursos para el financiamiento de las actividades del Estado.

- Subsidios. Tienen por finalidad estimular el consumo o la producción de un bien o servicio en favor de ciertos grupos.

- Campañas de educación, información y persuasión que buscan alterar conductas pre - existentes. 


\subsubsection{La etapa de implementación o ejecución.}

Asimismo, Corzo indica, "En la fase de implementación de la política pública se inicia la puesta en marcha del plan de acción que ha sido delineado en la etapa de diseño de política pública” (2014, s.p.).

La implementación está referida a "aquellas acciones efectuadas por individuos (o grupos) públicos y privados, con miras a la realización de objetivos previamente decididos. A estas acciones pertenecen tanto los esfuerzos momentáneos por traducir las decisiones en propuestas operativas como los esfuerzos prolongados para realizar los cambios grandes y pequeños, ordenados por las decisiones políticas" (Van Meter y Van Horn, citado por Aguilar, p. 99-100).

En esta fase se busca lograr los objetivos trazados en el diseño y formulación, por lo que, la elección de los instrumentos para la ejecución de la política, definirá el éxito o fracaso de la misma ( Hill y Hupe, ciato por Sulca, D., 1984).

De acuerdo a lo señalado por Franco Corzo, en esta etapa se realiza el proceso de presupuestación, la creación legal del programa, el entrenamiento del equipo que lo llevará a cabo y la comunicación dentro de la institución que lo implementará y la ciudadanía, para lo cual se utiliza las estructuras institucionales (recursos humanos y económicos) (Corzo, J., 2014).

Cabe señalar, que esta fase es determinante para el desarrollo de la política, ya que el contenido y los posibles efectos de la política pública pueden ser modificados por la forma en que ésta se ejecuta (Hill y Hupe, citado por Corzo, J., 2014), por lo que es necesario constante monitoreo y coordinación. 
Corzo, recomienda que, para implementar una política pública, se debe responder al menos tres preguntas clave:

- $\quad$ ¿Cuál es la mejor forma de ejecutar una política pública?

- $\quad$ ¿Cómo planear y administrar los recursos para ejecutarla?

- Cómo comunicar a la población la nueva política pública? (2014, s.p.).

\subsubsection{Evaluación de impacto.}

Es una etapa fundamental del ciclo de políticas públicas porque permite realizar una retroalimentación del proceso, por eso Franco Corzo, señala que esta evaluación puede llevarse a cabo, durante el diseño, la implementación y su ejecución.

La evaluación que se realiza en la etapa de diseño se denomina ex-ante. La evaluación en la etapa de implementación se denomina evaluación concomitante y la evaluación de impacto se denomina ex-post.

La evaluación ex-ante tiene como objetivo realizar un análisis previo a la decisión de la política. La evaluación concomitante, que se realiza durante la implementación o ejecución, permite efectuar los ajustes necesarios a la política pública para lograr los objetivos previamente establecidos. La evaluación ex-post permite conocer los efectos de la política pública en la población objetivo, es decir, permite conocer de qué manera ha cambiado una situación una vez que se ha implementado una política pública. 
Ballart (1993), indican que la evaluación permite corregir también el diseño de las políticas, la evaluación trata de:

a) Conocer el objetivo central de la política, b) fijar criterios previos de evaluación claros, c) describir lo que ha pasado y si los resultados se adecuan a lo esperado, d) entender por qué se han producido los resultados registrados y e) prescribir consejos para mejorar el programa o política pública.

En la evaluación ex-post, se informa del resultado obtenido, es decir si se han logrado los efectos esperados (metas, productos, resultados), cuál ha sido el impacto en la población objetivo, permite conocer si los bienes o servicios generados llegaron a esta población y de qué manera se ha visto beneficiada, para conocer el valor público generado.

\section{Olavarría señala:}

La determinación del impacto busca responder la pregunta de ¿cómo cambió la realidad por aplicación de la política?, ¿hay incrementos en el bienestar de las personas que recibieron los bienes y/o servicios distribuidos por la política pública?, ¿es el incremento en el bienestar de las personas observado consecuencia de la implementación de la política?. (2007, p. 86).

Esta etapa permitirá determinar, si las políticas implementadas se deben mantener, modificar o terminar o si se debe mejorar el diseño de nuevas políticas (Olavarría, M., 2007).

\subsection{Enfoque integrado de políticas públicas}

De acuerdo a lo señalado por Esser, Hillebrand, Messner y Meyer-Stamer (1996), los países que desarrollen políticas públicas deben tener en cuenta los factores determinantes de la competitividad sistémica.

En sentido, el enfoque integrado de políticas públicas, está referido al concepto de competitividad sistémica, que es la interacción compleja y dinámica entre niveles económicos 
y sociales de un sistema: los niveles micro, meso, macro y meta, "entre los cuales se presenta la necesidad un trabajo en conjunto bajo el esquema de colaboración mutua, ya que sí se impulsan de manera coordinada y coherente estrategias, políticas u otros esfuerzos, se tendrá como resultado una competitividad”(Benavides, Muñoz y Parada, 2004).

\section{Competitividad sistémica}

El concepto de "competitividad sistémica" se basa en el reciente debate de la OCDE. En ese sentido, Esser, Hillebrand, Messner y Meyer-Stamer (1996), observaron la inexistencia o la insuficiencia del eficaz entorno empresarial en los países en desarrollo, lo que no impide la creación de competitividad. Es decir, cuando una empresa se ve ante la necesidad de aumentar su eficiencia o salir del mercado, hará los esfuerzos para ser competitiva, pero sino cuenta con el apoyo de externalidades, servicios e instituciones, de un entorno eficaz se limita su capacidad de competitividad duradera. Esto sucede debido a que la empresa tendrá que producir lo que necesita, en lugar de recurrir al apoyo de estos servicios externos, viendo limitada su concentración en su actividad productiva principal, por lo que no se producirá el mejoramiento continuo que distingue a las empresas de eficiencia duradera.

Los países deben incrementar su competitividad, no solo a nivel empresarial sino a nivel internacional, debido a la fuerte competencia y avance tecnológico. Por ello, señalan estos autores, que las empresas se hacen competitivas cuando:

- Son sometidas a una fuerte presión de competencia que las obliga producir mejores productos y ser más eficientes.

- Están insertas en redes articuladas dentro de las cuales los esfuerzos de cada empresa se vean apoyados por externalidades, servicios e instituciones.

Ambos requisitos a su vez están condicionados por factores situados en el nivel macro (contexto macroeconómico y político-administrativo) y en el nivel meso. 
Para estos autores el nivel de competitividad de una economía o territorio determinado, es el resultado del esfuerzo organizativo e institucional de la sociedad y de los agentes económicos, sociales e institucionales que interactúan en dicho territorio.

De acuerdo al concepto de competitividad sistémica ${ }^{9}$, un desarrollo industrial exitoso no se logra solo a través de una función de producción en el nivel micro, o de condiciones macroeconómicas estables en el nivel macro, sino también por la existencia de medidas específicas del gobierno y de organizaciones privadas de desarrollo orientadas a fortalecer la competitividad de las empresas (nivel meso). Además, la capacidad de vincular las políticas meso y macro está en función de un conjunto de estructuras políticas y económicas y de un conjunto de factores socioculturales y patrones básicos de organización (nivel meta)”.

Por lo que la competitividad sistémica es la interacción compleja y dinámica entre niveles económicos y sociales de un sistema: los niveles micro, meso, macro y meta.

En el gráfico siguiente, se puede apreciar la interacción que debe existir entre los niveles meta, macro, meso y micro, para encontrar el equilibrio adecuado entre las fuerzas de mercado y la formulación e implementación de políticas dirigidas a promover el desarrollo industrial y competitivo.

\footnotetext{
${ }^{9}$ Esser, Hillebrand, Messner y Meyer-Stamer (1996).
} 


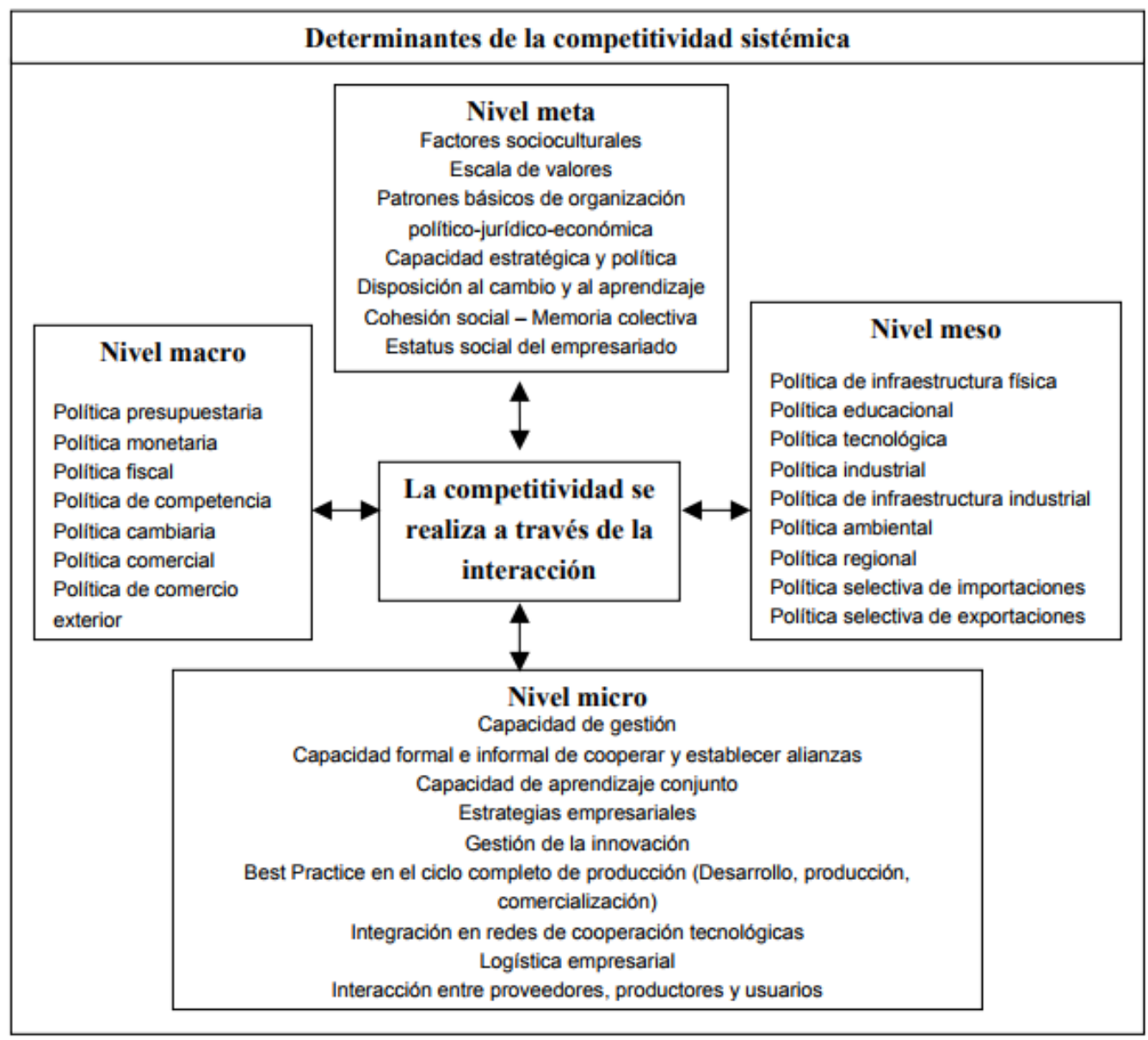

Gráfico 12. Factores determinantes de la competitividad sistémica.

Fuente: Revista CEPAL, la competitividad en el enfoque sistémico: niveles de competitividad sistémica, 1996, p. 41.

\section{Niveles de Competitividad Sistémica}

Esser, Hillebrand, Messner y Meyer-Stamer, señalan que los países más competitivos poseen:

a. En el nivel meta, estructuras básicas de organización jurídica, política y económica, capacidad social de organización e integración, y capacidad de los actores para la interacción estratégica; 
b. Un contexto macro, se refiere al marco macroeconómico y macropolítico estable y modelos normativos generales que permitan el correcto funcionamiento de los mercados de factores, materias primas y capital (políticas fiscales sólidas, política cambiaria favorable al mercado, etc);

c. Un nivel meso estructurado donde el Estado y los actores sociales desarrollan políticas de apoyo específico, fomentan la formación de estructuras y articulan los procesos de aprendizaje a nivel de la sociedad, y

d. En el nivel micro, se concentra en la gestión empresarial para fomentar simultáneamente la eficiencia, calidad, flexibilidad y rapidez de reacción, estando muchas de ellas articuladas en redes de colaboración recíproca. (1996, p. $41-43)$.

A continuación, se describe cada uno de los niveles analíticos:

\section{Nivel meta}

Como se puede apreciar en el gráfico 12, los aspectos determinantes de la competitividad sistémica a nivel meta son:

a.Estructuras básicas de organización política, jurídica y económica.

b.Factores socioculturales y valores compartidos que alienten la dinámica empresarial

c.Capacidad estratégica y política de los actores sociales para el logro de consenso en los objetivos y estrategias de largo plazo.

De acuerdo a lo señalado por Esser, Hillebrand, Messner y Meyer-Stamer, para optimizar la eficacia en los niveles micro, macro y meso es decisiva la capacidad del Estado en la conducción de la economía que busque el incremento de la 
competitividad y que permita cohesionar esfuerzos para motivar la capacidad creativa de la sociedad para lo cual es necesario la formación de estructuras sociales.

En ese sentido, si se establecen reformas macroeconómicas sin crear al mismo tiempo capacidad de regulación y conducción (reforma del estado, articulación de los actores estratégicos) y sin formar estructuras sociales, las tendencias a la desintegración social se agudizarán todavía más. (1996, p. 40).

Es importante la formación de estructuras sociales para complementar la formación de estructuras económicas, porque de esta manera, los diferentes grupos de actores pueden satisfacer los requerimientos tecnológico-organizativos, sociales, ambientales y los que demanda el mercado mundial.

En ese sentido, es necesario considerar la disposición al dialogo entre los actores sociales, como elemento que asegura la coordinación entre los cuatro niveles sistémicos. Se debe fomentar el diálogo entre los actores para fortalecer las ventajas nacionales de innovación y competitividad y poner en marcha procesos sociales de aprendizaje y comunicación.

Una consideración adicional, que señalan estos actores es que para alcanzar la capacidad de gestión necesaria a nivel meta se requieren los siguientes elementos:

a.Consenso acerca del modelo de "orientación de mercado, y de mercado mundial" b.Coincidencia en el rumbo concreto de las transformaciones y

c. Concordancia respecto a la necesidad de imponer los intereses del futuro a los bien organizados intereses del presente (Esser, K., Hillebrand, W., Messner, K., y MeyerStamer, J., 1996). 


\section{Nivel macro}

El nivel macro está referido a la estabilidad del contexto macroeconómico para poder competir en el mercado mundial.

Al respecto, Esser, Hillebrand, Messner y Meyer-Stamer, señalan que "la estabilización macroeconómica tiene que apoyarse sobre todo en una reforma de la política fiscal y presupuestaria, así como también de la monetaria y cambiaria" (1996, p. 42), con el fin de mantener un equilibrio en todo el sistema económico de manera sostenible que permita el éxito en el mercado mundial (Esser, K., Hillebrand, W., Messner, K., y Meyer-Stamer, J., 1996).

En el gráfico 12, se puede apreciar que en este nivel se encuentran: la Política presupuestaria, la Política monetaria, la Política fiscal, la Política de competencia, la Política cambiaria y la Política comercial.

Señalan también estos autores, que el paso de un contexto macroeconómico inestable a uno estable, a veces es difícil por lo siguiente:

a. La lucha contra la inflación mediante una política restrictiva de tipo presupuestario, tributario y monetario puede limitar no sólo el consumo, sino también las inversiones

b. Las medidas de estabilización a nivel macroeconómico suelen surtir efectos que van acompañados de prolongadas reformas estructurales paralelas, como son la reforma del sector económico estatal, el desarrollo de un sector financiero eficaz y la reforma de la política de comercio exterior, lo cual es una limitante por el tiempo de implementación que pueden darse en estas reformas;

c. Los costos del ajuste se dejan sentir de inmediato, mientras que sus beneficios demoran en hacer lo mismo, de modo que la producción, la inversión y la ocupación suelen decrecer en la fase inicial, y 
d. Los grupos sociales no son afectados de un modo uniforme por las medidas estabilizadoras del contexto macroeconómico, por lo que tiene ganadores y perdedores y puede generar conflictos internos

Entonces la estabilización del contexto macroeconómico demanda no sólo un concepto congruente en términos tecnocráticos, sino también un esfuerzo político considerable. El éxito estará asegurado solo si el gobierno se muestra resuelto a imponer las difíciles y conflictivas reformas, si consigue organizar una coalición nacional de fuerzas reformadoras con miras a recobrar el equilibrio de la economía tanto interior como exterior, y si al mismo tiempo logra captar el apoyo internacional (Esser, K., Hillebrand, W., Messner, K., y Meyer-Stamer, J., 1996).

\section{Nivel meso}

Según Benavides, Muñoz y Parada: "El meso nivel se refiere al desarrollo de políticas de la estructura institucional de apoyo a la competitividad y que tienen que ver con el desarrollo de la infraestructura, la educación, la tecnología, las relaciones laborales, el medio ambiente y el desarrollo regional" (2004, p. 124).

Se trata de establecer una estructura institucional eficiente y de promover la capacidad de interacción entre actores privados y públicos (el Estado, las cámaras empresariales, las organizaciones gremiales, las universidades, los centros de investigación y capacitación, así como organismos nacionales e internacionales de cooperación técnica y financiera, entre otros).

Benavides, Muñoz y Parada (2004), señala que este tipo de acciones requieren de una gran organización y capacidad política, es decir de una estructura eficiente de instituciones en la que exista una estrecha interacción entre los actores públicos y privados con las empresas y, especialmente, con los agrupamientos de empresas (clusters o conglomerados). 
De acuerdo a lo señalado por Esser, Hillebrand, Messner y Meyer-Stamer:

Las políticas que configuran el nivel meso poseen una dimensión nacional y una regional o local. A nivel nacional, las políticas meso apuntan a desarrollar la infraestructura física (transportes, puertos, redes ferroviarias y de carreteras, telecomunicaciones, energía, agua, sistemas de abastecimiento y de eliminación de residuos, etc.) y la infraestructura inmaterial (sistemas educativos, etc.) adecuada a los conglomerados, siendo también importantes las políticas selectivas y activas de comercio exterior (política comercial, estrategias de penetración en los mercados). (1996, p. 49).

Así como son importantes los factores de la infraestructura física, cobran también importancia las políticas de apoyo a los conglomerados a nivel tanto regional como local, pues resulta necesaria la aplicación de políticas descentralizadoras.

Tal como se puede apreciar en el gráfico 12, se trata de políticas específicas para la creación de ventajas competitivas, por lo que de acuerdo a los autores Esser, Hillebrand, Messner y Meyer-Stamer:

Para crear ventajas competitivas se requiere, además de un contexto general favorable a la innovación (educación básica, incentivos tributarios para la investigación científica y tecnológica), la aplicación de meso políticas específicas y selectivas; el plano meso político apunta a "fortalecer a los fuertes, para generar núcleos industriales dinámicos y localizaciones industriales eficientes. (1996, p.48). 
En ese sentido, estructurar el nivel meso para que pueda crear capacidades y lograr la creación de ventajas competitivas, es una tarea permanente del sector público y del privado.

\section{Nivel micro}

Este nivel está referido a la actuación de las empresas y los factores que condicionan su comportamiento como productividad, costos, esquemas de organización, la innovación con la tecnología, el tamaño de la empresa, etc.

Estas capacidades pueden ser: de gestión, capacidad formal e informal de cooperar y establecer alianzas, capacidad de aprendizaje conjunto, estrategias empresariales, gestión de innovación, entre otros.

De acuerdo a lo señalado por Esser, Hillebrand, Messner y Meyer-Stamer (1996), el mercado nacional e internacional es cada vez más exigente, por lo que las empresas deben hacer esfuerzos significativos para lograr mayor productividad empresarial (eficiencia más eficacia) y mantener un nivel adecuado de competitividad. Al respecto, se tiene que tomar en cuenta elementos básicos relacionados con la teoría organizacional, como son: eficiencia, calidad, flexibilidad y sensibilidad innovadora y tecnológica y la búsqueda de una jerarquización plana, factores que son fundamentales para desarrollar las condiciones necesarias para aumentar la productividad y por ende la rapidez de respuesta y la competitividad en mercados cada vez más exigentes.

De acuerdo a lo señalado por Benavides, Muñoz y Parada:

Además, otro factor determinante para las empresas en la situación actual de los mercados es la gestión del recurso humano, la cual se debe orientar al fortalecimiento de la capacitación y las curvas de aprendizaje de la empresa, con lo que se fortalece la capacidad estratégica en la toma de decisiones y en la planificación de sus acciones y relaciones empresariales. 
Señalan también que las crecientes exigencias a las empresas van de la mano con requerimientos cada vez mayores a su entorno. Las empresas que actúan en el mercado mundial ya no compiten de una manera descentralizada y hasta aislada, sino como conglomerados industriales ${ }^{10}$. Por lo que la dinámica de su desarrollo, depende del contacto estrecho y permanente con universidades, instituciones educativas, centros de investigación científica y tecnológica, instituciones de información y extensión tecnológica, entidades financieras, agencias de información para la exportación, organizaciones sectoriales no estatales, entre otras entidades. (2004, p.133).

\subsection{Planificación estratégica del sector público}

Armijo, señala que:

La Planificación Estratégica, (PE), es una herramienta de gestión que permite apoyar la toma de decisiones de las organizaciones en torno al quehacer actual y al camino que deben recorrer en el futuro para adecuarse a los cambios y a las demandas que les impone el entorno y lograr la mayor eficiencia, eficacia y calidad en los bienes y servicios que se proveen. (2011, p.17).

La planificación estratégica (PE) permite establecer los objetivos a fin de determinar las estrategias que se deben realizar para su cumplimiento, en ese sentido, la PE es una herramienta clave para la toma de decisiones de las instituciones públicas.

Para utilizar la metodología de la planificación estratégica se debe realizar un diagnóstico de la situación actual de la institución a fin determinar las brechas existentes respecto hacia donde se quiere llegar, el futuro deseable, y en base a ello determinar las acciones que se tomarán.

\footnotetext{
${ }^{10}$ Conglomerados: como grupos empresariales organizados en redes de colaboración.
} 
A fin de establecer el presupuesto orientado a resultados, se debe identificar primero la misión, objetivos y planes de acción antes de determinar los indicadores estratégicos.

Con la definición de los objetivos estratégicos, indicadores y metas, se establece el marco para la Programación Anual Operativa, en base a lo cual se establece el proyecto de presupuesto.

La Planificación Estratégica es una herramienta imprescindible para determinar las prioridades y asignación de recursos de una gestión orientada a resultados.

La planificación estratégica se enfoca en el ambiente externo de la institución, es decir en los usuarios finales, a quienes se entrega el producto para medir el impacto de la intervención institucional a mediano y largo plazo. En cambio, la planificación operativa se refiere a la determinación de metas a corto plazo, tiene que ver con compromisos internos para lograr productos en la cantidad y el plazo requerido.

La planificación estratégica está referida a las grandes decisiones, al establecimiento de los objetivos estratégicos para cumplir la Misión y la Visión. Por lo tanto, la PE es un proceso que antecede al control de gestión, pues es la base para establecer los mecanismos de seguimiento y evaluación de dichos objetivos.

La planificación estratégica es un proceso que requiere constante retroalimentación para saber cómo están funcionando las estrategias, por lo que es importante el diseño de indicadores (Armijo, M., 2011).

\subsubsection{Componentes del proceso de planificación estratégica.}

La planificación estratégica en el ámbito público es un instrumento de gestión que ayuda al establecimiento de prioridades, objetivos y estrategias como apoyo a la definición de los recursos que se requieren para lograr los resultados esperados. 
Armijo señala que en el ámbito público no existe una metodología única para desarrollar un proceso de planificación estratégica, por lo que la elaboración de un plan estratégico debe ser simple y estar incorporado a la toma de decisiones directivas y al calendario presupuestario.

En la elaboración del plan estratégico se debe considerar: misión, visión, objetivos estratégicos, estratégicas, definición de indicadores y metas (Armijo, M., 2011).

De acuerdo a lo señalado por Armijo, en el siguiente gráfico, se muestra un modelo básico de planificación estratégica, en la que se deben responder a las siguientes preguntas, según la fase en que nos encontremos.

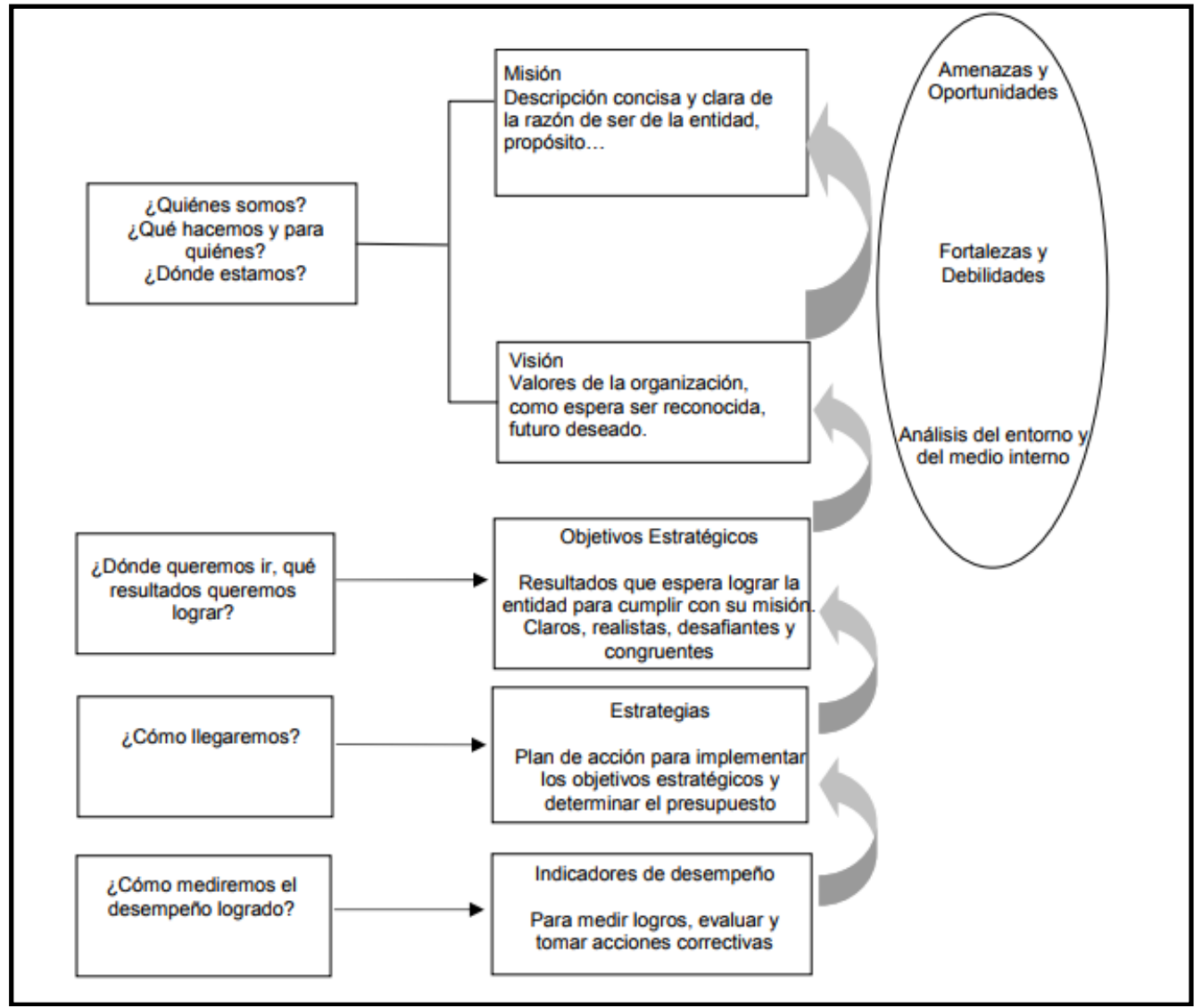

Gráfico 13. Fases del proceso de Planificación Estratégica.

Fuente: CEPAL, La planificación estratégica como instrumento de la gestión por resultados, 2011 p. 19. 
Armijo, indica: "La planificación estratégica apoya la toma decisiones en diferentes niveles gubernamentales y los enfoques metodológicos son variados” (2011, p. 21).

Armijo, señala que las mejores prácticas en el uso de la PE en el ámbito público enfatizan la necesidad de que la técnica utilizada cumpla ciertos requisitos:

- Participación de los responsables de los programas, áreas o divisiones que tienen a cargo la producción de los bienes y servicios, porque la perspectiva estratégica permitirá identificar las mejores alternativas respecto de cómo se deben asignar los recursos y las consecuencias respecto de la entrega de los bienes y servicios y los resultados.

- El proceso de planificación estratégica debe ser la base para la articulación de los objetivos institucionales con las metas sectoriales y nacionales, y además facilitar la definición de los planes operativos y la programación presupuestaria, de esta manera:

- La metodología y contenido del proceso debe responder algunas preguntas básicas para avanzar hacia un presupuesto orientado a resultados: qué productos se generan, para quienes, en qué condiciones, que resultados se compromete.

- La metodología de PE debe facilitar la identificación adecuada de los objetivos estratégicos, para ello se debe considerar los elementos del entorno institucional, tales como los compromisos derivados de los planes nacionales y sectoriales de desarrollo, así como las restricciones y fortalezas internas.

- Las metas y las líneas de acción de corto plazo deben estar alineadas con las definiciones estratégicas, lo que debe permitir la identificación de los requerimientos financieros y operativos para materializar el presupuesto.

- El proceso debe ajustarse con el calendario presupuestario (meses antes de la presentación del proyecto presupuestario).

- En el marco del proceso presupuestario anual, un proceso básico de PE puede ser abordado de forma oportuna, considerando los siguientes aspectos:

- Revisión del desempeño de los productos finales (estratégicos) del año anterior en base al monitoreo de los indicadores de desempeño.

- Revisión del desempeño actual y el comprometido para el año siguiente. 
- Breve análisis del entorno, especialmente de los aspectos presupuestarios, financieros, $\mathrm{u}$ otros establecidos por la institucionalidad gubernamental.

- Breve análisis del ambiente interno, que permita analizar los procesos en términos de su ajuste a los requerimientos de eficiencia, calidad, etc.

- Para saber si se han cumplido con los objetivos propuestos es necesario que la PE sea la fase previa del control de la gestión. (2011, p. 21-22).

El sistema de control de gestión que permita registrar los objetivos, indicadores y metas que cubra todos los niveles de la organización. Este sistema facilita el monitoreo del desempeño y la emisión de los informes respectivos. Esto implica abordar un requisito clave, asociado a la pregunta ¿Cómo sabemos si estamos logrando los resultados? Establecer los indicadores como fase final de la PE, implica definir cuáles son Indicadores Estratégicos y cuáles serán parte de los Indicadores Operativos del control de actividades necesarias para la implantación de los planes, proyectos, etc. (Armijo, M., 2011).

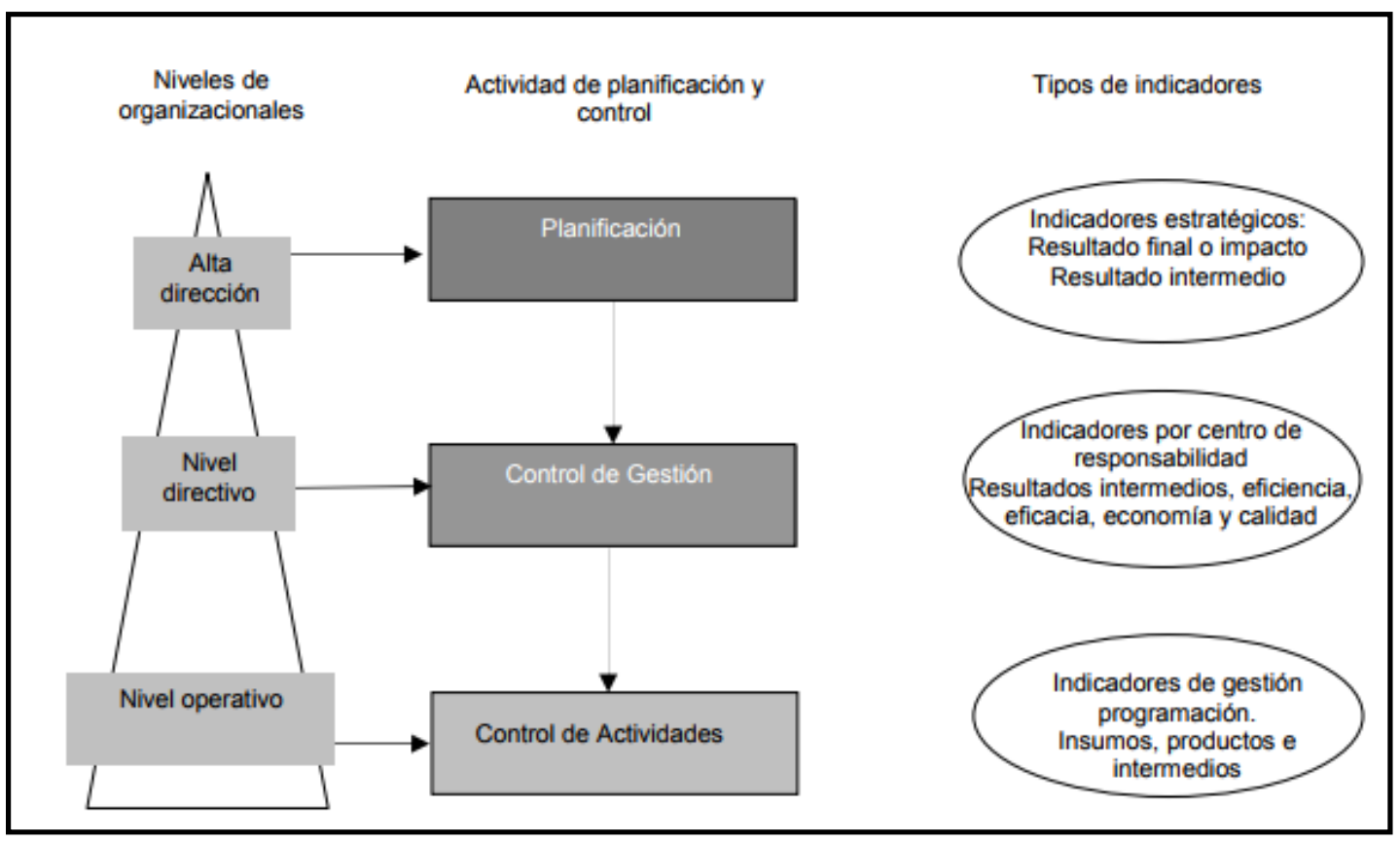

Gráfico 14. Actividades de planificación y tipos de indicadores.

Fuente: CEPAL, Requisitos de la planificación estratégica en el ámbito público, 1998, 2011, p.23. 


\subsection{Enfoques de gestión pública}

El Estado como organización política tiene por finalidad lograr condiciones de vida adecuadas y bienestar para la población. Para lograrlo, ejerce su poder a través de un gobierno, quien mediante políticas públicas responde a los intereses de la población y produce los resultados esperados por los ciudadanos, pero es la gestión pública como conjunto de medios, acciones y decisiones, la que permiten concretar o hacer realidad las políticas públicas.

Como señala el Instituto para la Democracia, la Asistencia Electoral - IDEA Internacional y Asociación Civil Transparencia:

El desempeño del Estado depende de la calidad y eficiencia de las políticas y las competencias de la gestión pública. Sin políticas públicas responsables y sostenidas, o sin una gestión pública moderna, la estabilidad macroeconómica y el desarrollo social terminan afectadas, haciendo poco útiles los restantes esfuerzos para el desarrollo de la competitividad, el bienestar colectivo y la reducción de la pobreza. (2008, p. 5).

\subsubsection{Tendencias de la Gestión Pública.}

\section{a. Modelo Burocrático o Weberiano}

El contrato de colaboración entre el sector público y el sector privado: una perspectiva jurídica, politológica y emocional; según Borja:

El gobierno basado en "Liberté, égalité, fraternité" defendido por el sociólogo alemán Max Weber a principios del siglo XX fue el germen del llamado modelo burocrático de Estado que encajaba perfectamente en el concepto de nación 
uniforme, significando el paso de un sistema de dominación patrimonialaristocrático a un sistema de dominación racional-legal. (2010., p.48).

Algunas características de este modelo son las siguientes:

- Servicio público apolítico, capaz de servir al gobierno de turno.

- Uso de formas organizacionales jerárquicas, regidas por reglas y procedimientos claros.

- Estabilidad laboral y ascenso por méritos.

- Establecimiento de servicios civiles institucionalizados y con cierto grado de autonomía.

- Restricciones al uso del cargo para beneficio personal.

- Es jerárquico y monocrático: las diversas posiciones en la cadena de mando están ocupadas por particulares y no por estructuras colegiadas.

- Tiene un sistema de división del trabajo formalizado.

- Procedimientos administrativos estandarizados.

- Reclutamiento de los funcionarios por concursos libres que aseguran su competencia.

Después de la segunda guerra mundial, el crecimiento del Estado de Bienestar (o Estado Social de Derecho), produjo una ampliación muy grande de los servicios públicos, lo que creó problemas de gestión y presupuestarios.

Dentro de las disfunciones más destacadas del modelo weberiano se encuentra la propia concepción del modelo burocrático tradicional, pensado más para dar respuesta a la protección de derechos y garantías que para gestionar servicios públicos.

Finalmente, cuando en la década de 1970 los gobiernos sociales intervencionistas no lograron relanzar el crecimiento económico ni controlar la inflación, dos condiciones básicas para la generación de bienestar y seguridad social, se mostraron los límites de la capacidad directiva del Estado social. 


\section{b. Modelo post burocrático}

El modelo pos burocrático da origen al Estado contractual o gestión por resultados, con un mayor interés en el beneficio que la sociedad percibe del accionar público. Desde la década de 1980 varios países habían iniciado cambios en sus modelos de gestión con el objetivo de mejorar la atención de las demandas de los ciudadanos.

En el caso del Estado peruano a principios de la década de 1990 se inician reformas económicas - como la desregulación del sector financiero- y reformas administrativas tendientes a reducir el tamaño del aparato estatal y dotarlo de eficacia y eficiencia. Así, el proceso de reformas para liberar los mercados avanzó muy rápido hasta 1994. Se impulsaron las privatizaciones, la desregulación, la flexibilización del mercado laboral y la reforma de administración tributaria.

Para asegurar los resultados, en la post burocracia se generan políticas de incentivo al talento y ejecución, así como a los estándares de calidad. Se considera que los procedimientos clave deben ser reformados en la perspectiva de optimizar el servicio a la ciudadanía y que los recursos financieros debían aplicarse de manera directa y vinculante con los resultados.

\section{c. Nueva Gestión Pública}

El Estado del Bienestar que detentaba un amplio compromiso de prestar servicios a los ciudadanos, se enfrenta a la fuerte crisis económica de la década de $1970^{11}$. La salida a la crisis fue la aplicación de políticas económicas neoliberales, éstas implicaban una menor intervención del Estado en la economía.

\footnotetext{
${ }^{11}$ Hasta la década de 1970, la economía internacional había conocido un periodo de gran expansión. Sin embargo, la economía comenzó a dar signos de profunda crisis, caracterizada por su estancamiento, la elevada inflación y el aumento del desempleo. Una de las principales causas fue el encarecimiento del petróleo desde el año 1973, originado por su utilización por los países árabes como instrumento de presión sobre los gobiernos occidentales en los enfrentamientos entre árabes e israelíes.
} 
El modelo neoliberal desmanteló progresivamente el Estado de bienestar y redujo la fuerza reivindicativa de los sindicatos, debilitados por el aumento del desempleo y el deterioro de los salarios, además de la política de privatización de las empresas y servicios públicos. En este contexto, surge lo que ha venido a denominarse la "New Public Management" o Nueva Gestión Pública (NGP).

El paradigma de la NGP pone énfasis en el uso de técnicas del sector privado en administración en la gestión de las organizaciones pública, tales como la gestión por resultados y la mayor responsabilidad de los gestores.

Celle, Sotomariano y Ugarte, indican:

Este nuevo estilo de gestión implica el desarrollo de sistemas de indicadores y de información orientados a medir el avance en el logro de objetivos, resultados e impactos; una mayor participación de los ciudadanos en la formulación y fiscalización de políticas, programas y proyectos y, por lo tanto, menor control jerárquico y mayor rendición de cuentas; la externalización de servicios provistos por el Estado; la entrega de bonos que premien la productividad de los empleados públicos, entre otros. (2011, p. 15).

\section{d. La Gestión Pública por Resultados (GpR)}

El Instituto para la Democracia y la Asistencia Electoral - IDEA Internacional \& Asociación Civil Transparencia: Gestión Pública por Resultados es un proceso estratégico, político y técnico, que parte del principio del "Estado contractual" en el marco de la Nueva Gestión, es decir la relación y vínculo formal que se da entre un principal (sociedad) y un agente (gobierno) en el cual ambas partes 
acuerdan efectos o resultados concretos a alcanzar con acción del agente y que influyen sobre el principal, creando valor público. (2009, p.19).

Se convierte así en un mecanismo que utiliza el Estado para incentivar la ejecución de las acciones estratégicas definidas en un plan, con un mayor compromiso de los funcionarios públicos respecto a los resultados de su gestión, con el consiguiente impacto (positivo) en la población.

Uno de los problemas del servicio público -aunque no exclusivo de éste- es la débil coordinación entre los mandos directivos y operativos, aspecto que recoge la teoría de los problemas de la agencia en la gestión de lo público, además de la diversidad de objetivos, asimetrías de información, entre otros.

Para superar estas debilidades proponen nuevas formas de vinculación en las que se defina claramente las responsabilidades y los compromisos mutuamente asumidos, mediante la implementación de un proceso de Modernización de la Gestión Pública, que incorpore nuevos enfoques de índole empresarial, tales como Reingeniería, Benchmarking, Outsourcing, entre otras. Asimismo, se eleve las competencias y capacidades de los recursos públicos con un mayor compromiso en la consecución de resultados en beneficio de la ciudadanía.

Según Celle, Sotomariano y Ugarte:

La reforma y modernización del Estado en el Perú, se inició de manera lenta, y no sistemática ni sistémica. Lo que contrasta con el avance rápido y profundo que si se tuvieron las reformas estructurales ligadas al sector privado - como la desregulación financiera a inicios de los 90s. Sin duda es una materia pendiente que debe ser abordada de manera definitiva por el gobierno central, a fin de poder proveer los servicios de calidad que requiere la población. (2011, p. 16). 


\section{e. Gestión con valor público}

Con la introducción de elementos del sector privado a la gestión pública, la NGP plantea asimismo una relación entre gobierno y ciudadano similar a la relación entre empresa y cliente, sin embargo, se generaron críticas a este modelo. Mintzberg en 1996, señaló que ambas relaciones eran muy distintas (Fleury, citado por Celle M., Sotomariano, N. y Ugart, M., 20011).

Asimismo, Fleury, citado por Celle, Sotomariano y Ugarte, escribió: “que la reducción de la primera a la segunda involucraría quitar legitimidad a la autoridad pública y desconocer los derechos ciudadanos que transcienden al consumo" (20011, p. 15).

En base a lo cual surge una nueva corriente que propugna una mayor democratización del Estado y una mayor participación ciudadana en las decisiones, la gestión y la rendición de cuentas de las administraciones públicas.

La participación de la ciudadanía en las decisiones sobre "qué" debe producir el Estado, directamente ligadas a sus necesidades insatisfechas, permite generar valor público, puesto que se sustentaría en base a valores públicos importantes (de interés directo del ciudadano); dispondría del apoyo y legitimidad del actor ciudadanía y de sus representantes políticos, correspondiéndole al directivo público disponer de los recursos y gestionar con sus pares la ayuda necesaria para la consecución de los objetivos. Es lo que se calificaría como el "triángulo estratégico de Moore". 


\section{CAPÍTULO III}

\section{GENERACIÓN DE LA POLÍTICA PÚBLICA}

\subsection{Gestación del problema}

\subsubsection{Antecedentes.}

-La informalidad es un tema que está en la agenda del gobierno desde el siglo pasado, cuando en 1976 se aprueba el primer régimen especial de promoción al sector de MYPEs, con el Decreto Ley $\mathrm{N}^{\circ}$ 21435, Ley de la pequeña empresa del sector privado (25.02.1976); desde entonces se han dado diversas normas con el objetivo de promover el desarrollo y formalización de la micro y mediana empresa; pero es mediados de la década de los 80 con la obra de Hernando de Soto (1986) "El Otro Sendero" que el tema toma una mayor relevancia y empiezan a plantearse diversos enfoques y propuestas sobre la pequeña y micro empresa por parte de los organismos públicos, la cooperación internacional, los gremios y las instituciones privadas de desarrollo.

-La publicación del Decreto Legislativo № 674, el 27 de setiembre de 1991 marcó un hito en la historia de nuestro país, pues con esta norma se plantea la reforma de la actividad empresarial del Estado y se comienza la privatización de las empresas públicas, y con ello, el despido masivo de trabajadores. La consiguiente apertura de nuestra economía al mercado internacional generó nuevos mercados, pero éstos no fueron accesibles para todos; generalmente pequeños y medianos empresarios y productores no estuvieron preparados para competir globalmente y fueron relegados o destinados a desaparecer; las empresas se vieron forzadas a reducir sus costos, a despedir empleados o contratarlos bajo acuerdos informales. Estos factores conjuntamente incrementaron el número de trabajadores independientes con pequeños negocios informales.

-A partir del 2001 los resultados macroeconómicos llegaron a ser muy positivos, al punto que el Perú pasó a ser considerado un país emergente; sin embargo a pesar de los buenos resultados económicos entre el 2001 y 2005, el punto débil se generó en la 
parte distributiva y de empleo. Durante este período el PBI creció en 20\%, pero la pobreza sólo se redujo en 2.7 puntos porcentuales, de 54.3\% a 51.6\% (Gonzales, E., 2007).

- Como señala Arias: "el crecimiento sería una condición necesaria para reducir la informalidad, pero no es suficiente. Existen además otros factores estructurales, institucionales y de política económica" (2017, p. 36).

Estos otros factores serían los que impidieron que los beneficios del crecimiento fueran inclusivos, que abarcaran a todos los peruanos; los mayores ingresos se concentraron en unos pocos sectores, especialmente en el sector minero, al cual se dirigió gran parte de la inversión extranjera, beneficiada por los altos precios de los minerales. Y si hubo un crecimiento en el empleo, éste no fue un empleo decente, pues el empleo informal se amplió inclusive en el sector formal.

-En línea con la promesa del gobierno de aquel quinquenio, de hacer llegar los beneficios del crecimiento a los más pobres, el 3 de julio de 2003 se publicó la Ley $\mathrm{N}^{\circ}$ 28015, "Ley de Promoción y Formalización de la Micro y Pequeña Empresa- Ley MYPE"; la misma que tiene por objeto "la promoción de la competitividad, formalización y desarrollo de las micro y pequeñas empresas para incrementar el empleo sostenible, su productividad y rentabilidad, su contribución al Producto Bruto Interno, la ampliación del mercado interno y las exportaciones, y su contribución a la recaudación tributaria".

La Ley MYPE instituyó al Ministerio de Trabajo y Promoción del Empleo como el órgano rector de las políticas nacionales para promover las MYPE; asimismo creó el Consejo Nacional para el Desarrollo de la Micro y Pequeña Empresa (CODEMYPE), espacio de diálogo y concertación donde el Estado, los gobiernos regionales y locales, las instituciones privadas, universidades, consumidores y representantes de asociaciones MYPE, proponen políticas, planes y programas en pro de la competitividad y del desarrollo de la Micro y Pequeña Empresa a nivel nacional. 
Bajo la coordinación del CODEMYPE se elaboró el primer plan MYPEs, Plan Nacional de Promoción y Formalización para la Competitividad y Desarrollo de las MYPEs 2005 - 2009, aprobado con Decreto Supremo N 009-2006-TR del 8 de Mayo del 2006.

Para el ámbito regional la Ley estableció que los gobiernos regionales debían crear los Consejos Regionales de las MYPEs (COREMYPEs), como espacios de concertación en su ámbito geográfico con el objeto de articular los planes y programas nacionales a los de su región.

Por otra parte, la Ley no establecía ningún tratamiento o régimen tributario especial para las MYPE, las cuales se sujetaban a los mismos regímenes tributarios que las empresas comunes.

- Posteriormente, con Decreto Legislativo N 1086 publicado el 28 de junio de 2008, "Ley de promoción de la competitividad, formalización y desarrollo de la micro y pequeña empresa y del acceso al empleo decente", se modifican las características concurrentes dadas por la Ley MYPE, específicamente las correspondientes a las pequeñas empresas que pasan a incluir a empresas de mayor tamaño y mayor volumen de ventas; pasando de 50 a 100 trabajadores con monto de ventas anuales que aumentan de 850 UIT a 1,700 UIT $^{12}$.

Asimismo, el Decreto Legislativo $\mathrm{N}^{\circ} 1086$ complementó el régimen laboral especial de las MYPE y modificó algunas disposiciones de la norma anterior. Así, se modificaron el Régimen Especial del Impuesto a la Renta (RER), elevando el límite de ingresos por ventas de S/. 360,000 a S/. 525,000, equivalente al límite de ingresos de las microempresas con el valor de la UIT del año 2008 de 3,500 soles; se simplificó la obligación de llevar libros contables a las microempresas si resultaban ser contribuyentes del Impuesto a la Renta e Impuesto General a las Ventas; reducción de la cuota mensual en sector Servicios, depreciación del monto de las adquisiciones de bienes muebles, maquinarias y equipos nuevos destinados a la realización de la

\footnotetext{
${ }^{12}$ Las microempresas se mantuvieron con un número de trabajadores de 1 a 10 y un volumen de ventas de hasta 150 UIT.
} 
actividad generadora de renta gravadas en el plazo de tres (3) años, de las pequeñas empresas, entre otros.

Con estos cambios se esperaba que un mayor grupo de pequeñas empresas optasen por formalizarse e implementasen las condiciones laborales a sus trabajadores. Sin embargo, las estadísticas públicas de SUNAT no muestran que se haya producido un incremento sustancial en el registro de contribuyentes en dicho período.

- Seguidamente, mediante Ley No 29271 del 21 de octubre de 2008, se transfirieron las funciones y competencias sobre la micro y pequeña empresa, del Ministerio de Trabajo y Promoción del Empleo al Ministerio de la Producción, así como la adscripción del órgano consultivo CODEMYPE, lo cual se mantiene hasta la fecha.

- Casi cinco años después, el 02 de julio de 2013 se publica la Ley $N^{\circ}$ 30056, que modifica diversas leyes para facilitar la inversión, impulsar el desarrollo productivo y el crecimiento empresarial y dispone que se promulgue el "Texto Único Ordenado de la Ley de Impulso al Desarrollo Productivo y al Crecimiento Empresarial”, aprobado con Decreto Supremo N 013-2013-PRODUCE, texto que integra lo dispuesto en la Ley Mype $\mathrm{N}^{\mathrm{o}} 28015$, el Decreto Legislativo $\mathrm{N}^{\mathrm{o}} 1086$ y las Leyes $\mathrm{N}^{\mathrm{o}} 29034^{13}, \mathrm{~N}^{\mathrm{o}}$ $29566^{14}, \mathrm{~N}^{\mathrm{o}} 29903^{15}$ y No 30056 .

La Ley No 30056 amplia el objeto de la Ley a las medianas empresas y elimina la condición concurrente de cantidad de trabajadores, ajustando las características de las micro, pequeñas y medianas empresas (MIPYMEs) sólo a las ventas anuales:

\footnotetext{
${ }^{13}$ Referida a homologación de los contratos de obra y contratos de bienes y servicios que efectúen las MYPE con el Estado.

${ }^{14}$ Comprende una modificación al TUO de la Ley Mype referente a simplificación de trámites para la constitución jurídica de una Mype.

${ }^{15}$ Referente a las retenciones a los trabajadores independientes por los aportes que éstos deben efectuar al Sistema Nacional de Pensiones.
} 


\begin{tabular}{|l|l|}
\hline Categoría & Ventas anuales \\
\hline Microempresa & Hasta 150 UIT \\
\hline Pequeña empresa & Más de 150 y hasta 1,700 UIT \\
\hline Mediana empresa & Más de 1,700 y hasta 2,300 UIT \\
\hline
\end{tabular}

Cuadro 4. Clasificación por Ventas anuales (MIPYMES).

Fuente: Adaptado de Art. 10 de la ley 30056, El Peruano, 2013.

- Finalmente, uno de los últimos dispositivos normativos en materia de reactivación económica y formalización, sobre la base de la delegación de facultades otorgada por el Congreso de la República al Poder Ejecutivo ${ }^{16}$, es el Decreto Legislativo $\mathrm{N}^{\circ} 1269$, publicado el 20 de Diciembre de 2016; el mismo que aprueba el Régimen MYPE Tributario del Impuesto a la Renta (RMT).

Podemos resaltar tres aspectos de este nuevo régimen; en primer lugar, las micro y pequeñas empresas podrán emitir todos los comprobantes de pago, entre éstos, facturas, con lo cual se incorporan a la cadena de comercialización al poder vender a medianas y grandes empresas que podrán recuperar el IGV; en segundo lugar, facilita el pago gradual del impuesto a la renta, al permitirle pagar al microempresario solo $10 \%$ de IR por las primeras 15 UIT $(60,750$ soles en el 2017) de utilidad; sobre el exceso, la tasa del impuesto es de $29,5 \%$. En tercer lugar, la norma establece un formato simplificado de los registros de ventas, compras y libro diario, para aquellos que tengan ingresos netos anuales hasta 300 UIT, con lo cual se simplifica el pago.

El RMT se encuentra vigente desde el 01 de enero de 2017. Los resultados del período enero-abril de 2017, señalan que el $96 \%$ de los contribuyentes de este nuevo régimen son contribuyentes que provienen de otros regímenes, principalmente del régimen general $(88,9 \%)$, en tanto sólo el 4\% son nuevos contribuyentes (Gestión, 2017).

\footnotetext{
${ }^{16}$ Delegación de facultades otorgada al Poder Ejecutivo con Ley $\mathrm{N}^{\circ} 30506$, mediante la cual se le faculta entre otros, a establecer un régimen jurídico-tributario especial para la micro y pequeñas empresas.
} 


\subsubsection{Contexto interno y externo - agenda gubernamental.}

\subsubsection{Contexto interno.}

El Estado ha realizado esfuerzos para promover la formalización de las Micro y Pequeñas empresas a través de la Ley MYPE, en la que se establece el marco institucional de las políticas de promoción y formalización de las MYPEs. Para acogerse a estos beneficios, las MYPEs deben estar registradas en el Registro de la Micro y Pequeña empresa (REMYPE).

Entre las principales medidas que se han impulsado con esta Ley, podemos citar las siguientes:

a. Se implementará un sistema de constitución de empresas en línea en un plazo no mayor de 72 horas, a cargo de las siguientes entidades estatales: la Presidencia del Consejo de Ministros - PCM, el Ministerio de la Producción - PRODUCE, la Superintendencia Nacional de Administración Tributaria - SUNAT, la Superintendencia Nacional de Registros Públicos - SUNARP y el Registro de Identificación y Estado Civil - RENIEC.

b. La no obligación de constituirse como persona jurídica para acogerse a los beneficios de la ley.

c. Se señalan los instrumentos de promoción para el desarrollo y competitividad de las MYPE.

d. Se promueve la oferta de servicios en capacitación y asistencia técnica.

e. Tienen acceso a los beneficios del Fondo de Investigación y Desarrollo para la Competitividad.

f. Las MYPE se pueden asociarse para tener un mayor acceso a los mercados privados y a las compras estatales.

g. Se promueve la participación de las MYPE en eventos feriales y exposiciones regionales, nacionales e internacionales.

h. Cuentan con un mecanismo denominado Exporta Fácil, que permite facilitar sus exportaciones. 
i. Se pueden crear Programas para fomentar emprendimientos de las MYPEs. j. Se promueve el acceso al financiamiento, estando a cargo de la gestión a través de los intermediarios financieros, COFIDE (Corporación Financiera de Desarrollo).

k. Se facilita el acceso a las contrataciones y adquisiciones del Estado, para lo cual se debe reservar el $40 \%$ de compras estatales a favor de las MYPEs.

1. Cuentan con un régimen laboral especial, que implica menores costos para el empleador y brinda ciertos derechos laborales fundamentales a los trabajadores, como: remuneración mínima vital, jornada laboral de ocho horas, descanso semanal y en feriados, indemnización por despido injustificado, afiliación al seguro social, entre otros.

m. Se establece el régimen tributario para facilitar la tributación de las MYPEs. Se otorgan beneficios tributarios: en el nuevo Régimen Especial de Renta (RER), las MYPEs acogidas solo pagarán el 1.5\% de sus ingresos al mes como Impuesto a la Renta, mientras que antes pagaban $2.5 \%$.

A continuación, se detalla, los avances logrados en los aspectos: financiero, simplificación administrativa, capacitación y tributación de la Ley MYPE:

\section{a) Financiamiento:}

La Corporación Financiera de Desarrollo - COFIDE, es la entidad financiera encargada de gestionar la obtención de recursos de las diferentes fuentes y fondos en fideicomiso, y los canaliza a través de las Instituciones Financieras Intermediarias (IFI) hacia las MYPEs.

Como parte de sus funciones, COFIDE administra el Fondo de Garantía Empresarial (Fogem), que se constituyó con 300 millones de soles y que tiene por objetivo garantizar los créditos que las entidades del sistema financiero nacional otorguen a favor de las MYPEs. 
Con relación al sistema financiero nacional, se puede apreciar en el gráfico 15 que la cantidad de entidades orientadas a atender a las MYPEs, ha crecido en los últimos cinco años; las Entidades de Desarrollo para la Pequeña y Micro Empresa y las Financieras, crecieron a un ritmo más acelerado que la Banca Comercial, pese a que la Banca cuenta con mayor número de Oficinas y créditos colocados.

En ese sentido, actualmente el segmento empresarial de las MYPEs es atendido por todas las entidades del Sistema Financiero.

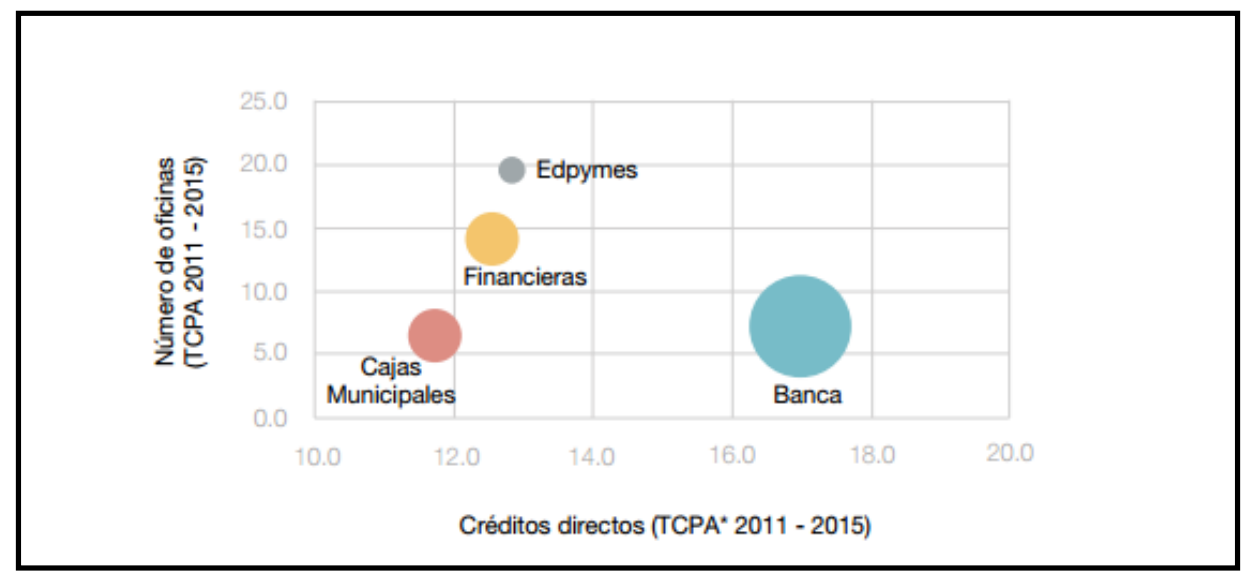

Gráfico 15. Dinámica de la Oferta de Oficinas y créditos, 2011-2015.* TCPA Tasa de Crecimiento Promedio Anual.

Fuente: Superintendencia de Banca, Seguros y AFP (SBS), Ministerio de la Producción, 2017, MIPYME en cifras 2015, p. 125.

Sin embargo, a pesar de la oferta de entidades financieras existente, el acceso a los créditos para las MYPEs, todavía es reducido, tal como se puede observar en la siguiente tabla, la participación de las microempresas en el sistema financiero es solo del $5.4 \%$, la pequeña empresa participa con el $45.8 \%$ y la Mediana con el $65.8 \%$, sin embargo, la participación de las Micro, Mediana y Pequeña Empresa - MIPYMEs en el Sector Financiero representa solo el 7.2\% del total de empresas registradas en SUNAT. Ello se debe a que el costo de acceso al financiamiento para este segmento es bastante alto (tasa de interés promedio de $43.1 \%$ ), y a la falta de garantías aceptables por el sistema. 
Tabla 4.

\begin{tabular}{|c|c|c|c|}
\hline 2015 & $\begin{array}{c}\mathrm{N}^{0} \text { de empresas } \\
\text { registradas en } \\
\text { SUNAT }\end{array}$ & $\begin{array}{c}N^{\circ} \text { de empresas } \\
\text { en el S. F. Dic } \\
2015\end{array}$ & $\begin{array}{c}(\%) \\
\text { participación } \\
\text { en el S.F }\end{array}$ \\
\hline Microempresa & $1,607,305$ & 86,007 & $5.4 \%$ \\
\hline Pequeña & 72,664 & 33,283 & $45.8 \%$ \\
\hline Mediana & 2,712 & 1,784 & $65.8 \%$ \\
\hline MIPYME & $1,682,681$ & 121,074 & $7.2 \%$ \\
\hline Gran & 8,781 & 6,612 & $75.3 \%$ \\
\hline Total & $1,691,462$ & 127,686 & $7.5 \%$ \\
\hline
\end{tabular}

Fuente: Reporte Crediticio de Deudores - Diciembre 2015 - SBS, Ministerio de la Producción, 2017, Las MIPYME en cifras 2015, p.126.

\section{b) En el aspecto tributario:}

Con relación al aspecto tributario, desde la entrada en vigencia de la Ley MYPE, se señala que el Estado debe promover campañas de difusión sobre el régimen tributario y que es la SUNAT, la institución encargada de establecer las medidas para fortalecer su rol de entidad recaudadora y fiscalizadora de los tributos MYPE.

Al respecto, ninguna de las normas implementadas anteriormente dispuso beneficios especiales para las MYPE, sino que éstas podían acogerse al régimen tributario establecido para los contribuyentes con actividad empresarial.

Recién con la vigencia del Régimen MYPE Tributario establecido mediante Decreto Supremo No 1269, vigente desde Enero de 2017, el régimen está orientado exclusivamente a las MYPEs.

\footnotetext{
${ }^{17}$ Se contabiliza cualquier tipo de crédito utilizado por una empresa, una sola vez en el período en cuestión.
} 
En el siguiente cuadro se detallan los regímenes a los que se pueden acoger las MYPE:

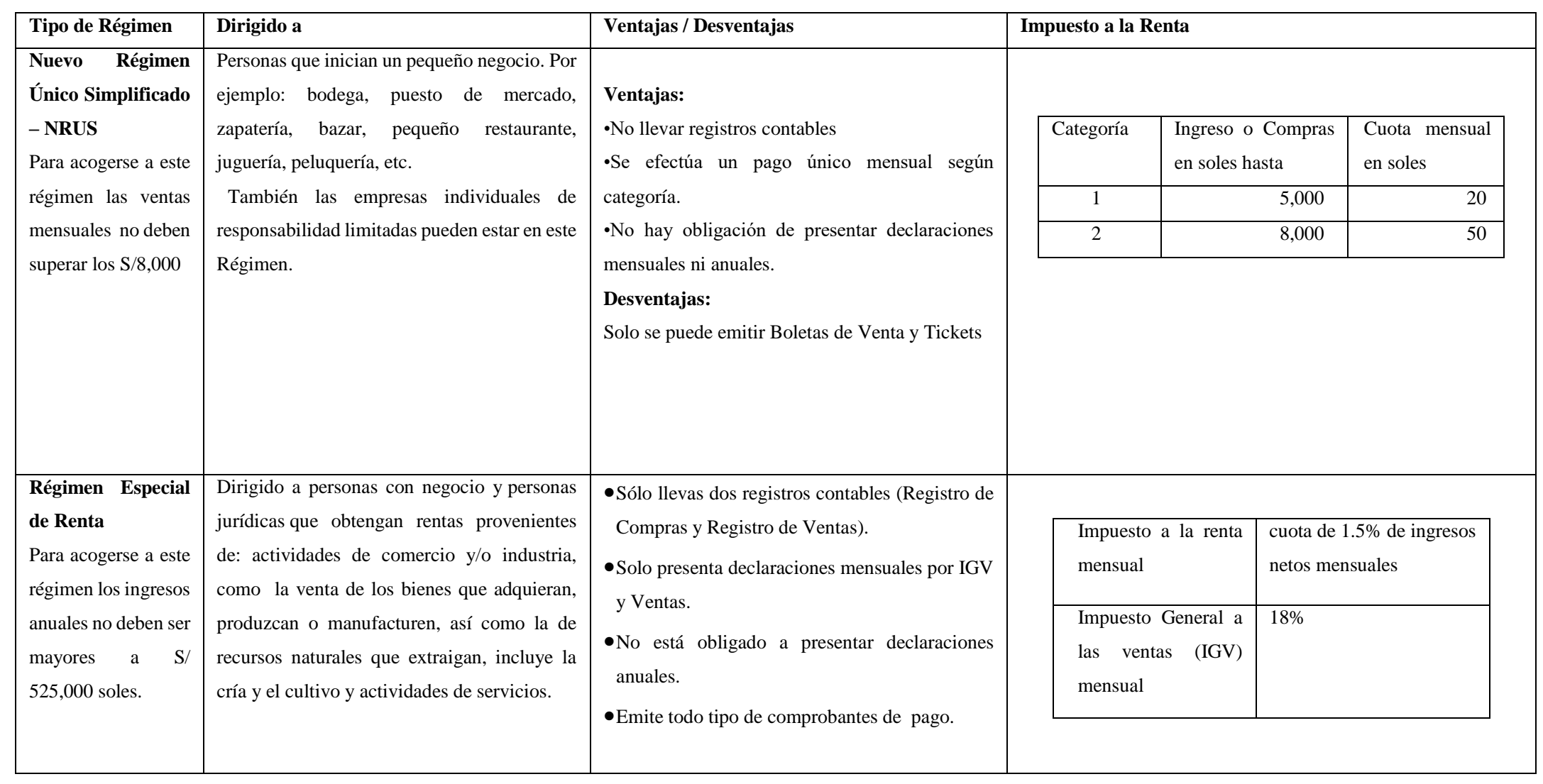




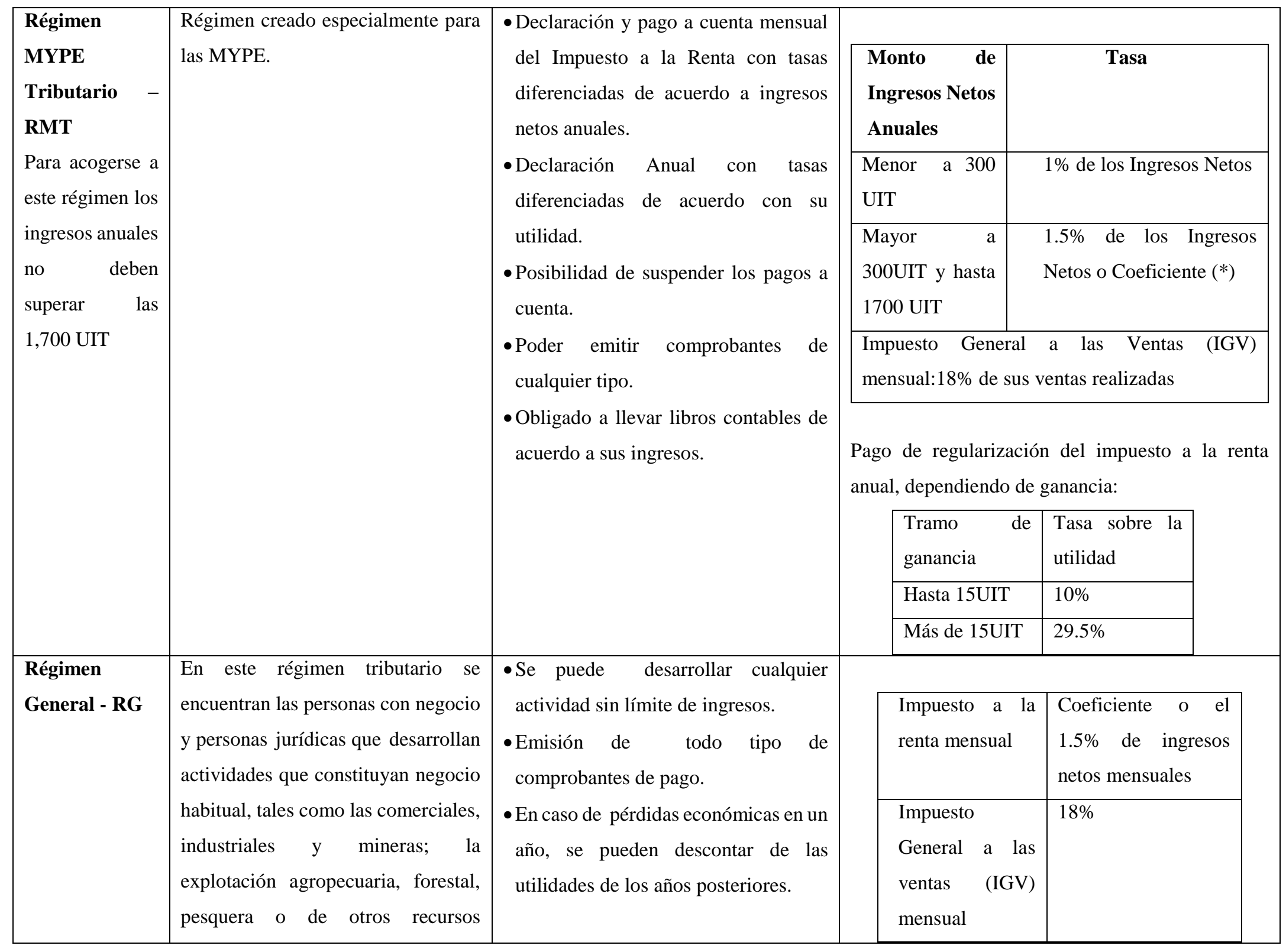




\begin{tabular}{|c|c|c|}
\hline & 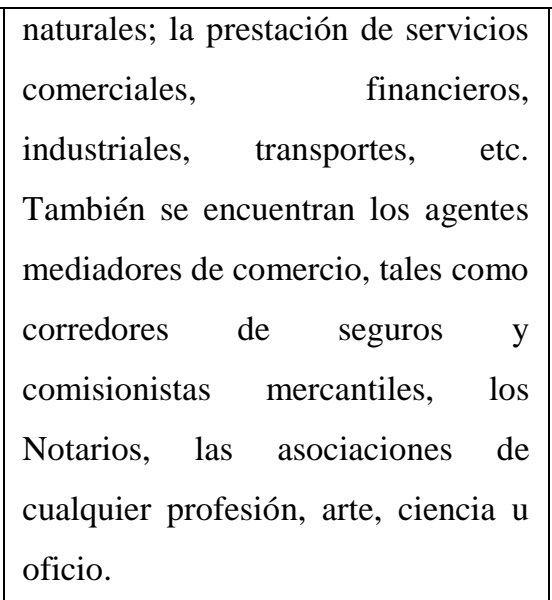 & $\begin{array}{l}\text { Pago de regularización del impuesto a la renta } \\
\text { anual: } 29.5 \% \text { sobre la ganancia. }\end{array}$ \\
\hline
\end{tabular}

Cuadro 5. Regímenes a los que se pueden acoger las MYPE. Adaptado de sección emprender de SUNAT. Elaboración propia. 


\section{c) Formalización}

Para formalizar un negocio se debe realizar la inscripción del RUC ante SUNAT, para lo cual se debe tener en cuenta si se trata una persona individual con negocio o de una persona jurídica (empresa).

Si se trata de una persona individual con negocio, se debe inscribir al RUC ante SUNAT $^{18}$, pudiendo realizarlo mediante pre inscripción por internet o de manera presencial, para lo cual solo es necesario contar con DNI.

De tratarse de una persona jurídica, se puede realizar la constitución de la empresa en línea. Al respecto, el Estado estableció que la constitución de empresas en línea en un plazo no mayor 24 horas, participando las siguientes entidades estatales: la Presidencia del Consejo de Ministros - PCM, el Ministerio de la Producción PRODUCE, la Superintendencia Nacional de Administración Tributaria - SUNAT, la Superintendencia Nacional de Registros Públicos - SUNARP y el Registro de Identificación y Estado Civil - RENIEC (SUNARP, 2016).

Para ello, a fines del 2014, SUNARP desarrolló el Sistema de Intermediación Digital SID - SUNARP, que permite constituir una persona jurídica (empresa) en línea en los Registros Públicos, sin tener que acudir a una oficina de SUNARP ni llenar formularios físicos, para lo cual se ingresa a este aplicativo de SUNARP, el que se interconecta con los sistemas de RENIEC, SUNAT y los Notarios afiliados (SUNARP, 2016).

En este sentido, el Estado a través del Ministerio de la Producción ha venido realizando esfuerzos para simplificar el proceso de constitución de empresas en línea; en Abril del 2017, mediante Decreto Supremo No 006-2017-PRODUCE, se aprobó el Reglamento del Decreto Legislativo $N^{0} 1332$, que facilita la constitución de empresas a través de los Centros de Desarrollo Empresarial - CDE, exonerándose por tres años del

\footnotetext{
${ }^{18}$ Los pasos a seguir se pueden consultar en http://emprender.sunat.gob.pe/como-me-inscribo-en-el-ruc
} 
pago de las tasas registrales siempre que el capital social sea menor a 1UIT (S/ 4,050 soles) (El Peruano, 2017).

Mediante esta nueva disposición, se incorpora a los Centros de Desarrollo Empresarial (CDE), designados por el Ministerio de Producción, para realizar la constitución de empresas en línea, en cuyo caso, se exonerará del pago de los gastos registrales, conforme a lo señalado en el párrafo anterior.

Los CDE han sido creados por el Ministerio de la Producción para optimizar los servicios de asesoría y asistencia técnica en la constitución de una empresa.

Los CDE pueden interoperar con la información de RENIEC, SUNARP, SUNAT y las notarías para que la constitución de la empresa se realice en máximo 48 horas, para lo cual se han realizado adecuaciones a la herramienta SID - SUNARP, a fin de incluir a los notarios como CDE, y el Ministerio de la Producción ha implementado el módulo CDE - PRODUCE, que permite interconectarse al SID -SUNARP.

Así, se han realizado importantes avances en la constitución de empresas en línea, utilizando a los $\mathrm{CDE}$ como centros de atención gratuita para facilitar la constitución de empresas, lo que ha permitido el logro de importantes medidas de simplificación como: la asignación automática del RUC, la Escritura Pública Unilateral y la firma digital del notario.

En el gráfico 16, se puede ver el flujo del proceso de constitución de empresas en línea, vigente desde agosto de este año, en el que se evidencia la interconexión con las entidades involucradas: RENIEC, SUNARP, SUNAT y Notarías. Con este proceso simplificado, se puede constituir una empresa en línea hasta en 48 horas, a través de los CDE, que se comunican con SUNARP para la constitución de la empresa y con SUNAT para la generación del RUC. 


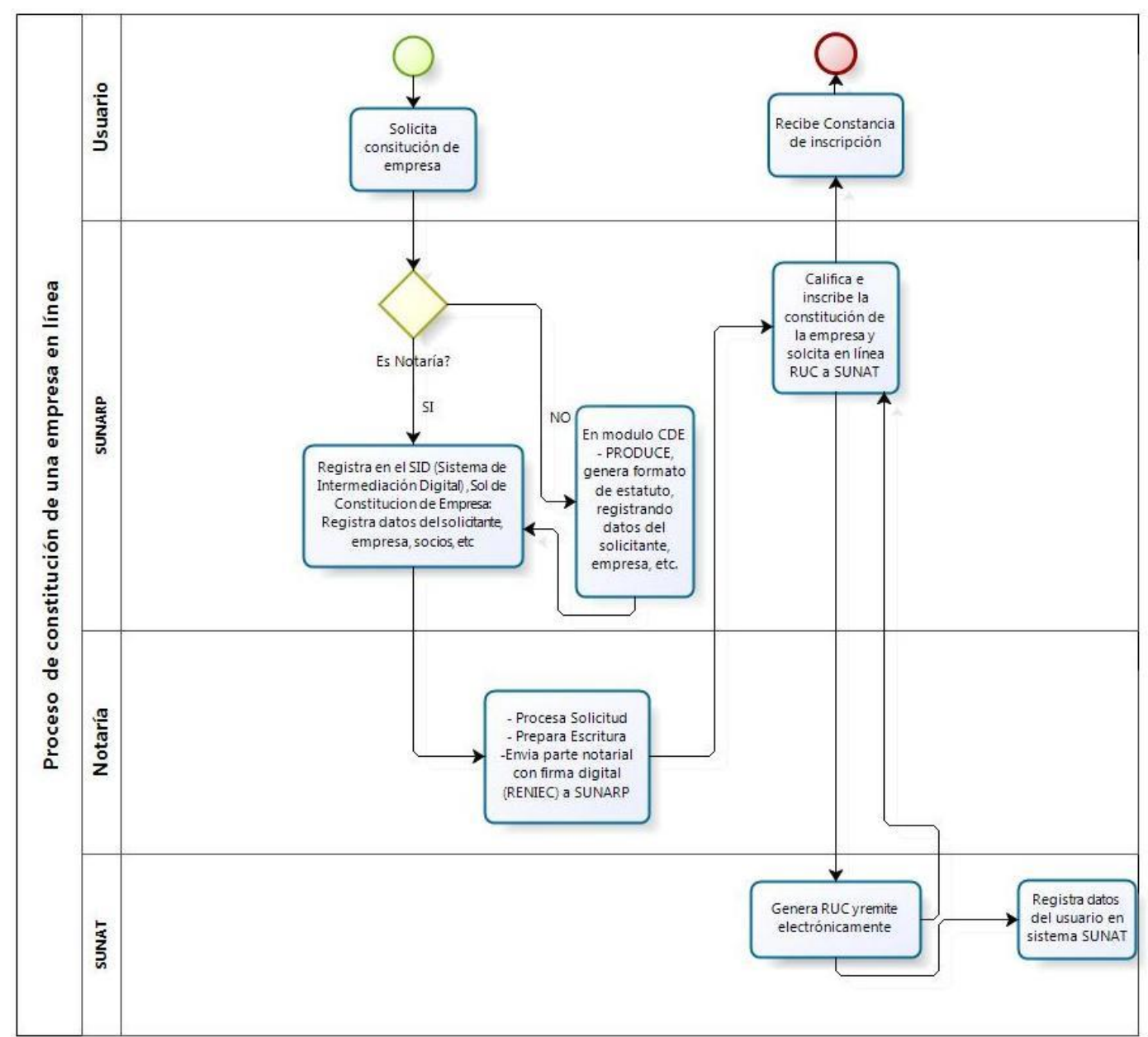

Gráfico 16. Constitución de empresas en línea.

Elaboración propia.

\section{d) Capacitación y Asistencia Técnica:}

Respecto a la capacitación, el Estado ha tratado de promover la oferta y demanda de los servicios de capacitación, desde la aprobación de la Ley No 28015 - Ley de Promoción y Formalización de la Micro y Pequeña Empresa, en el año 2003, en la que se señala que los programas y proyectos, deben estar orientados a los siguientes temas:

- La creación de empresas

- La organización y asociatividad empresarial

- La gestión empresarial

- La producción y productividad 
- La comercialización y mercadotecnia

- El financiamiento

- Las actividades económicas estratégicas

- Los aspectos legales y tributarios

Inicialmente CODEMYPE estuvo a cargo de la promoción de la oferta y demanda de servicios de capacitación y asistencia Técnica, sin embargo, en el año 2013, se retira este encargo, señalándose de manera genérica que el Estado es el que promueve esta actividad.

De la evaluación realizada, se ha verificado que no existe un Programa de Capacitación, no se cuenta con una unidad responsable de la gestión de la capacitación y asistencia técnica de las MYPEs.

Por lo que las instituciones públicas, realizan las actividades de capacitación de manera aislada, sin llevar un control centralizado de las capacitaciones realizadas y de las necesidades de capacitación existente. Tampoco se he evaluado si la temática propuesta en la Ley, debe mantenerse o modificarse de acuerdo a las necesidades de las MYPEs.

Al respecto, cabe señalar que el Ministerio de Producción ha creado los CDE, para brindar servicios de constitución de empresas, asesoría personalizada en formalización, tributación, crecimiento y gestión empresarial y asistencia técnica a emprendedores y empresarios MYPEs en el inicio de sus negocios.

COFIDE, también brinda cursos de financiamiento, para que las MYPEs aprovechen las ofertas y condiciones de financiamiento que pueden obtener del sistema financiero. 
Por su parte, SUNAT ha creado en su portal web, el link http://emprender.sunat.gob.pe/ dirigido a las MYPEs, en donde brinda información de manera didáctica y sencilla de cómo iniciar un negocio, los beneficios de ser MYPE, como se debe tributar, detallando los diferentes tipos de regímenes, como se debe exportar, como se debe importar, entre otros.

Otro incentivo promovido por el Estado en materia de capacitación es que las pequeñas, medianas y microempresas que capaciten a su personal, tienen derecho a un crédito tributario contra el Impuesto a la Renta por el monto equivalente a dicho gastos, por un monto no mayor al $1 \%$ del costo de su planilla anual de trabajadores. Este incentivo no es aprovechado, porque las MYPE han priorizado la reducción de costos para mantenerse en el mercado y poder competir con otras empresas, formales e informales.

\subsubsection{Contexto Externo.}

A pesar de las medidas que el Estado ha dado para impulsar la formalización de las MYPE, todavía no se han obtenido los resultados esperados, debido a que los incentivos no parecen ser los correctos, pues la estructura empresarial se mantiene atomizada y altamente informal.

A fin de conocer las necesidades de las micro y pequeñas empresas, se ha utilizado la Encuesta Nacional de Empresas 2015 (INEI, 2015).

Al respecto, tal como se ha señalado en el Diagnóstico del Problema, de una lista de 22 opciones, las empresas mencionaron que en el año 2014 los tres principales factores que restringieron su crecimiento fueron: la informalidad (39.5\%), la demanda limitada $(36.7 \%)$ y la dificultad de financiamiento $(34.8 \%)$. 
Por otro lado, la ciudadanía percibe que los servicios ofrecidos por el gobierno no son de gran calidad, y la presencia y control del estado son débiles, por lo que un $73 \%$ de peruanos cree que el gobierno gasta inadecuadamente los impuestos que recauda y solo el $17 \%$ cree que los gasta adecuadamente (Datum, 2017).

Algunas de las razones que declaran las unidades informales no agropecuarias, por la cual no se ha registrado en la SUNAT, son las siguientes:

El 47.5\% responde que "no lo considera necesario"; al respecto, la definición de "necesario" de la Real Academia Española, indica: "Dicho de una persona o cosa que hace falta indispensablemente para algo", "que forzosa o inevitablemente ha de suceder", "opuesto a voluntario y espontáneo", a partir de lo cual podemos entender que este grupo lo que quiere decir es - la SUNAT no me hace falta, no obtengo ningún beneficio, sólo a la fuerza (involuntariamente) me registraría.

Otro gran grupo de $34.3 \%$ considera que no se registra en SUNAT porque "su negocio es pequeño/produce poca cantidad", volviendo a la RAE: la definición de “pequeño" señala: "Que tiene poco tamaño o un tamaño inferior a otros de su misma clase", "modesto, de escasos recursos o influencia..."; lo que nos sugiere, primero el desconocimiento que el registro no depende del tamaño del negocio, pero fundamentalmente, que sus ingresos son bajos y no podría asumir gastos adicionales.

En ese sentido, los incentivos para formalizar a las MYPEs deben estar orientados a satisfacer sus demandas, con beneficios que impacten en su desarrollo y rentabilidad, dirigiéndose principalmente a facilidades para el financiamiento, simplificación de trámites para su formalización, capacitación y mayores incentivos tributarios. 


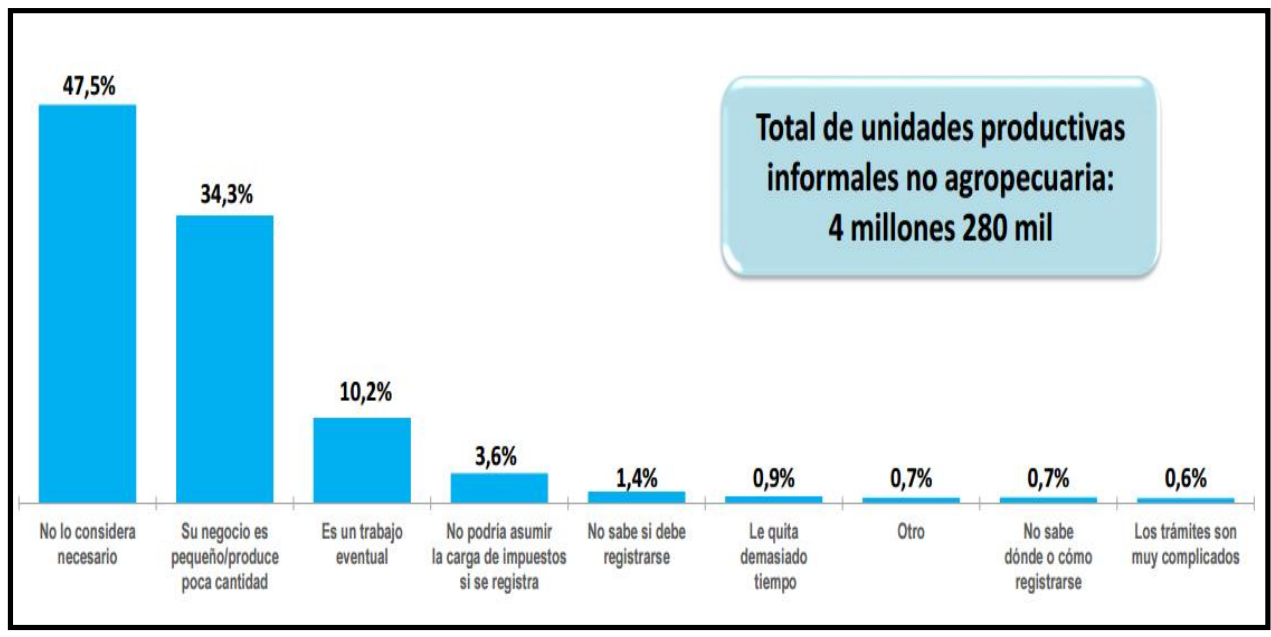

Gráfico 17. Unidades Informales No Agropecuarias y Razón por la cual No se ha Registrado en la SUNAT, 2015 (participación porcentual).

Fuente: INEI-ENAHO, 2015, p. 30.

\subsection{Diagnóstico de la situación}

\subsubsection{Contexto Político.}

En la historia del Perú quedó registrado que en la década de los 90, después de más de ocho años de un gobierno autoritario, el Perú retornó a la senda de la democracia de la mano de un gobierno de transición (Octubre de 2000 - Julio de 2001); sin embargo, ni la democracia, ni las altas tasas de crecimiento económico que siguieron durante esa década lograron disminuir la desigualdad en la distribución de los beneficios de dicho crecimiento, pues la estabilidad macroeconómica que se logró, parece haberse desarrollado en otro mundo, diferente al de la creciente informalidad y la baja productividad que alcanza a más del $70 \%$ de las unidades económicas de nuestro país.

Al respecto, es conocido que los que toman las decisiones de cómo gastar los ingresos de un país es la clase política. Sobre el particular, Moore, nos señalaba que los propósitos públicos se establecen normativamente a través de la política, y que la política concebida a partir del acuerdo político debe reflejar la voluntad popular sobre qué bienes producir con los recursos públicos. 
En la misma línea, respecto a la influencia de la situación política en la economía de nuestro país, Parodi señala que "Existen dos escenarios para implementar reformas: a través del consenso o de manera vertical. El primer camino es más largo, pero conduce a resultados más sostenibles y es el mecanismo normal de las democracias representativas. El segundo tiende a ocurrir en gobiernos con características autoritarias" (2013, s.p.).

En este contexto es de vital importancia que los ciudadanos se sientan representados por los políticos que eligieron y éstos a su vez sepan generan consenso entre las diversas tiendas políticas para atender las necesidades insatisfechas de la población. Sin embargo, la realidad peruana es otra; vamos a encontrar promesas políticas incumplidas, hechas con el único afán de ganar votos, políticos que velan por sus propios intereses, escándalos por casos de corrupción que consumen la mayor parte de su tiempo en largos procesos de fiscalización, entre otros, retrasando el trabajo de planificar y normar las reformas que la población espera. Este ambiente de incertidumbre y sensación de caos impactará en las futuras inversiones tanto nacionales como extranjeras. Así, una "mala política" tendrá una influencia negativa sobre el desenvolvimiento saludable de la economía (Parodi, C., 2013).

Esta situación desventajosa que padece el Perú respecto a su clase política con impacto en la democracia y en la forma como se toman las decisiones políticas, económicas y sociales, de acuerdo a Murakami (2012), tiene su origen en la tendencia histórica caudillista de nuestro país, en la lucha por el poder entre las fuerzas políticas participantes, con el fin de hacer prevalecer sus intereses particulares, gestionados por el caudillo o persona influyente que construye la fuerza política.

En este contexto, Murakami también indica, "el país nunca ha vivido un proceso de institucionalización de alto grado - concebido como compartir reglas, normas y conductas respecto de la toma de decisiones o llegar a un punto de encuentro sobre las políticas concretas a aplicar en el mediano y largo plazo - entre las fuerzas principales" (2012, s.p. ). 
Esto explicaría la falta de planificación en el quehacer público en el mediano y largo plazo y la fragmentación política que divide al país en parcelas que quieren ser manejadas a su antojo por cada caudillo; esta fragmentación se presenta inclusive dentro del gobierno de las instituciones públicas. Así, sin consenso para definir qué es lo más importante para el país y cuáles son las líneas de desarrollo con inclusión que debemos seguir, independientemente de la agrupación política que la lleve a cabo, estamos condenados a "tejer y destejer" ante la angustiante espera de los ciudadanos más desfavorecidos y el incremento de la incertidumbre y desconfianza generalizada.

Murakami, respecto a sus conclusiones indica:

Un estudio sobre los mecanismos para lograr una democracia estable en algunos países europeos con sociedades marcadamente fragmentadas hace dos sugerencias (Lijphart 1977). La primera es conformar coaliciones, explícitas o implícitas, entre las fuerzas políticas principales, con el objetivo de forjar una base duradera para la estabilidad y gobernabilidad política y establecer relaciones colaborativas entre ellas, así como para continuar la ejecución de ciertas políticas. La segunda sugerencia es que las coaliciones se basen en un consenso o, por lo menos, un entendimiento sobre determinadas líneas políticas o medidas eficaces y factibles con relación a temas específicos o problemas de importancia. El pacto no debe limitarse a los acuerdos acerca del marco democrático, la distribución del poder o el reparto de bienes; por el contrario, debe extenderse hacia acciones concretas y factibles. (2012, s.p.). 
Si bien estos pactos entre agrupaciones políticas de nuestro país también existen, no son estables y muchas veces no se limitan al quehacer público sino también a ejercer un espíritu de cuerpo ante situaciones poco éticas o cuando sus intereses particulares pueden verse afectados, o por el contario, romperse cuando una de las partes siente que se afectan sus intereses o que su poder puede verse disminuido. Esta situación ha decantado, desde la crisis de partidos políticos de la década de los 80, o mucho antes, en ciudadanos apolíticos y desconfiados, resignados a sobrevivir como sea, pero de igual forma, resistiéndose a solventar a un Estado que poco hace por satisfacer sus necesidades. Dado lo cual, consideramos que el gobierno debe impulsar, promoviendo el consenso entre las diversas fuerzas políticas, acciones o decisiones "public policy" que conduzcan al país hacia la superación de la desigualdad y la pobreza.

\subsubsection{Contexto Económico.}

Posteriormente al período de elevado crecimiento económico entre 2002 y 2010, la economía peruana empezó un proceso de desaceleración influenciado por el cambio en el entorno económico externo y fundamentalmente por la caída en el crecimiento de la economía China. En la primera década de este siglo, China creció $10 \%$ en promedio anual, hacia adelante, alrededor de 6,5\%, esto ha impactado fuertemente en los altos precios de los metales que existieron entre 2003 y 2010, lo que le permitió a nuestro país crecer a una tasa promedio anual de $6,3 \%$.

Esta dependencia primario exportadora del país ha sido analizada en el Estudio multidimensional del Perú: Volumen 2, Análisis detallado y Recomendaciones OCDE presentado por la OCDE (2016), señala que para llegar a ser una economía de ingreso alto y superar la llamada trampa del ingreso medio, se requerirá diversificar la economía más allá de su dependencia en los recursos naturales y aumentar los niveles de productividad en varios sectores. Se identifican tres aspectos cruciales en la agenda para el crecimiento inclusivo del Perú: Diversificar la economía, mejorar la conectividad en el transporte y hacer frente a la informalidad. 
El nivel de productividad que el Perú requiere para llegar a ser una economía de ingreso alto es bastante elevada, sin embargo existe evidencia de países de la región como Chile que lo han logrado. En el gráfico adjunto podemos observar que la productividad laboral del Perú es aproximadamente un 30\% de la que corresponde a la OECD, asimismo que la sobresaliente posición de Chile lo ubica por delante de grandes economías como México y Brasil.

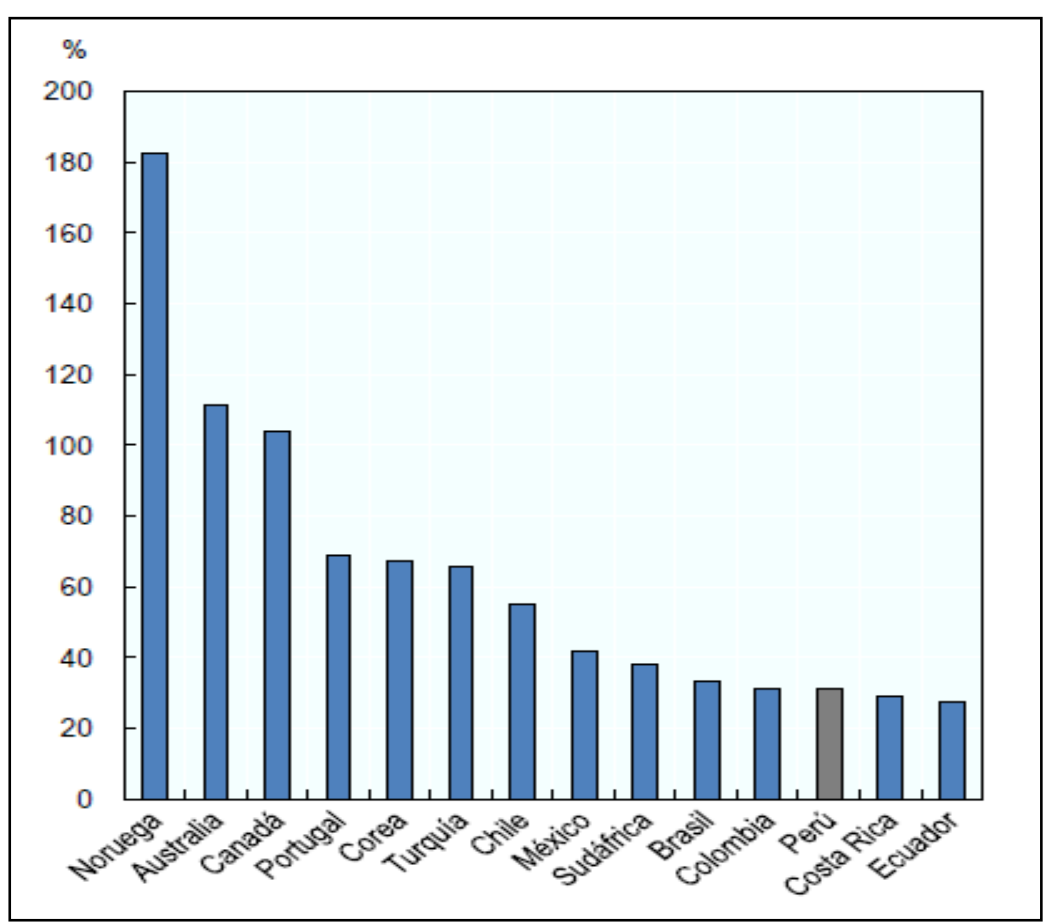

Gráfico 18. Productividad laboral por hora trabajada (\% del promedio de países miembros de la OECD, 2016).

Nota: Productividad laboral por hora trabajada en USD de 2015 (convertido al nivel de precios de 2015 con las PPA actualizadas de 2011.

Fuente: OCDE, Estudio multidimensional del Perú Volumen 2. Análisis detallado y recomendaciones: mensajes principales, p. 13.

Por otra parte, de acuerdo a la OIT la cifra de informales en Latinoamérica y el Caribe representa el 47,7\% del total de trabajadores; encontrándose el Perú $(68,8 \%)$ entre los países que sobrepasan la tasa promedio, además de: Honduras (70,7\%), Paraguay (65,8\%), El Salvador $(65,7 \%)$, Colombia (56,8\%), México $(54,2 \%)$, Ecuador $(52,2 \%)$ y República Dominicana 
$(50 \%)^{19}$ (América economía, 2013) ; entre éstos no se identifica a Chile, país que hasta junio de 2017 alcanzaba una tasa de 36\% de informalidad laboral.

De acuerdo a lo señalado por diversos economistas y lo observado en el caso chileno, podemos admitir la relación inversa entre informalidad y productividad y en consecuencia los menores ingresos de la fuerza laboral, que en concreto en nuestro país no permitirán su salida de la trampa de ingresos medios; de ahí que la informalidad deba tratarse como uno de los temas fundamentales a los que hay que enfrentar para mejorar la posición económica y social de nuestro país.

\subsubsection{Contexto Social.}

La informalidad es un fenómeno multidimensional que influye sobre el bienestar de todos los agentes económicos. Y aunque las actividades informales son las que proporcionan los ingresos básicos para aquellas personas que no pudieron insertarse en el mercado formal, conlleva grandes costos para éstos, traducidos en bajos salarios, ausencia de beneficios laborales y protección en salud, afectando desproporcionalmente a determinados grupos vulnerables del mercado de trabajo.

Según la ENAHO-2014, y la definición de empleo informal del INEI, ocho de cada diez mujeres (76.1\%), y siete de cada diez hombres (70.3\%), tienen un empleo informal en nuestro país; concentrándose en los grupos etarios más jóvenes, 79.8\% de los jóvenes de 14 a 29 años de edad tiene un empleo informal, en comparación con el 69.8\% de adultos mayores de veintinueve años (INEI, 2014).

Los departamentos con menores ingresos por persona, como Apurímac, Puno y Huánuco, han presentado elevadas tasas de empleo informal, lo cual implica que la informalidad laboral tiene mayor incidencia en las zonas más pobres del país.

\footnotetext{
19 La OIT señala que Nicaragua también debe estar incluido entre los países con mayor informalidad, pero que no se tienen estadísticas actualizadas al respecto.
} 


\section{CEPLAN, indica:}

La evidencia sugiere una relación inversa (con diferentes matices) entre la informalidad del empleo y los niveles de ingresos de los trabajadores; a pesar de ello, la informalidad está presente en los diferentes estratos socioeconómicos. En Perú, según la ENAHO-2014 y la definición de empleo informal del INEI, la cuarta parte de los ocupados más pobres (primer cuartil) tiene una tasa de empleo informal de $98.8 \%$, mientras que la cuarta parte de los trabajadores más ricos (cuarto cuartil) tiene una tasa de 33.3\%. (2016, p. 21).

La relación entre Informalidad y pobreza fue demostrada con un modelo aplicado por WIEGO $^{20}$ en seis países en desarrollo -Costa Rica, Egipto, El Salvador, Ghana, la India y Sudáfrica- mediante un análisis de los datos nacionales de estos países. Alter, señala "En todos los países, los ingresos medios bajaron y el riesgo de pertenecer a un hogar pobre aumentó mientras más baja la situación de empleo del trabajador en el modelo de WIEGO” (2012, p.8).

El nivel educativo tiene asimismo una relación directa con el empleo informal. Los trabajadores con bajos niveles de escolaridad poseen las mayores tasas de empleo informal. El 78.9\% de personas que posee nivel de secundaria tiene un empleo informal, en comparación con los que tienen educación superior, quienes poseen una tasa de $45.2 \%$. Por categoría ocupacional, el $89.3 \%$ de trabajadores informales son independientes y el 21.6\% labora de manera informal en el sector público (INEI, 2014).

\footnotetext{
${ }^{20}$ WIEGO, fundada en 1997, es una red global dedicada a la acción, la investigación y las políticas que busca mejorar la situación de los trabajadores pobres en la economía informal, especialmente la de las mujeres. Consultar www.wiego.org
} 
Hasta este punto y con la diversa información bibliográfica que no hacen más que confirmar la relación entre informalidad y pobreza, sin perjuicio de la calidad del marco normativo formulado hasta hoy por nuestros legisladores, es preciso indagar sobre qué otros factores estarían influyendo para que la informalidad no se reduzca, aún en los períodos de mayor crecimiento económico.

De acuerdo a Webb, esos otros factores están referidos al aspecto cultural, llega a esta conclusión, considerando asimismo la explicación de la economista Claudia Cooper, "Han sido múltiples los esfuerzos para mejorar el marco normativo, dice, pero estos son derrotados por la discrecionalidad de las personas que aplican las normas. Igual sucede con los esfuerzos para crear instituciones, que también caen víctimas de la arbitrariedad en la gestión” (2015, s.p.).

En este contexto, es necesario replantear las estrategias implementadas y la forma de hacer las cosas hasta hoy; es preciso como señala Moore (1998) que los directivos públicos se centren en crear valor público, para ello deben cambiar su manera de pensar a una dinámica y estratégica, abierta y preparada para plantear soluciones innovadoras que se adapten a las nuevas demandas; desarrollen sus habilidades para generar consensos, acuerdos sostenibles entre la variedad de actores que facilite la implementación y seguimiento de las estrategias y finalmente la evaluación de los resultados; es precisamente lo que debemos considerar en la propuesta de política pública.

\section{Como indica Webb:}

Hoy, finalmente, sabemos que la informalidad es un concepto central para explicar la mayor parte de los males de nuestra sociedad, como el crimen, la corrupción, la falta de partidos políticos, el exceso de pequeñas empresas, la desprotección laboral de los trabajadores, la poca recaudación, el caos del tráfico, la limitada productividad empresarial $\mathrm{y}$, por lo tanto, la persistente pobreza nacional. (2015, s.p.). 
Ya tenemos el conocimiento, pero poco se ha avanzado - según las estimaciones de la OIT tendrán que pasar unos 50 años para reducir la informalidad a la mitad- los peruanos no deben esperar tanto tiempo, es necesario un cambio drástico con oportunidades para las nuevas generaciones, especialmente para los más vulnerables, es una oportunidad y un derecho que el Estado tiene la obligación de proveer. 


\section{CAPÍTULO IV}

\section{FORMULACIÓN DE LA POLÍTICA PÚBLICA}

\subsection{Generación de valor público}

De acuerdo a Moore (1998), un directivo público se asegurará de que la estrategia organizativa genera valor público cuando logra alinear tres factores o dimensiones: dimensión sustantiva, dimensión política y dimensión operativa, satisfaciendo sus correspondientes pruebas, según se señala a continuación:

\begin{tabular}{|l|l|l|}
\hline \multicolumn{2}{|l|}{ Dimensiones de la estrategia organizativa } & \multicolumn{1}{|c|}{ Pruebas } \\
\hline $\begin{array}{l}\text { 1. Declara el propósito general de la } \\
\text { organización sobre la base de valores } \\
\text { públicos importantes. }\end{array}$ & $\begin{array}{l}\text { La estrategia es valiosa para la comunidad en } \\
\text { su conjunto. Perciben beneficios para la } \\
\text { ciudadanía en general. }\end{array}$ \\
\hline $\begin{array}{l}\text { 2. Explica las fuentes de apoyo legítimo } \\
\text { (político). }\end{array}$ & $\begin{array}{l}\text { Tiene el apoyo político y los recursos } \\
\text { económicos del entorno autorizador. }\end{array}$ \\
\hline $\begin{array}{l}\text { 3. Explica cómo se organizarán y } \\
\text { gestionarán las tareas. }\end{array}$ & $\begin{array}{l}\text { Se dispone de los recursos humanos, logísticos } \\
\text { y financieros de la organización o de otras } \\
\text { instituciones comprometidas con el mismo } \\
\text { propósito. }\end{array}$ \\
\hline
\end{tabular}

Cuadro 6: Dimensiones de la estrategia organizativa.

Fuente: Adaptado Gestión estratégica y creación de valor en el sector público, Moore, 1998, p. $115,116$.

A continuación, se explican las tres dimensiones que garantizarán el éxito de la política propuesta, "SUNAT: Incentivos para ampliar la base tributaria en el sector de Micro y Pequeñas empresas". 


\subsubsection{Dimensión Sustantiva de la Política.}

Sobre la base de la información estadística disponible, se determina que en el año 2015 el sector informal en el Perú alcanzó el 76.5\% de las unidades productivas del país, con un nivel de producción de aproximadamente 19\% del PBI nacional y una absorción de mano de obra de 56\% de la Población Económica Activa (PEA). En este contexto, el mayor porcentaje de micro y pequeñas empresas informales en el país son de baja productividad, con bajos niveles de ventas y con pocas posibilidades de generar empleo formal.

Las MYPEs informales, especialmente las microempresas de subsistencia, no tienen el nivel de productividad suficiente para cubrir los múltiples costos de ser formal (obligaciones laborales y tributarias, entre otros); a diferencia de las micro y pequeñas empresas de acumulación, aquellas que han logrado un cierto nivel de operaciones para cubrir los costos de producción y que con los incentivos adecuados podrán generar una rentabilidad suficiente para invertir en capital y seguir creciendo; no obstante, aun tienen que enfrentar altos costos financieros que dificultan su acceso al financiamiento y capital de trabajo, lo que sumado al desconocimiento de información sobre su sector o los mercados en los que compite, las hace menos competitivas y dificulta su crecimiento hacia un mayor nivel de acumulación.

No obstante, el sector informal igualmente consume y congestiona los servicios públicos, aun cuando no contribuya con los ingresos tributarios necesarios para mantenerla, como sí lo hacen los formales; es lo que Loayza (2008), identifica como el factor externo negativo de la informalidad, que se agrega a su efecto adverso sobre la eficiencia y pone en riesgo las perspectivas de crecimiento del país.

Dada la complejidad y el impacto multidimensional de esta problemática pública, el Estado debe implementar una política integral sobre la base de las necesidades del micro y pequeño empresario informal. En este contexto, la SUNAT como organismo encargado de proporcionar los recursos necesarios para la sostenibilidad fiscal y la estabilidad macroeconómica, debe impulsar una política de incentivos en el sector de Micro y Pequeñas 
empresas que contribuya a mejorar su rentabilidad, a fin de ampliar efectivamente la base tributaria en el segmento MYPE.

\subsubsection{Dimensión Operativa de la Política.}

La implementación de la política propuesta requerirá la activa participación de las siguientes instituciones públicas: MEF, PRODUCE, SUNAT, COFIDE y SUNARP, las cuales están comprometidas con el propósito de incentivar la formalización de las MYPE. A continuación, se detallan los recursos humanos, logísticos y financieros que se requerirán para la organización y gestión de las actividades necesarias para cumplir con los objetivos de la política pública, lo que contribuirá a garantizar su continuidad en el tiempo.

\subsubsection{Recursos Humanos.}

Los recursos humanos requeridos y algunas de las principales tareas, son los siguientes:

a. Profesionales y directivos del Ministerio de Economía y Finanzas

-Elaborar proyecto para la conformación de un fondo de financiamiento en el marco de una "ley de incentivos para ampliar la base tributaria en el sector MYPE”.

- Observar proyecto de exoneración de impuestos para las microempresas que se formalicen en el marco de la "ley de incentivos para ampliar la base tributaria en el sector MYPE".

-Elaborar convenio de administración del fondo de financiamiento con COFIDE.

b. Profesionales y directivos de la Corporación Financiera de Desarrollo (COFIDE).

Responsables de convocar, evaluar y seleccionar a las entidades financieras nacionales o internacionales, que puedan ofrecer a las MYPE colocaciones a una tasa de interés referencial de $10 \%$ en promedio anual. 
c. Profesionales y directivos de la Superintendencia de Banca, Seguros y AFP (SBS).

Establecer los lineamientos de regulación y supervisión de las entidades financieras que se acojan al programa de acceso financiero de las MYPEs.

d. Profesionales y directivos de SUNAT

-Elaborar proyecto de exoneración de impuestos para las microempresas que se formalicen con el programa.

- Participar en el programa de capacitación de MYPEs en los temas tributarios

-Difundir beneficios del programa en Centros de Atención y otras herramientas de contacto disponibles.

- Participación en campañas de difusión masiva sobre los incentivos para la formalización.

-Registro y seguimiento de empresas que se formalizan.

e. Profesionales y directivos del Ministerio de la Producción (PRODUCE)

- Realizar convenios con Colegio de Notarios respecto a la reducción de costos notariales a las MYPEs que se constituyen como persona jurídica.

-Elaborar, a través de CODEMYPE el programa de capacitación integral para las MYPEs formalizadas.

- Coordinar y establecer convenios con Universidades e Institutos, para que brinden el servicio de capacitación.

-Elaboración de campañas de difusión masiva sobre nuevos incentivos para la formalización de las MYPEs.

f. Profesionales y directivos de la Superintendencia Nacional de Registros Públicos.

-Elaborar y aprobar el proyecto de exoneración de costos registrales de las MYPEs que se formalicen con el programa

-Mantenimiento del Sistema de Intermediación digital, SID-SUNARP. 


\subsubsection{Recursos Logísticos.}

Los recursos logísticos requeridos para la implementación de la política pública son los siguientes:

a. Sistema de registro de la SUNAT, al que se le hará una adecuación para la identificación y seguimiento de las MYPEs acogidas al programa.

b. Sistema de declaraciones de la SUNAT; adecuación para la exoneración de tributos a las microempresas registradas con el programa, durante el período establecido.

c. Material de difusión y herramientas de contacto con los nuevos inscritos para seguimiento.

d. Desarrollo de un campus virtual MYPE, como plataforma de educación online.

e. Locales, mobiliarios y equipos de cada institución

\subsubsection{Recursos Financieros.}

La implementación de la política pública se financia con cargo al presupuesto institucional de las entidades involucradas: MEF, PRODUCE, SUNARP, SUNAT.

- Costos de capacitación financiado con el presupuesto del Ministerio de Producción (PRODUCE).

- Costos de constitución y formalización de empresas, con presupuesto de SUNARP.

- Recursos humanos financiados con el presupuesto de cada entidad involucrada. 


\subsubsection{Dimensión Política de la Política.}

4.1.3.1 Identificación de los grupos de interés.

Los actores políticos que juegan un rol importante para la implementación de la política propuesta y van a permitir la promoción y formalización de las MYPE son:

\section{Del Sector Público:}

a. Ministerio de Producción (PRODUCE).- Es el órgano rector, que establece la política general y las normas de promoción, competitividad y desarrollo de las MYPE y coordina con el sector público y privado las políticas sectoriales.

b. Ministerio de Economía y Finanzas (MEF).- Está encargado de planear, dirigir y controlar los asuntos relativos a presupuesto, tesorería, endeudamiento, contabilidad, política fiscal, inversión pública y política económica y social.

c. Ministerio del Trabajo y Promoción del Empleo.- Se encarga de formular, planificar, dirigir, coordinar, ejecutar, supervisar y evaluar las políticas nacionales en materias socio laborales, derechos fundamentales en al ámbito laboral, seguridad y salud en el trabajo.

d. Congreso de la República.- A través de su función legislativa, está a cargo del debate y aprobación de las leyes vinculadas al sector MYPE, orientadas a su promoción y desarrollo.

e. Superintendencia Nacional de Administración tributaria (SUNAT).Está a cargo de la administración del Registro Nacional de la Micro y Pequeña Empresa (REMYPE). Entre sus funciones está la administración de los tributos internos del Gobierno Nacional y los conceptos tributarios y no tributarios que se le encargue por Ley o de acuerdo a Convenios Interinstitucionales.

f. Superintendencia Nacional de Registros Públicos (SUNARP).- Es el ente rector del Sistema Nacional de Registros Públicos y es el encargado de dictar las políticas y normas técnico - registrales de los registros públicos que 
integran el Sistema Nacional, además dirige y supervisa la inscripción y publicidad de actos y contratos en los Registros que conforman el Sistema.

g. Registro Nacional de Identificación y Estado Civil (RENIEC).- Es el responsable de organizar y mantener el Registro Único de identificación de las personas naturales, además de adoptar mecanismos para garantizar la seguridad de la confección de los documentos de identidad e inscribir los hechos y actos relativos a su capacidad y estado civil.

h. Corporación Financiera de Desarrollo (COFIDE).- Apoya a las MYPE, mediante operaciones de intermediación financiera, canalizando los recursos a través de instituciones financieras intermediarias para proveer de recursos a las pequeñas y medianas empresas.

i. Gobiernos Regionales.- Fomentan el desarrollo regional, promoviendo la inversión pública y privada, así como el empleo y conducen la gestión pública regional. Promueven el desarrollo, la formalización y la competitividad de las MYPE en su ámbito.

j. Gobiernos Locales.- Se encargan de la administración local de un pueblo o de una ciudad, planifican el desarrollo urbano y rural de sus circunscripciones y participan en la gestión de las actividades y servicios inherentes al Estado.

\section{Del Sector Privado:}

\section{a. Micro y pequeñas empresas del sector informal.}

b. Micro y pequeñas empresas del sector formal

\section{c. Medianas y grandes empresas formales}

d. Instituciones Financieras.- Facilitan los servicios financieros a sus clientes. Actúan como intermediarios financieros.

e. Universidades e Institutos Técnicos.- Brindan el servicio de enseñanza superior, investigación y creación de cultura. Pueden incluir en su oferta educativa las orientadas a la capacitación de los empresarios y personal del sector MYPE, de acuerdo a sus necesidades para mejorar su competitividad. 
f. Notarías.- Garantiza la legitimidad de los documentos en los que interviene.

g.Centros de Desarrollo Empresarial - CDE.- Brindan servicios de constitución empresarial, asesoría personalizada y asistencia técnica para promover el desarrollo empresarial.

h. Medios de comunicación.- Son los encargados de informar y comunicar las noticias del acontecer nacional e internacional.

\section{De la Sociedad Civil:}

a. Trabajadores asalariados informales, empleado informal

b. Ciudadanía, Son los beneficiarios indirectos de la política.

\section{c. Gremios MYPE:}

- Federación de gremios de MYPEs del Norte del Perú - Normype

- Federación de empresarios de Gamarra - FEDAGA

- Federación de trabajadores en Tejidos del Perú

- Federación Nacional de trabajadores en Mercados del Perú

- Federación de trabajadores de la industria manufacturera y afines del Perú CGTP - Industria Manufacturera

- Federación Nacional de trabajadores de agroindustria y afines FENTAGRO.

- Federación del Industrial del Perú - FENAIP

\subsubsection{Elaboración del Mapa Político (posicionamiento de actores).}

La posición de los actores políticos frente a la política propuesta se muestra en el cuadro siguiente: 


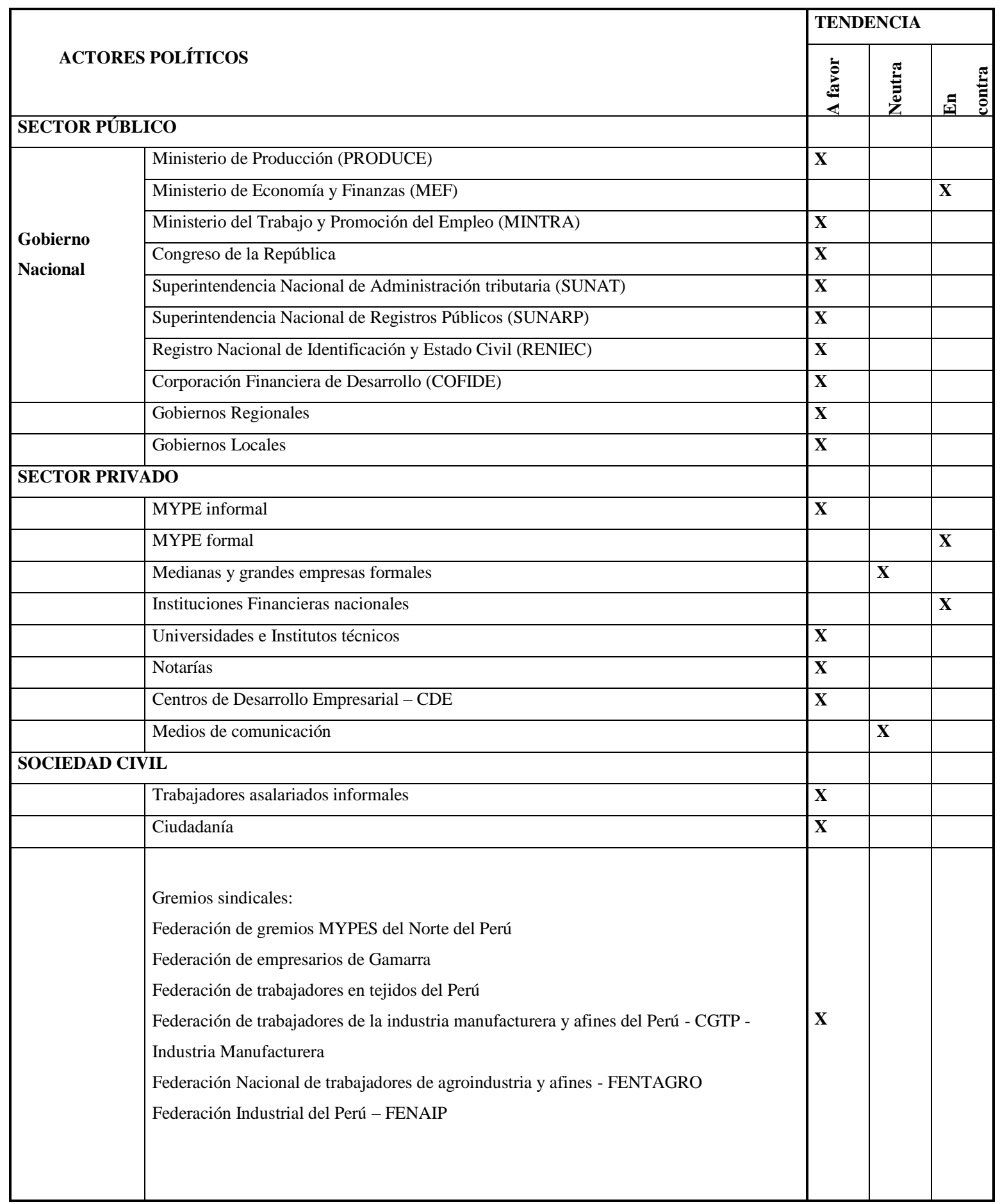

Cuadro 7. Actores políticos.

Elaboración propia. 
Los actores con tendencia en contra son:

- Ministerio de Economía y Finanzas (MEF), porque desde su perspectiva es de alto riesgo conformar un fondo de financiamiento para las MYPEs informales, adicionalmente, no cobrar impuestos los dos primeros años de su formalización significará dejar de percibir ingresos para incrementar la caja fiscal.

- Instituciones Financieras, porque que el criterio para participar del programa es que las entidades financieras sean mas competitivas, con una propuesta de tasa de interés referencial de $10 \%$ en promedio anual, que afectará su rentabilidad.

- Microempresa formal, porque las exoneraciones tributarias otorgadas con esta política no serán aplicables para las empresas ya formalizadas.

\subsubsection{Elaboración de la Tipología de Intereses de los Grupos de Interés.}

En el siguiente cuadro se puede ver los tipos de intereses de los actores políticos involucrados. 


\begin{tabular}{|c|c|c|c|c|}
\hline \multirow{2}{*}{\multicolumn{2}{|c|}{ ACTORES POLÍTICOS }} & \multicolumn{3}{|c|}{ INTERESES } \\
\hline & & $\begin{array}{l}\stackrel{0}{0} \\
\stackrel{\Xi}{0} \\
\end{array}$ & 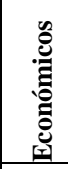 & 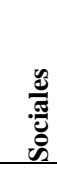 \\
\hline \multicolumn{5}{|c|}{ SECTOR PÚBLICO } \\
\hline \multirow{8}{*}{$\begin{array}{l}\text { Gobierno } \\
\text { Nacional }\end{array}$} & Ministerio de Producción (PRODUCE) & $\mathbf{X}$ & & $\mathbf{X}$ \\
\hline & Ministerio de Economía y Finanzas (MEF) & $\mathbf{X}$ & & $\mathbf{X}$ \\
\hline & Ministerio del Trabajo y Promoción del Empleo (MINTRA) & $\mathbf{X}$ & & $\mathbf{X}$ \\
\hline & Congreso de la República & $\mathbf{X}$ & & $\mathbf{X}$ \\
\hline & Superintendencia Nacional de Administración tributaria (SUNAT) & $\mathbf{X}$ & & $\mathbf{X}$ \\
\hline & Superintendencia Nacional de Registros Públicos (SUNARP) & $\mathbf{X}$ & & $\mathbf{X}$ \\
\hline & Registro Nacional de Identificación y Estado Civil (RENIEC) & $\mathbf{X}$ & & $\mathbf{X}$ \\
\hline & Corporación Financiera de Desarrollo (COFIDE) & $\mathbf{X}$ & & $\mathbf{X}$ \\
\hline & Gobiernos Regionales & $\mathbf{X}$ & & $\mathbf{X}$ \\
\hline & Gobiernos Locales & $\mathbf{X}$ & & $\mathbf{X}$ \\
\hline \multicolumn{5}{|c|}{ SECTOR PRIVADO } \\
\hline & MYPE informal & & $\mathbf{X}$ & \\
\hline & MYPE formal & & $\mathbf{X}$ & \\
\hline & Medianas y grandes empresas formales & & $\mathbf{X}$ & \\
\hline & Instituciones Financieras nacionales & & $\mathbf{X}$ & \\
\hline & Universidades e Institutos técnicos & & $\mathbf{X}$ & \\
\hline & Notarías & & $\mathbf{X}$ & \\
\hline & Centros de Desarrollo Empresarial - CDE & & $\mathbf{X}$ & \\
\hline & Medios de comunicación & & $\mathbf{X}$ & \\
\hline \multicolumn{5}{|c|}{ SOCIEDAD CIVIL } \\
\hline & Trabajadores asalariados informales & & $\mathbf{X}$ & $\mathbf{X}$ \\
\hline & Ciudadanía & & $\mathbf{X}$ & $\mathbf{X}$ \\
\hline & $\begin{array}{l}\text { Gremios sindicales: } \\
\text { Federación de gremios MYPES del Norte del Perú } \\
\text { Federación de empresarios de Gamarra } \\
\text { Federación de trabajadores en tejidos del Perú } \\
\text { Federación de trabajadores de la industria manufacturera y afines del Perú - CGTP - } \\
\text { Industria Manufacturera } \\
\text { Federación Nacional de trabajadores de agroindustria y afines - FENTAGRO } \\
\text { Federación Industrial del Perú - FENAIP }\end{array}$ & & $\mathbf{X}$ & $\mathbf{X}$ \\
\hline
\end{tabular}

Cuadro 8. Intereses de los actores.

Elaboración propia. 
Se puede observar que los actores del Sector Público tienen intereses políticos y sociales, mientras que los intereses del Sector Privado son económicos, por otro lado, los actores de la Sociedad Civil tienen intereses económicos y sociales.

Se detallará los intereses de los actores en contra, por ser los mismos, a quienes se tiene que aplicar las estrategias para el reposicionamiento:

a. El Ministerio de Economía y Finanzas, tiene intereses políticos y sociales porque el control y administración de los recursos del presupuesto debe estar orientado a brindar servicios que generen valor público.

b. MYPE formal, su interés es recibir incentivos del gobierno que le ayuden a crecer y ser competitivas para mantenerse en el mercado.

c. Instituciones Financieras nacionales, su interés es económico, orientado básicamente a incrementar sus colocaciones y rentabilidad que asegure la liquidez y solvencia de la empresa.

\subsubsection{Análisis del Poder de los Grupos de Interés.}

En el siguiente cuadro, se puede ver el tipo de poder que tiene cada uno de los actores políticos. 


\begin{tabular}{|c|c|c|c|c|}
\hline \multirow{2}{*}{\multicolumn{2}{|c|}{ ACTORES POLÍTICOS }} & \multicolumn{3}{|c|}{ TIPO DE PODER } \\
\hline & & $\stackrel{\mathscr{e}}{\stackrel{0}{\Xi}}$ & 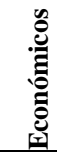 & $\begin{array}{l}\frac{\mathscr{U}}{\pi} \\
\frac{\pi}{\mathscr{E}} \\
\ddot{n}\end{array}$ \\
\hline \multicolumn{5}{|c|}{ SECTOR PÚBLICO } \\
\hline \multirow{8}{*}{$\begin{array}{l}\text { Gobierno } \\
\text { Nacional }\end{array}$} & Ministerio de Producción (PRODUCE) & $\mathbf{X}$ & & \\
\hline & Ministerio de Economía y Finanzas (MEF) & $\mathbf{X}$ & & \\
\hline & Ministerio del Trabajo y Promoción del Empleo (MINTRA) & $\mathbf{X}$ & & \\
\hline & Congreso de la República & $\mathbf{X}$ & & \\
\hline & Superintendencia Nacional de Administración tributaria (SUNAT) & $\mathbf{X}$ & & \\
\hline & Superintendencia Nacional de Registros Públicos (SUNARP) & $\mathbf{X}$ & & \\
\hline & Registro Nacional de Identificación y Estado Civil (RENIEC) & $\mathbf{X}$ & & \\
\hline & Corporación Financiera de Desarrollo (COFIDE) & $\mathbf{X}$ & & \\
\hline & Gobiernos Regionales & $\mathbf{X}$ & & \\
\hline & Gobiernos Locales & $\mathbf{X}$ & & \\
\hline \multicolumn{5}{|c|}{ SECTOR PRIVADO } \\
\hline & MYPE informal & & & $\mathbf{X}$ \\
\hline & MYPE formal & & & $\mathbf{X}$ \\
\hline & Medianas y grandes empresas formales & & $\mathbf{X}$ & \\
\hline & Instituciones Financieras nacionales & & $\mathbf{X}$ & \\
\hline & Universidades e Institutos técnicos & & $\mathbf{X}$ & \\
\hline & Notarías & & $\mathbf{X}$ & \\
\hline & Centros de Desarrollo Empresarial - CDE & & $\mathbf{X}$ & \\
\hline & Medios de comunicación & & $\mathbf{X}$ & \\
\hline \multicolumn{5}{|c|}{ SOCIEDAD CIVIL } \\
\hline & Trabajadores asalariados informales & & & $\mathbf{X}$ \\
\hline & Ciudadanía & & & $\mathbf{X}$ \\
\hline & $\begin{array}{l}\text { Gremios sindicales: } \\
\text { Federación de gremios MYPES del Norte del Perú } \\
\text { Federación de empresarios de Gamarra } \\
\text { Federación de trabajadores en tejidos del Perú } \\
\text { Federación de trabajadores de la industria manufacturera y afines del Perú - CGTP - } \\
\text { Industria Manufacturera } \\
\text { Federación Nacional de trabajadores de agroindustria y afines - FENTAGRO } \\
\text { Federación Industrial del Perú - FENAIP }\end{array}$ & & & $\mathbf{X}$ \\
\hline
\end{tabular}

\section{Cuadro 9. Grado de poder de los actores.}

Elaboración propia. 
Con relación al tipo de poder que tienen los actores en contra:

- El Ministerio de Economía y Finanzas tiene poder político, porque decide la asignación de recursos económicos de las instituciones públicas.

- Las MYPE formal tienen Poder Social, porque si no están de acuerdo con las políticas planteadas pueden generar descontento en el sector, que de no ser atendido, se puede convertir en conflicto social.

- Las instituciones financieras tienen poder económico e influencia en la economía, que puede influir en las decisiones políticas del gobierno.

\subsubsection{Elaboración de Estrategias para reposicionamiento de actores.}

De acuerdo a lo señalado en el Mapa Político, los actores con tendencia en contra son:

a. Ministerio de Economía y Finanzas, tiene intereses políticos y económicos.

b. Instituciones financieras nacionales, tienen interés económico.

c. MYPE formal, tienen interés económico.

Asimismo, los actores con tendencia neutral son: COFIDE, los medios de comunicación y las medianas y grandes empresas formales.

La estrategia a plantear está orientada a revertir la posición de los actores en contra, dependiendo del tipo de poder e intereses de los mismos.

\section{Ministerio de Economía y Finanzas (MEF)}

A partir de la Encuesta Nacional de Empresas ejecutada por primera vez en el año 2015, a solicitud y cooperación del Ministerio de la Producción, el Estado tiene evidencia de que los cuatro principales factores que limitan el crecimiento empresarial son: la informalidad (39.5\%), la demanda limitada (36,7\%), la dificultad para acceder al financiamiento $(34,8 \%)$ y excesiva regulación tributaria $(30,6 \%)$. A partir de la 
identificación de estas necesidades, el gobierno se encuentra dispuesto a implementar las políticas públicas que generen los resultados esperados por la población.

La gestión de los Fondos por parte de COFIDE tienen resultados positivos, los resultados pueden verificarse en cada memoria anual de la institución, no obstante, en la última del 2017, se señala que el FORPRO no está alcanzando los objetivos esperados y requiere modificarse. Por otra parte, en la situación actual las microempresas informales no aportan a la recaudación; con la exoneración del pago de impuestos durante los dos primeros años de formalizada la microempresa, bajo ciertas características que debe cumplir, no se afectará la caja fiscal, generándose la probabilidad de que asuma el pago de sus impuestos tributarios, al tercer año.

\section{Instituciones Financieras}

Generación de competencia entre las instituciones financieras existentes en el mercado, al convocar a las instituciones financieras nacionales e internacionales a ingresar al Programa para atender los créditos financieros del sector MYPE recientemente formalizado; por lo que una menor tasa de interés puede ser contrarrestado con todo el potencial de crédito de este sector que podría bancarizarse. Asimismo, considerando que el microcrédito requiere tratamiento especial y tramite especial, la tasa referencial de $10 \%$ podría subir 2 o 3 puntos para incorporar estos costos.

\section{MYPE formal}

Difusión de los otros incentivos a los que puede acceder las MYPE formal con la implementación de la política, como son el acceso al financiamiento a una mejor tasa de interés y el acceso al nuevo programa de capacitación presencial y virtual, con énfasis en: Gestión de la Excelencia, Apertura de Mercados y Administración de Recursos Humanos. 


\subsubsection{Elaboración del Balance Político.}

Con las estrategias planteadas, se espera que el Ministerio de Economía y Finanzas, se traslade de tener una tendencia negativa a una tendencia positiva, las MYPE formales pasarán de tener tendencia en contra a una tendencia neutral y las Instituciones Financieras se trasladarán de una tendencia en contra a una tendencia a favor, es decir que estos actores inicialmente en contra, no se opondrán a la política propuesta.

Por otro lado, todos los actores de la Sociedad Civil tienen tendencia a favor, por lo que la política planteada será de alto impacto social. 


\begin{tabular}{|c|c|c|c|c|c|c|c|}
\hline \multirow{2}{*}{\multicolumn{2}{|c|}{ ACTORES POLÍTICOS }} & \multicolumn{3}{|c|}{ TENDENCIA inicial } & \multicolumn{3}{|c|}{ TENDENCIA final } \\
\hline & & 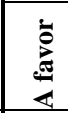 & Zّ̃ & 토 & 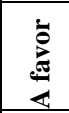 & Z̃ & 도 \\
\hline \multicolumn{8}{|c|}{ SECTOR PÚBLICO } \\
\hline \multirow{8}{*}{$\begin{array}{l}\text { Gobierno } \\
\text { Nacional }\end{array}$} & Ministerio de Producción (PRODUCE) & $\mathbf{X}$ & & & $\mathbf{X}$ & & \\
\hline & Ministerio de Economía y Finanzas (MEF) & & & $\mathbf{X}$ & $\mathbf{X}$ & & \\
\hline & Ministerio del Trabajo y Promoción del Empleo (MINTRA) & $\mathbf{X}$ & & & $\mathbf{X}$ & & \\
\hline & Congreso de la República & $\mathbf{X}$ & & & $\mathbf{X}$ & & \\
\hline & Superintendencia Nacional de Administración tributaria (SUNAT) & $\mathbf{X}$ & & & $\mathbf{X}$ & & \\
\hline & Superintendencia Nacional de Registros Públicos (SUNARP) & $\mathbf{X}$ & & & $\mathbf{X}$ & & \\
\hline & Registro Nacional de Identificación y Estado Civil (RENIEC) & $\mathbf{X}$ & & & $\mathbf{X}$ & & \\
\hline & Corporación Financiera de Desarrollo (COFIDE) & $\mathbf{X}$ & & & $\mathbf{X}$ & & \\
\hline & Gobiernos Regionales & $\mathbf{X}$ & & & $\mathbf{X}$ & & \\
\hline & Gobiernos Locales & $\mathbf{X}$ & & & $\mathbf{X}$ & & \\
\hline \multicolumn{8}{|c|}{ SECTOR PRIVADO } \\
\hline & MYPE informal & $\mathbf{X}$ & & & $\mathbf{X}$ & & \\
\hline & MYPE formal & & & $\mathbf{X}$ & & $\mathbf{X}$ & \\
\hline & Medianas y grandes empresas formales & & $\mathbf{X}$ & & & $\mathbf{X}$ & \\
\hline & Instituciones Financieras nacionales & & & $\mathbf{X}$ & $\mathbf{X}$ & & \\
\hline & Universidades e Institutos técnicos & $\mathbf{X}$ & & & $\mathbf{X}$ & & \\
\hline & Notarías & $\mathbf{X}$ & & & $\mathbf{X}$ & & \\
\hline & Centros de Desarrollo Empresarial - CDE & $\mathbf{X}$ & & & $\mathbf{X}$ & & \\
\hline & Medios de comunicación & & $\mathbf{X}$ & & & $\mathbf{X}$ & \\
\hline \multicolumn{8}{|c|}{ SOCIEDAD CIVIL } \\
\hline & Trabajadores asalariados informales & $\mathbf{X}$ & & & $\mathbf{X}$ & & \\
\hline & Ciudadanía & $\mathbf{X}$ & & & $\mathbf{X}$ & & \\
\hline & $\begin{array}{l}\text { Gremios sindicales: } \\
\text { Federación de gremios MYPES del Norte del Perú } \\
\text { Federación de empresarios de Gamarra } \\
\text { Federación de trabajadores en tejidos del Perú } \\
\text { Federación de trabajadores de la industria manufacturera y afines del Perú - } \\
\text { CGTP - Industria Manufacturera } \\
\text { Federación Nacional de trabjadores de agroindustria y fines - FENTAGRO } \\
\text { Federación Industrial del Perú - FENAIP }\end{array}$ & $\mathbf{X}$ & & & $\mathbf{X}$ & & \\
\hline
\end{tabular}

Cuadro 10. Balance Político.

Elaboración propia. 


\subsection{Enfoque integrado de políticas públicas}

El enfoque integrado de políticas públicas haciendo referencia al concepto de "competitividad sistémica" busca aprovechar las ventajas competitivas que genera la interacción de los múltiples parámetros que se activan o movilizan en la ejecución de los cuatro niveles de políticas: meta, macro, micro y meso, y que no podría lograr una por sí sola.

Así, la política de incentivos para ampliar la base tributaria en el sector de micro y pequeñas empresas generando valor público, es una política de nivel macro que requiere apoyarse en el nivel meta con una estructura básica de organización política y económica orientada a mejorar la productividad y competitividad de las MYPEs; en el nivel meso, con la simplificación de los procesos de formalización y constitución de empresas aprovechando tecnologías de información y en el nivel micro, con la capacitación técnica necesaria para mejorar la eficiencia y calidad en la gestión de las MYPEs.

\subsubsection{Identificación de Políticas de Apoyo.}

\subsubsection{Políticas Nivel Meta.}

De acuerdo al marco normativo revisado, se han identificado diversas políticas orientadas a mejorar la competitividad de las MYPEs e incentivar su formalización, pero con una baja capacidad de los actores para la interacción estratégica, organización e integración, con ausencia de tareas de seguimiento y monitoreo.

En este sentido, la política propuesta debe ir acompañada de una clara declaración de interés nacional, de mejorar la productividad y competitividad de las MYPE en todos sus niveles y sectores con objetivos medibles y adecuadamente monitoreados por los responsables políticos de la misma.

Así como la concientización del sector empresarial y sociedad civil sobre las consecuencias nocivas de la informalidad, proyectando los beneficios de la 
formalización en relación a la disminución del sector informal, en la cual están comprometidos e involucrados los grupos de principales actores. Sin perjuicio de ello los directivos públicos involucrados deben abrirse a soluciones innovativas a fin de lograr mejores resultados a los logrados hasta ahora.

\subsubsection{Políticas Nivel Macro.}

Comprende dos aspectos:

- Promover el acceso a crédito financiero a tasas de interés competitivas en el mercado.

- Exonerar del pago de impuestos a las microempresas, bajo las características que se definan, que se formalicen con el programa.

\subsubsection{Políticas Nivel Meso.}

Simplificar el trámite de formalización y constitución de empresas a un costo cero, aprovechando las tecnologías de información disponibles.

\subsubsection{Políicas Nivel Micro.}

Orientada al diseño de un programa de capacitación para mejorar la competitividad de las MYPEs, con énfasis en tres aspectos: Gestión de la excelencia, apertura de mercados y administración de recursos humanos. 


\section{CAPÍTUL O V}

\section{IMPLEMENTACIÓN DE LA POLÍTICA PÚBLICA}

\subsection{Planificación estratégica de la política con enfoque de valor público}

Si bien han sido varios los intentos del Estado de reducir la economía informal a través de diversos incentivos relacionados a los aspectos laboral, tributario y de simplificación administrativa, a la fecha no se observa una mejora sustancial del problema. El bajo estímulo que generan los incentivos para formalizarse, ofrecidos por el Gobierno, en este amplio sector de la población que genera la quinta parte del PBI y absorbe las dos terceras parte de la PEA, exige que sobre la base del modelo de gestión pública con valor público, la SUNAT impulse un plan integral de incentivos que satisfaga las principales necesidades de las micro y pequeñas empresas para mejorar su productividad y competitividad, a fin de cambiar su percepción y aceptar que los beneficios de formalizarse son mayores a los costos de acceso y permanencia en el sistema.

\subsubsection{Elaboración de la Gestión Estratégica de la Política.}

Según el Plan Estratégico Institucional de la SUNAT, del período 2017-2019, aprobado con Resolución de Superintendencia N³36-2016/SUNAT, los objetivos estratégicos de la SUNAT son los siguientes:

- OE1: Mejorar el cumplimiento tributario y aduanero.

- OE2: Reducir los costos de cumplimiento de las obligaciones tributarias y aduaneras.

- OE3: Fortalecer la capacidad de gestión interna 
El OE1 tiene una relación causal con el objetivo estratégico sectorial OES3 y la Acción Estratégica Sectorial AES3.3, del Plan Estratégico Sectorial Multianual del MEF. (SUNAT, 2017).

\begin{tabular}{|c|c|c|c|}
\hline $\begin{array}{l}\text { Objetivo Estratégico } \\
\text { Sectorial (OES) }\end{array}$ & $\begin{array}{l}\text { Acción Estratégica } \\
\text { Sectorial (AES) }\end{array}$ & $\begin{array}{c}\text { Objetivo } \\
\text { Estratégico } \\
\text { Institucional } \\
\text { (OEI) }\end{array}$ & Relación Causal \\
\hline \multirow[t]{5}{*}{$\begin{array}{l}\text { OES3: Alcanzar una } \\
\text { mayor recaudación } \\
\text { de ingresos fiscales. }\end{array}$} & \multirow[t]{3}{*}{$\begin{array}{lrr}\text { AES3.1: } & \text { Fortalecer } & \text { la } \\
\text { politica y } & \text { mecanismos } \\
\text { orientados } & \text { a } & \text { la } \\
\text { estabilidad } & \text { de } & \text { los } \\
\text { ingresos fiscales. } & \end{array}$} & $\begin{array}{l}\text { OE1: Mejorar el } \\
\text { cumplimiento } \\
\text { tributario } \\
\text { aduanero. }\end{array}$ & $\begin{array}{l}\text { La SUNAT a través de sus } \\
\text { mecanismos de control } \\
\text { contribuye a mejorar el } \\
\text { cumplimiento tributario y por } \\
\text { ende alcanzar una mayor }\end{array}$ \\
\hline & & & $\begin{array}{l}\text { recaudación de los ingresos } \\
\text { fiscales. }\end{array}$ \\
\hline & & $\begin{array}{l}\text { OE2: Reducir } \\
\text { los costos de } \\
\text { cumplimiento de } \\
\text { las obligaciones } \\
\text { tributarias y } \\
\text { aduaneras. }\end{array}$ & $\begin{array}{l}\text { La SUNAT a través de la } \\
\text { reducción de costos del } \\
\text { cumplimiento } \\
\text { contribuye a } \\
\begin{array}{l}\text { tributario } \\
\text { cumplimiento facilitar el }\end{array} \\
\text { coadyuvando a mejorar la } \\
\text { recaudación de los ingresos } \\
\text { fiscales. }\end{array}$ \\
\hline & \multirow[t]{2}{*}{$\begin{array}{l}\text { AES3.2: Fortalecer la } \\
\text { capacidad de la gestión } \\
\text { de la administración } \\
\text { tributaria y aduanera; así } \\
\text { como, de las instancias } \\
\text { de la recaudación } \\
\text { tributaria municipal. }\end{array}$} & $\begin{array}{l}\text { OE1: Mejorar el } \\
\text { cumplimiento } \\
\text { tributario y } \\
\text { aduanero. }\end{array}$ & $\begin{array}{l}\text { La SUNAT a través de sus } \\
\text { mecanismos de control } \\
\text { contribuye a mejorar el } \\
\text { cumplimiento tributario y por } \\
\text { ende alcanzar una mayor } \\
\text { recaudación de los ingresos } \\
\text { fiscales. }\end{array}$ \\
\hline & & $\begin{array}{l}\text { OE2: Reducir } \\
\text { los costos de }\end{array}$ & $\begin{array}{l}\text { La SUNAT a través de la } \\
\text { reducción de costos del }\end{array}$ \\
\hline & & $\begin{array}{l}\text { Cumplimiento de } \\
\text { las obligaciones } \\
\text { tributarias y } \\
\text { aduaneras. }\end{array}$ & $\begin{array}{lr}\text { cumplimiento } & \text { tributario } \\
\text { contribuye a facilitar el } \\
\text { cumplimiento } & \text { tributario, } \\
\text { coadyuvando a mejorar la } \\
\text { recaudación de los ingresos } \\
\text { fiscales. }\end{array}$ \\
\hline & \multirow[t]{2}{*}{$\begin{array}{l}\text { AES3.3: Impulsar la } \\
\text { formalización de la de } \\
\text { pequeña y mediana } \\
\text { empresa, el control del } \\
\text { incumplimiento tributario; } \\
\text { así como, la lucha contra } \\
\text { el contrabando y el } \\
\text { tráfico ilicito de } \\
\text { mercancias. }\end{array}$} & $\begin{array}{l}\text { OE1: Mejorar el } \\
\text { cumplimiento } \\
\text { tributario } \\
\text { aduanero. }\end{array}$ & $\begin{array}{l}\text { La SUNAT impulsa la } \\
\text { formalización de la pequeña y } \\
\text { mediana empresa a través del } \\
\text { control del incumplimiento } \\
\text { tributario, contribuyendo a } \\
\text { alcanzar una mayor } \\
\text { recaudación de ingresos } \\
\text { fiscales basada en la } \\
\text { formalización de los agentes de } \\
\text { la actividad económica. }\end{array}$ \\
\hline & & $\begin{array}{l}\text { OE2: Reducir } \\
\text { los costos de } \\
\text { cumplimiento de } \\
\text { las obligaciones } \\
\text { tributarias y } \\
\text { aduaneras. }\end{array}$ & $\begin{array}{l}\text { La SUNAT a través de la } \\
\text { reducción de } \\
\text { costos del } \\
\text { cumplimiento } \\
\text { contribuye a facilitar el } \\
\text { cumplimiento } \\
\text { coadyuvando a mejorar la } \\
\text { recaudación de los ingresos } \\
\text { fiscales, contribuyendo así a la } \\
\text { formalización de los agentes de } \\
\text { la actividad económica. }\end{array}$ \\
\hline
\end{tabular}

Cuadro 11. Relación Objetivos Estratégicos Sectoriales e Institucionales. Fuente: SUNAT, PEI 2017-2019. 
Observamos que para contribuir a alcanzar el OES3: Alcanzar una mayor recaudación de ingresos fiscales", en el marco de la actividad sectorial OES3, la SUNAT propone "Mejorar el cumplimiento tributario y aduanero (OE1)", planteando la siguiente relación causal: "La SUNAT impulsa la formalización de la pequeña y mediana empresa a través del control del incumplimiento tributario, contribuyendo a alcanzar una mayor recaudación de ingresos fiscales basados en la formalización de los agentes de la actividad económica".

El planteamiento de impulsar la formalización sólo a través del control, es una posición que deberá ser enriquecida con otras estrategias para finalmente incentivar la formalización y lograr una real ampliación de la base tributaria; para lo cual se debe partir por reconocer la realidad económica de las MYPEs informales y sus necesidades insatisfechas que limitan su productividad y competitividad.

La SUNAT debe incorporar en su planeamiento estratégico, objetivos y actividades que mejoren la percepción de las MYPEs y de la ciudadanía en general, de que la institución está comprometida con la sostenibilidad y crecimiento de aquellas, como base fundamental para una efectiva ampliación de la base tributaria e incremento de la recaudación. El éxito de la estrategia se sustentará en el acuerdo sostenible entre los diversos actores que participan o se ven afectados por la política, desde los microempresarios hasta las instituciones financieras, pasando por el gobierno, quien en sus tres niveles tiene el desafío de generar valor público con impacto en la ciudadanía en general

En ese sentido, se propone que la nueva relación causal para el cumplimiento del OE1, debe ser: "La SUNAT impulsa la formalización de la pequeña y mediana empresa, promoviendo incentivos que mejoren su rentabilidad y controlando el incumplimiento tributario, contribuyendo a alcanzar una mayor recaudación de ingresos fiscales basados en la formalización de los agentes de la actividad económica". 


\subsubsection{Determinación de la Población Objetivo.}

A fin de implementar la estrategia con los objetivos que se desarrollan más adelante, previamente se debe determinar la población objetivo beneficiaria de la política.

\section{Población afectada}

El universo de población afectada está comprendido por todas las MYPEs informales del país, las que en el año 2016 se estimaban en 1 millón 973 mil 888²1. La estimación, realizada por PRODUCE, se obtiene de la diferencia entre el total de micro y pequeñas empresas estimadas con información de la ENAHO y las registradas en la base de la SUNAT. Según la metodología utilizada el número total de MYPEs se estima a través del número de conductores de negocios o empresas, que comprende a empleadores (patrono con uno o más trabajadores remunerados a su cargo) y trabajadores por cuenta propia, estos últimos con trabajadores familiares no remunerados (TFNR) a su cargo 22 (Ministerio de producción, 2017).

\section{Población postergada}

Dado que esta política busca ampliar la base tributaria con MYPEs que puedan cubrir los costos de ser formal, es preciso postergar a las microempresas de subsistencia y focalizarnos en las micro y pequeñas empresas de acumulación. De acuerdo a la definición del Sistema Integrado de Apoyo a la Pequeña Empresa BMI \& Banco Multisectorial de Inversiones (1997), concordante con la utilizada en el Plan MYPE 2005-2009, las microempresas de subsistencia corresponden a un estrato de MYPEs que no tienen capacidad de generar utilidades, sus ingresos sólo les permiten cubrir por lo

\footnotetext{
${ }^{21}$ Obtenido de tabla 3, Estimación del número de micro y pequeñas empresas informales, 2010-2016.

22 Según el Manual del Encuestador de la ENAHO, un empleador o patrono es la persona que explota su propia empresa o negocio o que ejerce por su cuenta una profesión u oficio y tiene uno o más trabajadores remunerados a su cargo. En tanto, un trabajador independiente es la persona que explota su propio negocio o que ejerce por su cuenta una profesión u oficio, no tiene trabajadores remunerados a su cargo.
} 
general necesidades básicas del hogar del microempresario (alimentación, vivienda, educación, etc.), limitando sus posibilidades de acumular, por tal motivo esta población se posterga, ya que no está en capacidad económica de afrontar la carga tributaria y/o asumir el costo de un eventual crédito financiero.

Por el contrario, las micro y pequeñas empresas de acumulación son aquellas que han logrado un cierto nivel de operaciones para cubrir los costos de producción y que con los incentivos adecuados podrán generar una rentabilidad suficiente para invertir en capital y seguir creciendo.

Para estimar las microempresas de subsistencia, se considera que son ingresos de subsistencia aquellos ingresos mensuales que sólo cubren el costo de la Canasta Básica de Consumo (CBC), considerando que este costo es el límite donde se traza la línea de pobreza monetaria (canasta alimentaria y no alimentaria), que separa a los pobres de los no pobres; la CBC para una familia de cuatro miembros es equivalente a S/ 1260 mensuales, con un gasto per cápita de S/ 315 (año 2015) (INEI, 2016).

Para cubrir la CBC mensual, MYPE debe generar un volumen mínimo de venta anual de $17 \mathrm{UIT}^{23}$, asumiendo una tasa de rentabilidad sobre las ventas de 22,7\%, tasa promedio determinada para empresas con ventas netas hasta 300 UIT, según el IV Censo Nacional Económico, 2008. En ese sentido, por definición, según el criterio de volumen de ventas, encontraremos que existen microempresas de subsistencia y microempresas de acumulación, en tanto todas las pequeñas empresas son empresas de acumulación.

Para determinar la cantidad de microempresas informales con ventas anuales menores o iguales a 17 UIT, se recurrió a la información disponible de MYPEs formales según rangos de venta anual, estimada por PRODUCE para el año 2016 (ver Tabla 5); en base a lo cual se calcula que el 77,6\% de MYPEs formales tiene un volumen de ventas que no excede las 17 UIT al año, las que constituyen el estrato de MYPEs de Subsistencia que será postergado; en tanto, el 22,4\% restante tiene volúmenes de venta

\footnotetext{
${ }^{23}$ UIT (2016) equivalente a S/ 3,950.
} 
mayores a 17 UIT al año, lo que constituye el estrato de MYPEs de acumulación (ver Tabla 6).

Es preciso anotar, que dentro del rango de [0 - 2] UIT, donde se concentra el $40 \%$ de las MYPEs formales, aproximadamente la mitad registran ventas igual a cero (Ministerio de Producción, 2017). Esto nos da una idea de que el crecimiento de la base tributaria que se ha dado en la última década no va aparejado con un efectivo crecimiento de la recaudación.

Tabla 5.

Perú: MYPES formales según rango de ventas, 2016.

\begin{tabular}{|c|c|c|c|}
\hline \multirow{2}{*}{$\begin{array}{l}\text { Rango de venta } \\
\text { anual (UIT) }\end{array}$} & \multicolumn{3}{|c|}{ MYPE } \\
\hline & Número & Part. (\%) & Acumulado \\
\hline$[0-2]$ & 688,878 & 39.9 & 39.9 \\
\hline ]2 - 5] & 248,769 & 14.4 & 54.3 \\
\hline ]5 - 13] & 334,894 & 19.4 & 73.7 \\
\hline ]13 - 20] & 116,359 & 6.7 & 80.5 \\
\hline ]20 - 25] & 50,660 & 2.9 & 83.4 \\
\hline ]25 - 50] & 104,412 & 6.0 & 89.4 \\
\hline ]50 - 75] & 48,410 & 2.8 & 92.3 \\
\hline ]75 - 100] & 28,214 & 1.6 & 93.9 \\
\hline ]100 - 150] & 31,475 & 1.8 & 95.7 \\
\hline ]150 - 300] & 35,190 & 2.0 & 97.7 \\
\hline ]300 - 500] & 17,296 & 1.0 & 98.7 \\
\hline ]500 - 850] & 11,782 & 0.7 & 99.4 \\
\hline ]850 - 1700] & 9,817 & 0.6 & 100.0 \\
\hline Total general & $1,726,156$ & 100.0 & \\
\hline
\end{tabular}

Fuente: Adaptado de MIPYME formales, según rango de ventas - 2015, 2016, p. 39. 
Tabla 6.

Perú: MYPES formales según volumen de ventas de subsistencia y acumulación, 2016.

\begin{tabular}{|c|c|c|c|c|}
\hline \multirow{2}{*}{$\begin{array}{c}\text { Volumen de } \\
\text { venta anual } \\
\text { (UIT) }\end{array}$} & \multicolumn{4}{|c|}{ MYPE } \\
\hline & Número & $\begin{array}{l}\text { Part. } \\
(\%)\end{array}$ & Estrato & $\begin{array}{l}\text { Part. } \\
(\%)\end{array}$ \\
\hline [0 - 17] & $1,339,032$ & 77.6 & Subsistencia & 77.6 \\
\hline ]17 - 50] & 204,940 & 11.9 & & \\
\hline ]50 - 150] & 108,099 & 6.3 & Acumulación & 22.4 \\
\hline ]150 - 1700] & 74,085 & 4.3 & & \\
\hline Total general & $1,726,156$ & 100.0 & & 100.0 \\
\hline
\end{tabular}

\section{Población objetivo}

Asumiendo que la distribución de MYPEs informales según rango de ventas es similar a las MYPEs formales, se estima que el estrato de micro y pequeñas empresas de acumulación que conformarán la población objetivo, es de aproximadamente 442 mil 683 empresas $(22,4 \%)$.

El estrato de microempresas de subsistencia en el sector informal que son excluidas ascienden a 1'531,205 (77,6\%). (ver figura 2). 


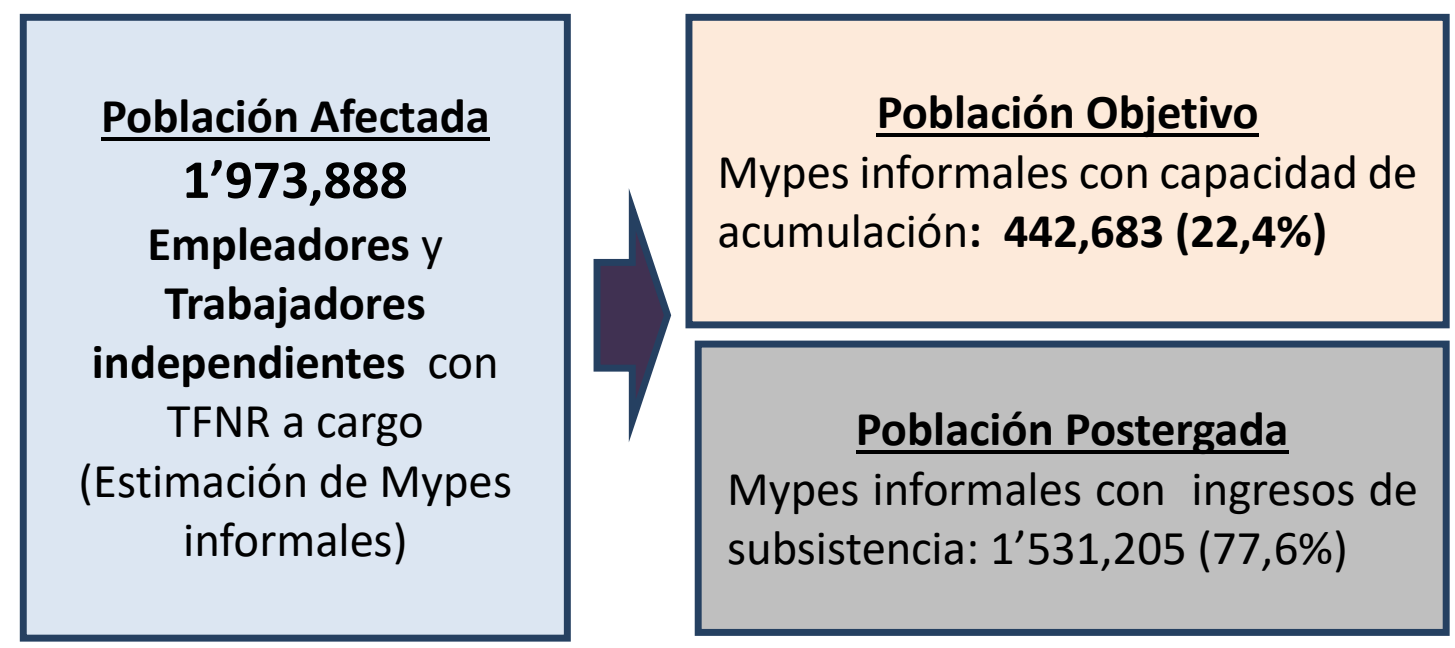

Figura 2. Estimación de población objetivo

Nota: Información extraída de PRODUCE.

Elaboración propia.

En la población objetivo, grupo con posibilidades de acumulación, es necesario distinguir las MYPEs de acumulación simple de las MYPEs de acumulación ampliada, previéndose el segundo como el estrato más solvente, con mayor probabilidad de pago a efecto de acceder a créditos financieros. Para tal efecto se estimó que con un volumen de ventas mayor a 16,700 soles mensuales, equivalente a 50 UIT de ventas al año, con una rentabilidad de 22,7\% (INEI, 2008), la MYPE puede generar un ingreso de 3,780 soles (aproximadamente el valor de 3 Canastas Básicas de Consumo), lo que le permitiría cubrir: los costos de subsistencia (S/ 1 260), el pago de al menos un salario mínimo vital (S/ 850) y la cuota de un crédito financiero (S/1 465), este último, considerando un crédito para capital de trabajo de S/ 16 700, a doce meses con una tasa de interés mínima de 10\% anual. En ese sentido, se considera MYPE de acumulación ampliada, aquélla con ventas anuales por encima de 50 UITs.

En la tabla 6 podemos observar que el porcentaje de micro y pequeñas empresas con ventas anuales por encima de 50 UIT, representan el 10,6\% de las MYPEs formales, las que constituirían el estrato MYPE de Acumulación Ampliada, en tanto el $11.9 \%$ restante con ventas entre 17 y 50 UIT conformarían el estrato de Microempresas de Acumulación Simple. Se determina pues, que las microempreas (volumen de ventas hasta 
150 UIT) pueden ser de de acumulación ampliada o de acumulación simple, en tanto todas las pequeñas empresas (volumen de ventas mayor a 150 UIT hasta 1700 UIT) son de acumulación ampliada.

En base a dicha información del sector formal, estimamos los estratos MYPE de Acumulación Ampliada y Microempresas de Acumulación Simple, en el sector informal, lo que viene a constituir la población objetivo. Se observa (ver Tabla 7) que el estrato de acumulación simple constituido totalmente por microempresas constituye el $53 \%$ de la población objetivo, en tanto el estrato de acumulación ampliada constituido por microempresas (28\%) y pequeñas empresas (19\%), representan el $47 \%$ restante. En general, la población objetivo se compone de un $81 \%$ de microempresas y $19 \%$ de pequeñas empresas.

Tabla 7.

Mypes informales de acumulación, según volumen de ventas, estrato y tamaño, 2016.

\begin{tabular}{|c|c|c|c|c|}
\hline \multirow{2}{*}{$\begin{array}{l}\text { Volumen de venta } \\
\text { anual (UIT) }\end{array}$} & \multicolumn{4}{|c|}{ MYPE informal } \\
\hline & Número & $\begin{array}{l}\text { Part. } \\
(\%)\end{array}$ & Estrato & Tamaño \\
\hline ]17 - 50] & 234,352 & 52.9 & $\begin{array}{l}\text { Acumulación simple } \\
(52.9 \%)\end{array}$ & \multirow{2}{*}{$\begin{array}{l}\text { Microempresas } \\
(80.9 \%)\end{array}$} \\
\hline ]50 - 150] & 123,613 & 27.9 & \multirow{2}{*}{$\begin{array}{l}\text { Acumulación ampliada } \\
(47,1 \%)\end{array}$} & \\
\hline ]150 - 1700] & 84,717 & 19.1 & & $\begin{array}{l}\text { Pequeña empresa } \\
(19.1 \%)\end{array}$ \\
\hline
\end{tabular}

Nota: Información extraída de PRODUCE.

Elaboración propia.

\subsubsection{Definición de Objetivo General.}

El objetivo general de la política pública propuesta es la siguiente:

“Incentivar la formalización de las Micro y Pequeñas empresas en el país.” 
Se pretende que con los incentivos positivos que brinde el Estado a las micro y pequeñas empresas informales, éstas conozcan y valoren los beneficios de la formalización en su desarrollo empresarial y el impacto positivo en la economía del país.

\subsubsection{Definición de Objetivos específicos.}

Para alcanzar el objetivo general, se plantean los objetivos específicos desarrollados a continuación:

a. Promover el acceso a crédito financiero a tasas de interés competitivas en el mercado

\section{Situación actual}

El Gobierno ha creado el Fondo para el Fortalecimiento Productivo de las MYPE- FORPRO, para la reactivación y fortalecimiento productivo de la micro y pequeña empresa afectada por el Fenómeno del Niño Costero, aprobado mediante Decreto de Urgencia Nº08-2017 del 22 de abril de 2017.

Se ha sustentado que las Micro y Pequeñas Empresas (MYPEs) al ser un segmento empresarial con limitado acceso al financiamiento por los altos costos financieros, respecto a las empresas de mayor tamaño, es necesario establecer medidas que fortalezcan sus actividades productivas a través del acceso a recursos financieros que les permita financiar su capital de trabajo, y reponer y/o adquirir activos fijos. (Ministerio de la Producción, 2017).

El FORPRO, con vigencia hasta el 31 de diciembre de 2018, es administrado por COFIDE S.A. en función al convenio suscrito por éste y la Dirección General de Endeudamiento y Tesoro Público del MEF. Ambos determinan los criterios y/o parámetros de elegibilidad de las Instituciones Financieras Intermediarias (IFI), supervisadas por la SBS, las cuales canalizarán los recursos a las MYPEs. Asimismo, la 
tasa de interés que paga la IFI se establece en el Contrato de canalización de Recursos; en tanto, la tasa de interés que paga la MYPEs la define la IFI.

Las MYPEs elegibles deben contar con ingresos netos anuales correspondientes al ejercicio fiscal anterior a la solicitud del préstamo que no superen las 1,700 UIT, e inscritas en el Régimen MYPEs Tributario (RMT) o Régimen General de Renta, así como tener la categoría de riesgo normal o no reportada en la central de riesgo de la SBS.

Por otra parte, de acuerdo a diversos artículos periodísticos en los que se han tomado declaraciones tanto del presidente de COFIDE como del presidente de la Federación Peruana de Cajas Municipales de Ahorro y Crédito (FEPCMAC), en el presente año, a propósito de la emergencia causada por el Fenómeno del Niño Costero, el Sr. Jorge Solís - presidente de la Fepcmac- señalaba que con costos de fondeo entre 4 y $5 \%$ que Cofide les otorgue, las cajas municipales podrán otorgar créditos en soles a MYPEs en emergencia a tasas entre 8 y $10 \%$ anual (Gestiòn, 2017).

Por su parte, el Sr. Pedro Grados - presidente de COFIDE, ha señalado que para efecto de que las IFI puedan otorgar créditos blandos a las MYPEs afectadas por el fenómeno costero, Cofide colocaría sus recursos a tasas que llegarían a 5\%, si bien las tasas de interés a esa fecha fluctuaban entre $6 \%$ y $12 \%$, dependiendo de su riesgo (Gestión, 2017).

Sin embargo, de acuerdo a declaraciones del gerente de desarrollo de Cofide, Sr. Luis Terrones, Cofide no tiene control de la tasa final que recibe el emprendedor. "Esa es una decisión de la entidad que provee el financiamiento" (Andina, 2014).

Según la página web de la Superintendencia de Banca y Seguros del Perú (SBS), la Tasa de interés promedio del sistema financiero para créditos a la microempresa al treinta de mayo del presente año, ascendía a $43.23 \%$ anual en moneda nacional y $9.94 \%$ anual en moneda extranjera y, siendo el objetivo del FORPRO impulsar la formalización de las mype a través del financiamiento de activo fijo y capital de trabajo, en especial 
las ubicadas en zonas afectadas por el fenómeno de El Niño, es amplio el porcentaje de MYPEs que demandando el mismo tratamiento no accederá a éste, puesto que es preciso sensibilizar a la MYPE informal que su acceso a crédito estará sujeto a su nivel de crecimiento, contando con acompañamiento y facilidades tributarias sólo en el sector formal.

\section{Meta}

Las MYPE de acumulación ampliada que se formalicen con el programa, pueden acceder a financiamiento a una tasa de interés referencial de $10 \%$ al año, lo cual es garantizado con el monitoreo efectuado por las entidades responsables.

Considerando que el microcrédito requiere tratamiento especial y tramite especial, esta tasa podría subir 2 o 3 puntos del que se presta al sistema formal. Así, una tasa de 10\% es referencial y se definirá en el momento que la política sea aplicada.

Por otra parte, el beneficio de poder acceder a crédito financiero a tasas de interés competitivas es asequible para las MYPEs de acumulación ampliada, con una antigüedad mínima de dos años de operaciones. Este beneficio genera a su vez un incentivo para que las microempresas de acumulación simple, crezcan y puedan acceder al mismo. Por su parte las microempresas de acumulación ampliada tienen el incentivo de crecer a fin de acceder a mayores montos de crédito financiero que compense el costo administrativo de la operación.

\section{Responsables}

-El Ministerio de Economía y Finanzas es responsable de autorizar los recursos necesarios para la conformación del Fondo de Financiamiento y el seguimiento de la colocación de los recursos del Fondo a través de COFIDE.

-El Banco de Desarrollo del Perú (Cofide), como banco de segundo piso del Estado peruano, es el encargado de gestionar el fondo del programa, así como 
monitorear el cumplimiento de las menores tasas de interés, cercanas a la tasa referencial de $10 \%$ anual, en las colocaciones de las IFI afiliadas al programa, sin perjuicio de los costos administrativos que esto demande.

-El Ministerio de la Producción es el encargado de monitorear que los créditos otorgados con recursos del Fondo sean canalizados preferencialmente a las MYPEs de acumulación que se formalicen con el programa; sin perjuicio de que las MYPEs formalizadas antes del programa, pueden acceder a los créditos del Fondo en condiciones similares.

\section{Lineamientos}

A fin de cumplir con este objetivo las entidades responsables deberán considerar, como mínimo, los siguientes lineamientos:

- Crear un fondo de financiamiento para la canalización de créditos a las MYPEs por un período de 3 años.

- Reglamentar que en los contratos con las IFI, las tasas de interés de préstamo en el otorgamiento de créditos a las MYPEs formalizadas con el programa, se fijen con una tasa referencial de $10 \%$ al año en moneda nacional, sin perjuicio de los costos administrativos que esto demande.

- Convocar a entidades financieras nacionales e internacionales que deseen participar del programa, para atender los créditos financieros a las MYPEs con una tasa de interés referencial de $10 \%$ anual, en moneda nacional.

- Realizar el seguimiento de los planes y estrategias en materia de formalización, en el marco de sus competencias.

- Implementar la creación de un sistema de información que permita consolidar diariamente la información de las MYPEs formalizadas con el programa y la aplicación de los créditos del Fondo de Financiamiento. 


\section{b. Proponer la exoneración del pago de impuestos a las microempresas que se formalicen con el programa, por un período de dos años.}

\section{Situación actual:}

El Gobierno promulgó el Decreto Legislativo N $^{\circ} 1269$ que aprueba el Régimen MYPEs Tributario del Impuesto a la Renta (RMT), vigente desde el 01 de Enero de 2017. Un régimen jurídico tributario especial para las micro y pequeñas empresas domiciliadas en el país con ingresos netos no superiores a las 1700 UIT en el ejercicio gravable, con el objetivo, entre otros, de incentivar la reactivación económica y la formalización.

En este nuevo régimen se resaltan tres aspectos: En primer lugar, incorpora a las micro y pequeñas empresas a la cadena de comercialización, dado que al poder emitir facturas pueden vender a medianas y grandes empresas que requieren recuperar el crédito fiscal; en segundo lugar, facilita el pago gradual del impuesto a la renta, al permitirle pagar al microempresario solo $10 \%$ de IR por las primeras 15 UIT de utilidad $(60,750$ soles en el 2017) y el $29,5 \%$ por lo restante. Así también, cuando los ingresos netos anuales del ejercicio no superen las 300 UIT, el pago a cuenta será el 1\% de los ingresos netos obtenidos en el mes.

Finalmente, para disminuir la complejidad del pago, la norma crea un registro de ventas y compras y un libro diario de formato simplificados, para aquellos que tengan ingresos netos anuales hasta 300 UIT.

De acuerdo a las estadísticas disponibles para el período Enero - Abril de 2017, este régimen es un buen incentivo para las MYPEs que actualmente ya asumen sus obligaciones tributarias. Así podemos observar que en el período indicado, el RMT registraba a 377,228 contribuyentes, de los cuales el 96\% provenían de otros regímenes, principalmente del régimen general $(88,9 \%)$, y solo el $4 \%(15,039)$ eran nuevos 
contribuyentes ${ }^{24}$. A junio de 2017, según la SUNAT (Gestión, 2017), "74,000 empresas que declaran bajo el RMT provienen del RER, NRUS, son nuevos contribuyentes o han reanudado actividades" (2017, s. p.), es decir, en dos meses el RMT se habría incrementado en aproximadamente 18 mil contribuyentes que migran de otros regímenes, no destacándose la tasa de crecimiento de nuevos contribuyentes; adicionalmente, la información disponible no permite diferenciar la proporción de nuevos contribuyentes que corresponden a nuevos emprendimientos o MYPEs provenientes del sector informal.

Sin embargo, la fuerte migración de los otros regímenes al RMT estaría explicando esencialmente la presencia de más del $90 \%$ de microempresas en la base tributaria, sobre lo cual debemos agregar que el $78 \%$ son microempresas de subsistencia con baja productividad; lo que nos permite determinar que de cierta manera el RMT está equilibrando la base tributaria al facilitarle el pago gradual de tributos a microempresas que en un 92\% vende menos de 75 UIT (S/ 303,750), aproximadamente el volumen de ventas anual para gozar de la utilidad de 15 UIT afecta al 10\% del IR, sin limitarla a participar en la cadena de comercialización con las medianas empresas.

No obstante, si bien los beneficios del RMT contribuyen a ordenar la situación tributaria de las MYPEs con la gradualidad en el cálculo del IR anual y facilitarles cierta liquidez con la menor tasa de pago a cuenta del IR, no son incentivos suficientes para una MYPEs informal que de pronto debe asumir todos los costos de la formalidad, sin percibir desde esta situación, los beneficios que percibe una empresa que ya asume los costos de ser formal. Pues si lo esperado es un ingreso masivo de MYPEs informales que reduzca drásticamente el tiempo proyectado para reducir la informalidad - según CEPLAN(2016), en un escenario tendencial; CEPLAN indica, "de no implementarse una política integral para la formalización, tendrían que pasar más de treinta años para que Perú registre similares niveles de producción informal que Chile en el 2010”25 (2017,

\footnotetext{
${ }^{24}$ Ver detalle en Gráfico 11.

${ }^{25} \mathrm{Al} 2050$ el PBI informal del Perú sería de 6\%, mientras que en 2010 Chile registraba 4.8\%.
} 
p.30), - es necesario una estrategia integral que incentive la movilidad hacia el sector formal.

Dado lo cual conjuntamente con las medidas para reducir las tasas de financiamiento a las MYPEs, es preciso que el segmento de microempresas de menores ingresos, como son las microempresas de acumulación simple, que se formalicen con el programa dentro de un período establecido, pueda gozar de exoneración tributaria que le permita reducir sus costos de ingreso a la formalidad por un período determinado, a la par que se van consolidando en el sector formal.

\section{Meta:}

Las microempresas informales de acumulación simple se formalizan con el programa y son exoneradas del pago de impuestos tributarios por un período de dos años, a partir de su formalización.

La exoneración tributaria es un beneficio que se otorgará sólo a las microempresas de acumulación simple que se formalicen durante los dos primeros años del programa; la duración de la exoneración es de dos años, desde la fecha de su formalización. Asimismo, estas microempresas deben demostrar que ya operaban antes de la entrada en vigencia del programa, debiendo ser registradas en el régimen tributario MYPE y cumplir con las declaraciones establecidas.

\section{Responsables:}

-El Ministerio de Economía y Finanzas es el responsable de emitir lineamientos para la exoneración tributaria de las microempresas que se formalicen con el programa.

-La SUNAT es la responsable de llevar el control de las microempresas exoneradas de tributos, de instruirlas sobre la presentación de sus declaraciones 
mensuales y anuales que correspondan, así como el seguimiento y monitoreo del registro de MYPEs formalizadas con el programa.

\section{Lineamientos}

A fin de cumplir con este objetivo las entidades responsables deberán considerar, como mínimo, los siguientes lineamientos:

- Realizar las modificaciones necesarias en la normativa del régimen tributario MYPE a efecto de la exoneración tributaria por un período de dos años, a partir de su formalización, de las microempresas que realizando actividad empresarial en el sector informal, se registren en SUNAT durante los dos primeros años del programa.

- Contemplar que la exoneración tributaria no excluye al contribuyente de su obligación de presentar las Declaraciones tributarias y llevar los registros correspondientes al régimen tributario MYPE.

- Implementar los mecanismos necesarios para prevenir el mal uso del régimen de exoneración tributaria de las microempresas formalizadas con el programa.

- Realizar el seguimiento y monitoreo de la continuidad de la actividad empresarial de las MYPEs formalizadas con el programa.

\section{c. Simplificar el trámite de formalización y constitución de empresas de} acumulación a un costo cero.

\section{Situación actual:}

Actualmente para formalizar un negocio se debe realizar la inscripción del RUC ante SUNAT, debiendo tenerse en cuenta si se trata de una persona individual con negocio o de una persona jurídica (empresa). 
Si se trata de una persona individual con negocio $(78 \%$ de la base tributaria de persona jurídica), se debe inscribir al RUC ante $\mathrm{SUNAT}^{26}$, lo cual se puede realizar mediante pre inscripción por internet o de manera presencial, siendo necesario solo contar con el DNI.

Para la constitución de una persona jurídica (22\% de la base tributaria de persona jurídica), desde el 2014 se puede realizar la constitución de empresas en línea, a través del Sistema de Intermediación Digital SID - SUNARP. Este sistema permite la interacción con SUNAT, RENIEC y las Notarías; así, transmitida la solicitud el Notario valida la información con RENIEC y SUNAT, y SUNARP entrega la Constancia de Inscripción y el número de RUC para ser activado ante SUNAT (Ministerio de Producción, 2017).

En abril del 2017 se emite el D.S N 006-2017-PRODUCE, que aprueba el Reglamento del Decreto Legislativo $\mathrm{N}^{\circ} 1332$, que facilita la constitución de empresas a través de los Centros de Desarrollo Empresarial - CDE, exonerándose de los pagos registrales a las MYPE que cuenten con un capital social menor a 1UIT (S/ 4,050 soles) por un período de tiempo de 03 años.

Al respecto, el Ministerio de la Producción ha implementado el módulo CDE PRODUCE que se interconecta al módulo SID -SUNARP, asimismo este último ha sido adecuado para incorporar a los notarios como CDE. La interconexión de estos módulos permite que los CDE pueden interoperar con la información de RENIEC, SUNARP, SUNAT y las notarías para que la constitución de la empresa se realice en máximo 48 horas.

Asimismo, el Ministerio de la Producción ha estado gestionando la reducción de los costos notariales para la constitución de empresas a un monto no mayor de 100 soles (Diario Gestión, 2017).

\footnotetext{
${ }^{26}$ Los pasos a seguir se pueden consultar en http://emprender.sunat.gob.pe/como-me-inscribo-en-el-ruc
} 
En ese sentido, cabe señalar que si bien se han logrado importantes avances en la simplificación para la constitución de empresas, como que esta se realice en línea en 48 horas y sin pago de gastos registrales, este beneficio que se aplica a las MYPEs que cuenten con capital social menor a $1 \mathrm{UTI}(\mathrm{S} / 4,050)$ se debe mantener.

Con relación a los gastos notariales que deben pagar las MYPE, las tasas son altas y oscilan entre S/300, S/400, S/500 y hasta S/800 soles, por lo que se debe retomar las negociaciones con las notarías a fin de suscribir convenios para hacer efectiva la reducción de los costos notariales a un costo menor a 100 soles.

\section{Meta:}

Las MYPE que se formalizan dentro de los 2 primeros años del programa a través de los CDE son exoneradas del pago de los gastos registrales y pagan gastos notariales que no exceden los 100 soles.

La exoneración de costos registrales y reducción de costos notariales, es un incentivo que se aplicará a todas las MYPE de la población objetivo, con un capital no mayor a 1 UIT.

La constitución jurídica de las MYPEs genera la posibilidad de asociatividad entre empresas y mayores oportunidades de acceder a mercados.

\section{Responsables:}

- Ministerio de Producción, es el responsable de implementar los mecanismos necesarios para la exoneración de los gastos registrales y reducción de los gastos notariales para las MYPEs que se formalizan con el programa.

- SUNARP, es responsable de la disponibilidad del sistema informático para la constitución de empresas en línea.

\section{Lineamientos}


A fin de cumplir con este objetivo las entidades responsables deberán considerar, como mínimo, los siguientes lineamientos:

- Establecer convenios con Notarías para la reducción de los gastos notariales.

- SUNAT realiza el seguimiento y monitoreo del registro de las MYPEs formalizadas con el programa a través de la activación de su RUC.

\section{d. Diseñar un programa de capacitación orientado a mejorar la competitividad de las MYPE, con énfasis en tres aspectos: Gestión de la excelencia, apertura de mercados y administración de recursos humanos.}

\section{Situación actual:}

Desde la aprobación de la Ley N $N^{\circ} 28015$ - Ley de Promoción y Formalización de la Micro y Pequeña Empresa, en el año 2003, el Estado ha tratado de promover la capacitación de las MYPEs, encargando al CODEMYPE la responsabilidad de la promoción de la oferta y demanda de servicios de capacitación y asistencia técnica, orientados a: creación de empresas, organización y asociatividad empresarial, gestión empresarial, producción y productividad, comercialización y mercadotecnia, financiamiento, actividades económicas estratégicas y aspectos legales y tributarios.

Sin embargo, en la última modificatoria del año 2013 se le retira esa responsabilidad al CODEMYPE, señalándose de manera general, que es el Estado el encargado de hacerlo. A la fecha, no existe un Programa de Capacitación Integral, y no se cuenta con una unidad responsable de la gestión de la capacitación y asistencia técnica de las MYPEs.

Por lo que las instituciones públicas, realizan las actividades de capacitación de manera aislada, priorizando sus objetivos particulares, sin llevar un control centralizado de las capacitaciones realizadas y de las necesidades de capacitación existente. Tampoco se ha evaluado si la temática propuesta en la Ley, debe mantenerse o modificarse de 
acuerdo a las necesidades de las MYPEs, ni se ha designado una institución o entidad que se encargue de dar impulso a las necesidades de capacitación y que desarrolle un Programa de capacitación dirigido a las MYPEs.

Así, el Ministerio de la Producción a través de los CDE brinda, además de los servicios de constitución de empresas, asesoría personalizada en formalización, tributación, crecimiento y gestión empresarial, así como asistencia técnica a emprendedores y empresarios MYPE en el inicio de sus negocios.

Por su lado COFIDE, también brinda cursos de financiamiento y de gestión empresarial, que pueden consultarse en su página Web, para que las MYPEs aprovechen las ofertas y condiciones de financiamiento que pueden obtener del sistema financiero.

Por su parte, la SUNAT a través de su portal web brinda información a las MYPEs, de manera didáctica y sencilla temas referidos a cómo iniciar un negocio, los beneficios de ser MYPE, cómo se debe tributar, detallando los diferentes tipos de regímenes existentes.

De acuerdo a Luis Terrones, "más del $80 \%$ de las micro y pequeñas empresas peruanas desarrollan su actividad de modo intuitivo y carecen de los elementos necesarios para ser competitivas en un mercado globalizado como el que enfrenta el país” (2014, s.p.). En ese contexto, es necesario que las MYPEs estén capacitadas y preparadas para hacer frente a los nuevos retos del mercado internacional, por lo que se debe desarrollar sus capacidades en temas de: Gestión de la Excelencia27, Apertura de mercados y Administración de Recursos Humanos, aprovechando el uso de las tecnologías de información, con la finalidad de realizar capacitaciones masivas que pueda llegar a todas las MYPEs que se formalizan.

\footnotetext{
${ }^{27}$ La gestión de excelencia se fundamenta en el uso de los Modelos de Gestión Excelencia basados en la calidad y en la orientación al cliente
} 


\section{Meta:}

Las MYPEs formalizadas con el programa reciben capacitación, en temas orientados a fortalecimiento de capacidades y de gestión, con énfasis en: Gestión de la Excelencia, Apertura de Mercados y Administración de Recursos Humanos.

La capacitación es un beneficio a la que podrán acceder todos los conductores de las MYPEs formalizadas; con énfasis en procesos de calidad que le permita acceder a mercados y competir en licitaciones del Estado, así como generar esquemas de asociatividad con volúmenes de venta para grandes compradores.

Considerando que para acceder a mercados internacionales e incluso en el mercado nacional para venderle al Estado, es necesario que las empresas conozcan y adopten procesos de calidad que contribuyan a mejorar su competitividad y en consecuencia a incrementar sus ingresos.

\section{Responsables:}

El Ministerio de la Producción a través del CODEMYPE es el responsable de la implementación y seguimiento del Programa de capacitación integral MYPE, en coordinación con las entidades involucradas.

\section{Lineamientos:}

A fin de cumplir con este objetivo las entidades responsables deberán considerar, como mínimo, los siguientes lineamientos:

- Aprobar el Programa de capacitación integral MYPE de periodicidad anual

- Implementar los mecanismos necesarios para el desarrollo del campus virtual de capacitación MYPE.

- Convocar la participación de universidades e institutos (escuelas de negocio) en la provisión de capacitación presencial. 
- Realizar el seguimiento y monitoreo de las actividades de capacitación programadas.

\subsubsection{Elaboración de la Matriz Estratégica de Gestión.}

A continuación, se presenta la Matriz estratégica de gestión con los objetivos, estrategias, actividades, resultados, indicadores de medición y responsables.

El cálculo de los indicadores de ampliación de la base tributaria y la recaudación se registra en las tablas 9 y 12 . 


\begin{tabular}{|c|c|c|c|c|c|}
\hline OBJETIVOS & ESTRATEGIAS & ACTIVIDADES & RESULTADOS & INDICADORES & RESPONSABLE \\
\hline \multirow{2}{*}{$\begin{array}{l}\text { OG: Incentivar la } \\
\text { formalización de } \\
\text { las Micro y } \\
\text { Pequeñas } \\
\text { empresas en el } \\
\text { país. }\end{array}$} & \begin{tabular}{|l|} 
Proponiendo un \\
Programa que atienda de \\
manera integral las \\
principales necesidades \\
de las MYPE: mejores \\
condiciones financieras, \\
tributarias, simplificación \\
y de fortalecimiento de \\
capacidades. \\
\end{tabular} & \multirow{2}{*}{$\begin{array}{l}\text { - Elaborar propuesta y elevar al MEF } \\
\text { para consenso } \\
\text { - Coordinar con los actores políticos } \\
\text { involucrados } \\
\text { - Aplicar las estrategias previstas con } \\
\text { los actores políticos con tendencia } \\
\text { negativa } \\
\text {-Coordinar campaña de difusión con } \\
\text { PRODUCE. }\end{array}$} & \multirow[t]{2}{*}{$\begin{array}{l}\text { Se ha aumentado el } \\
\text { número de Mypes } \\
\text { formales de } \\
\text { acumulación. }\end{array}$} & $\begin{array}{l}\text { Las MYpe de } \\
\text { acumulación } \\
\text { formalizadas crecen en } \\
15 \% \text { en promedio } \\
\text { anual, alcanzando un } \\
\text { crecimiento de } 52 \% \\
\text { culminados los tres } \\
\text { primeros años del } \\
\text { programa. }\end{array}$ & $\begin{array}{l}\text { Vice ministro de } \\
\text { MYPE e Industria }\end{array}$ \\
\hline & \begin{tabular}{|l|} 
Difundiendo los \\
beneficios del Programa y \\
las condiciones para \\
acceder a éste, mediante \\
campañas de difusión \\
adecuadas al sector MYPE \\
informal.
\end{tabular} & & & $\begin{array}{l}\text { La recaudación en el } \\
\text { sector Mype se } \\
\text { incrementa en } 11 \% \text { en } \\
\text { promedio anual } \\
\text { durante los tres } \\
\text { primeros años del } \\
\text { programa. }\end{array}$ & $\begin{array}{l}\text { Superintendente } \\
\text { Nacional de } \\
\text { Aduanas y de } \\
\text { Administración } \\
\text { Tributaria. }\end{array}$ \\
\hline $\begin{array}{l}\text { OE1: Promover } \\
\text { el acceso a } \\
\text { crédito } \\
\text { financiero a } \\
\text { tasas de interés } \\
\text { competitivas en } \\
\text { el mercado. }\end{array}$ & $\begin{array}{l}\text { - Gestionando la creación } \\
\text { de un Fondo de } \\
\text { Finananciamiento con } \\
\text { tasas de interés } \\
\text { competitivas para las } \\
\text { Mype } \\
\text { - Convocando a } \\
\text { instituciones financieras } \\
\text { nacionales e } \\
\text { internacionales a ingresar } \\
\text { al Programa para atender } \\
\text { los créditos financieros } \\
\text { del sector MYPE } \\
\text { recientemente } \\
\text { formalizado, con una tasa } \\
\text { de interés referencial de } \\
10 \% \text { al año. }\end{array}$ & $\begin{array}{l}\text { - Crear el fondo de financiamiento } \\
\text { vigente por un período de tres años. } \\
\text { - Especificar los criterios de elegibilidad } \\
\text { de las Mype sujetas al financiamiento. } \\
\text { - Definir las condiciones para la } \\
\text { afiliación de las IFI al programa de } \\
\text { financiamiento a tasas competitivas. } \\
\text { - Difundir a las instituciones financieras } \\
\text { los beneficios de que participen del } \\
\text { Programa. } \\
\text { - Elaborar y aprobar la normativa que } \\
\text { regula el proceso entre MEF, COFIDE e } \\
\text { IFls. } \\
\text { - Seleccionar y registrar a Instituciones } \\
\text { financieras participantes. } \\
\text { - Difundir las condiciones del programa } \\
\text { y convocar a las MYPE a participar. }\end{array}$ & $\begin{array}{l}\text { Se ha promovido el } \\
\text { acceso a crédito } \\
\text { financiero a tasas } \\
\text { competitivas en el } \\
\text { sector MYPE de } \\
\text { acumulación } \\
\text { ampliada. }\end{array}$ & $\begin{array}{l}\text { El } 47 \% \text { de las MYPE } \\
\text { formalizadas acceden a } \\
\text { crédito financiero del } \\
\text { programa }\end{array}$ & $\begin{array}{l}\text { - Director General } \\
\text { de Endeudamiento } \\
\text { y Tesoro Público } \\
\text { del MEF } \\
\text { - Gerente General } \\
\text { de COFIDE }\end{array}$ \\
\hline
\end{tabular}




\begin{tabular}{|c|c|c|c|c|c|}
\hline OBJETIVOS & ESTRATEGIAS & ACTIVIDADES & RESULTADOS & INDICADORES & RESPONSABLE \\
\hline $\begin{array}{l}\text { OE2:Exonerar } \\
\text { del pago de } \\
\text { impuestos a las } \\
\text { microempresas } \\
\text { que se } \\
\text { formalicen con } \\
\text { el programa, por } \\
\text { un período de } \\
\text { dos años. }\end{array}$ & $\begin{array}{l}\text {-Reduciendo los costos de } \\
\text { ingreso a la formalidad } \\
\text { por un período de dos } \\
\text { años, en el que } \\
\text { conjuntamente con los } \\
\text { demás incentivos, las } \\
\text { microempresas puedan } \\
\text { mejorar su rentabilidad. }\end{array}$ & $\begin{array}{l}\text { - Elaborar proyecto de Ley en } \\
\text { coordinación con el MEF } \\
\text { - Especificar los criterios de elegibilidad } \\
\text { de las microempresas sujetas a la } \\
\text { exoneración } \\
\text { - Difundir las condiciones del programa } \\
\text { y convocar a las MYPE a participar. }\end{array}$ & $\begin{array}{l}\text { Se ha exonerado de } \\
\text { impuestos } \\
\text { tributarios a todas } \\
\text { las microempresas } \\
\text { de acumulación } \\
\text { simple formalizadas } \\
\text { con el Programa } \\
\text { durante los dos } \\
\text { primeros años } \\
\text { siguientes a su } \\
\text { formalización. }\end{array}$ & $\begin{array}{l}\text { El } 100 \% \text { de las } \\
\text { microempresas de } \\
\text { acumulación simple } \\
\text { formalizadas con el } \\
\text { programa son } \\
\text { exoneradas de } \\
\text { impuestos tributarios } \\
\text { durante los dos } \\
\text { primeros años a partir } \\
\text { de su formalización. }\end{array}$ & $\begin{array}{l}\text { Superintendente } \\
\text { Nacional de } \\
\text { Aduanas y de } \\
\text { Administración } \\
\text { Tributaria. }\end{array}$ \\
\hline $\begin{array}{l}\text { OE3: Simplificar } \\
\text { el trámite de } \\
\text { formalización y } \\
\text { constitución de } \\
\text { empresas a un } \\
\text { costo cero. }\end{array}$ & $\begin{array}{l}\text { Reduciendo los costos de } \\
\text { ingreso a la formalidad y } \\
\text { difundiendo el uso del } \\
\text { CDE-PRODUCE en la } \\
\text { constitución de empresas } \\
\text { en línea. }\end{array}$ & \begin{tabular}{|l|}
-Mantener exoneración de cobro de \\
gastos registrales por un período de \\
dos años a partir de la entrada en \\
vigencia del Programa. \\
-Elaborar convenios con Notarías \\
afiliadas al Programa para la reducción \\
de gastos notariales. \\
- Difundir las condiciones del programa \\
y convocar a las MYPE a participar.
\end{tabular} & $\begin{array}{l}\text { Se ha exonerado } \\
\text { pago de costos } \\
\text { registrales y } \\
\text { reducido gastos } \\
\text { notariales a MYPEs } \\
\text { formalizadas como } \\
\text { persona jurídica, } \\
\text { dentro de dos } \\
\text { primeros años del } \\
\text { programa. }\end{array}$ & $\begin{array}{l}\text { El } 100 \% \text { de las MYPE } \\
\text { registradas como } \\
\text { persona jurídica a } \\
\text { través de los CDE, } \\
\text { dentro de los dos } \\
\text { primeros años del } \\
\text { programa, están } \\
\text { exoneradas de los } \\
\text { gastos registrales y } \\
\text { tienen tasa notariales } \\
\text { reducidas. }\end{array}$ & $\begin{array}{l}\text { Vice ministro de } \\
\text { MYPE e Industria }\end{array}$ \\
\hline $\begin{array}{l}\text { OE4: Diseñar un } \\
\text { programa de } \\
\text { capacitación } \\
\text { orientado a } \\
\text { mejorar la } \\
\text { competitividad, } \\
\text { con énfasis en } \\
\text { tres aspectos: } \\
\text { Gestión de la } \\
\text { Excelencia, } \\
\text { Apertura de } \\
\text { Mercados y } \\
\text { Administración } \\
\text { de Recursos } \\
\text { Humanos }\end{array}$ & $\begin{array}{l}\text { - Elaborando y } \\
\text { gestionando un programa } \\
\text { de capacitación integral } \\
\text { Mype } \\
\text { - Desarrollando una } \\
\text { plataforma virtual para la } \\
\text { capacitación masiva } \\
\text { online (campus virtual } \\
\text { MYPE) } \\
\text { - Aprovechando las } \\
\text { capacidades de las } \\
\text { universidades e institutos } \\
\text { técnicos del país }\end{array}$ & \begin{tabular}{|l|}
-Elaborar un Programa de Capacitación \\
integral MYPE. \\
-Firmar convenios con Universidades e \\
Institutos Técnicos para que brinden los \\
servicios de capacitación \\
-Contratar el desarrollo de un campus \\
virtual para brindar capacitación a \\
traves de una plataforma de educación \\
online. \\
- Difundir las condiciones del programa \\
y convocar a las MYPE a participar. \\
-Identificar nuevas necesidades de \\
capacitación a través de encuestas de \\
retroalimentación.
\end{tabular} & $\begin{array}{l}\text { Se ha capacitado a } \\
\text { las MYPE } \\
\text { formalizadas en } \\
\text { temas de: Gestión } \\
\text { de la Excelencia, } \\
\text { Apertura de } \\
\text { Mercados y } \\
\text { Administración de } \\
\text { Recursos Humanos. }\end{array}$ & $\begin{array}{l}\text { El } 60 \% \text { de los } \\
\text { conductores de las } \\
\text { MYPE formalizadas por } \\
\text { año son capacitados. }\end{array}$ & $\begin{array}{l}\text { Vice ministro de } \\
\text { MYPE e Industria, } \\
\text { a través de } \\
\text { CODEMYPE }\end{array}$ \\
\hline
\end{tabular}

Cuadro 12. Matriz Estratégica de Gestión.

Elaboración propia. 
A manera de resumen, en la tabla adjunta se muestra la distribución de la población objetivo así como la proporción de cada estrato como beneficiarios de la política diseñada. La población objetivo la conforman las MYPEs de acumulación, que para efecto de la aplicación de las diferentes estrategias ha sido necesario diferenciarlas entre microempresas de acumulación simple y micro y pequeñas empresas de acumulación ampliada.

Tabla 8.

Distribución de población objetivo según estrategia de formalización.

\begin{tabular}{|c|c|c|c|c|c|c|c|c|}
\hline \multirow[b]{2}{*}{$\begin{array}{c}\text { Volumen de } \\
\text { venta anual } \\
\text { (UIT) }\end{array}$} & \multicolumn{4}{|c|}{ MYPES INFORMALES } & \multicolumn{4}{|c|}{ ESTRATEGIA } \\
\hline & Número & Part. (\%) & Estrato & Tamaño & $\begin{array}{c}\text { Acceso a } \\
\text { crédito } \\
\text { financiero }\end{array}$ & $\begin{array}{c}\text { Exoneración } \\
\text { tributaria }\end{array}$ & $\begin{array}{c}\text { Formalización y } \\
\text { constitución de } \\
\text { empresas a costo } \\
\text { cero }\end{array}$ & Capacitación \\
\hline ]17 50] & 234,352 & $53 \%$ & Acumulación simple & microempresa & & $x$ & $\mathrm{x}$ & $x$ \\
\hline ]50 150] & 123,613 & $28 \%$ & Acumulación ampliada & microempresa & $x$ & & $x$ & $x$ \\
\hline
\end{tabular}

Elaboración: propia. 


\section{CAPÍTULO VI}

\section{EVALUACIÓN DE LA POLÍTICA}

\subsection{Análisis de la sostenibilidad de la política}

La política propuesta es sostenible en el tiempo, puesto que se cumplen simultáneamente los tres factores del triángulo estratégico de Moore (1998):

a) Dimensión sustantiva: la informalidad es un problema de interés público, que afecta a un importante sector de la población con consecuencias nocivas para su desarrollo personal y el de la sociedad en su conjunto. No existe en la población, la percepción de que el gobierno esté solucionado el problema con las políticas actuales.

b) Dimensión política: se han identificado a los actores afectados por la política y se ha logrado el balance político, con las estrategias adecuadas para los actores con tendencia negativa o en contra que pondrían en riesgo la implementación de la política.

c) Dimensión operativa: La política es viable con el apoyo y recursos de diferentes instituciones públicas involucradas con el objetivo de reducir la informalidad en el país.

\subsection{Evaluación del impacto de la política}

La política de formalización con incentivos para ampliar la base tributaria tendrá un alcance inicial en aproximadamente 442, 683 MYPEs con capacidad de acumulación. Con la implementación de la política se espera una mayor movilidad desde el estrato de microempresas de acumulación simple al estrato de micro y pequeñas empresas de acumulación ampliada, dada las mejores condiciones en las tasas de financiamiento, la exoneración de impuestos y la plataforma de capacitación que contribuirá a mejorar su productividad. 


\subsubsection{Impacto en la base tributaria.}

El impacto en la ampliación de la base tributaria no sólo se refleja en un incremento del número de MYPEs registradas en la SUNAT, si no que éstas pertenecen a los estratos de acumulación, con mejores condiciones para impulsar su crecimiento empresarial y mejorar su competitividad, en consecuencia, mayor rentabilidad y capacidad para asumir los costos permanentes de la formalidad, entre éstos, el pago de los impuestos tributarios.

Según la Tabla 9, en el período 2012-2016 las MYPEs formales registraron la mayor tasa de crecimiento en el año 2013; se determinan tres hechos que habrían impulsado el crecimiento de la base tributaria MYPE: la creación del Sistema de Emisión Electrónica desde los Sistemas del Contribuyente, que empezó con un piloto ejecutado por SUNAT entre junio y setiembre de 2012, a partir de lo cual se hace inminente la obligatoriedad de ciertos contribuyentes grandes y medianos a la emisión de facturas electrónica, generando riesgo en las micro y pequeñas empresas colaboradoras de éstas, que las obliga a formalizarse para participar de las cadenas productivas de empresas formales. Asimismo, la publicación de la Ley 30056 el 02 de julio de 2013, con diversas medidas de simplificación y facilidades para contratar con el Estado; así como la dación de diversas normas orientadas a la formalización de las actividades de pequeña minería, no obstante, la obligatoriedad culminó en el mes de octubre de 2014.

Dado lo señalado y considerando los incentivos de la presente propuesta, es factible plantear como meta de formalización en el primer año del programa, una tasa de crecimiento de la base tributaria MYPE de acumulación igual a la del año 2013, de 13\%; asimismo, con los incentivos del programa en marcha y consecuente difusión de los beneficios, se espera que ésta se amplíe en $15 \%$ en el segundo año y $17 \%$ en el tercero (para efecto de la estimación se asume que una vez formalizadas permanecen en el sector formal), sustentándonos en que las MYPES de acumulción ampliada buscarán beneficiarse con las tasas de interes competitivas (una de sus principales limitantes para crecer) y, las microempresas de acumulación simple, con la exoneración tributaria que beneficiará a las que se inscriban dentro de los dos primeros años del programa, ello en un primer momento, posteriormente acceder a los créditos financieros, en la medida que demuestren el crecimiento necesario para ello (acumulación ampliada). 
Por su parte las microempresas de acumulación ampliada tienen el incentivo para crecer a fin de acceder a mayores montos de crédito financiero que compense el costo administrativo de la operación.

Con la incorporación de las MYPEs informales de acumulación al sector formal, al finalizar el tercer año del programa la base tributaria MYPE de acumulación se habría incrementado en 52\% respecto al año 2016. La composición de las MYPEs que se incorporan a la base tributaria comprende un $81 \%$ de microempresas y $19 \%$ de pequeñas empresas (ver Tabla 10).

Tabla 9.

MYPEs de acumulación formales y a formalizar - impacto en la base tributaria.

\begin{tabular}{|c|c|c|c|c|c|c|}
\hline \multirow{2}{*}{ Año } & \multicolumn{3}{|c|}{ Mypes formales } & \multirow{2}{*}{$\begin{array}{c}\text { Mypes a } \\
\text { formalizar 1/ }\end{array}$} & \multirow{2}{*}{$\begin{array}{c}\text { Base } \\
\text { ampliada }\end{array}$} & \multirow{2}{*}{ Variac. (\%) } \\
\hline & Total & De Acumulación & Variac. (\%) & & & \\
\hline 2012 & $1,345,390$ & 308,094 & & & & \\
\hline 2013 & $1,518,469$ & 347,729 & $13 \%$ & & & \\
\hline 2014 & $1,597,061$ & 365,727 & $5 \%$ & & & \\
\hline 2015 & $1,687,798$ & 394,945 & $8 \%$ & & & \\
\hline 2016 & $1,734,113$ & 388,441 & $-2 \%$ & & & \\
\hline Año 1 & & & & 50,497 & 438,939 & $13 \%$ \\
\hline Año 2 & & & & 65,841 & 504,779 & $15 \%$ \\
\hline Año 3 & & & & 85,813 & 590,592 & $17 \%$ \\
\hline Total & & & & 202,151 & & $52 \%$ \\
\hline
\end{tabular}

Fuente: PRODUCE.

Elaboración: propia.

Tabla 10.

MYPEs de acumulación formalizadas, según tamaño y año de formalización (tres primeros años).

\begin{tabular}{|l|r|r|r|r|r|}
\multicolumn{1}{|c|}{ Tamaño } & \multicolumn{1}{c|}{$\begin{array}{c}\text { 1er año } \\
\text { (13\%) }\end{array}$} & $\begin{array}{c}\text { 2do año } \\
\mathbf{( 1 5 \% )}\end{array}$ & $\begin{array}{c}\text { 3er año } \\
\mathbf{( 1 7 \% )}\end{array}$ & $\begin{array}{c}\text { Total } \\
\text { formalizado }\end{array}$ & \multicolumn{1}{c|}{ Part. (\%) } \\
\hline Micro & 40,834 & 53,241 & 69,390 & 163,465 & 0.81 \\
\hline Pequeñas & 9,664 & 12,600 & 16,422 & 38,686 & 0.19 \\
\hline Total & 50,497 & 65,841 & 85,813 & 202,151 & 1.00 \\
\hline
\end{tabular}

Elaboración: propia. 


\subsubsection{Impacto en la Recaudación.}

Para estimar el impacto en la recaudación durante los tres primeros años del programa, asumimos además de los supuestos establecidos respecto a la base tributaria, que el pago promedio de las MYPEs formales según tamaño en el año 2016, es el mismo para las nuevas empresas a formalizar y que se mantiene constante durante los tres primeros años (ver Tabla 11). Asimismo, de acuerdo a los incentivos de la presente política, se considera que las microempresas de acumulación simple formalizadas durante los dos primeros años del programa, gozarán de exoneración tributaria por dos años a partir de su formalización, por tanto, durante este período sólo sumarán a la recaudación los pagos que realicen las micro y pequeñas empresas de acumulación ampliada formalizadas con el programa, las que constituyen el $47,1 \%$ de la población objetivo.

De acuerdo a la información de SUNAT, en el año 2016, la recaudación en el sector MYPE creció aproximadamente un 2.4\% respecto al año 2015; con la implementación de la política y cumplida la meta de formalización, la recaudación crecería en 9,2\% en el primer año y 10,9\% en el segundo año, sólo con la recaudación proveniente de las MYPEs de acumulación ampliada y, en 13,3\% en el tercer año, donde empiezan a tributar las microempresas de acumulación simple formalizadas en el primer año (Ver Tabla 12).

Es importante mencionar que el aporte a la recaudación, de las microempresas de acumulación simple, en su primer año de tributación (tercero del programa), es de sólo 65,8 millones, aproximadamente el 1,4\% de lo que se recaudaría en dicho año; determinándose, por una parte, que la recaudación que dejaría de percibirse con la exoneración a las microempresas de acumulación simple que se formalicen es mínima, más aun cuando en el presente tampoco se recauda de éstas. Por otra parte, de acuerdo a las estimaciones, el $28 \%$ de las microempresas formalizadas serían de acumulación ampliada, con un volumen de ventas anual entre 50 y 150 UIT, apto para acceder a financiamiento con el programa, con la posibilidad de mejorar su productividad y competitividad, mejorando sus probabilidades de crecimiento y con ello un mayor aporte tributario. 
Tabla 11.

Recaudación MYPE formal (en miles de soles) según tamaño de empresa, 2016.

\begin{tabular}{|l|r|r|r|r|}
\hline \multicolumn{1}{|c|}{ Tamaño } & \multicolumn{4}{|c|}{ MYPE formal } \\
Mímero & \multicolumn{1}{|c|}{ Total Pagos } & $\begin{array}{c}\text { Part. Pagos } \\
(\mathbf{\%})\end{array}$ & \multicolumn{1}{c|}{$\begin{array}{c}\text { Pago } \\
\text { promedio }\end{array}$} \\
Pequeño & $1,652,071$ & $4,069,391$ & $32 \%$ & 2.5 \\
Total & 74,085 & $8,682,314$ & $68 \%$ & 117.2 \\
\hline
\end{tabular}

Nota: Información extraída de SUNAT.

Elaboración propia.

Tabla 12.

Recaudación MYPE formal 2015-2016 y proyectada (Año 1 - año 3), según tamaño de empresa a formalizar (en miles de soles).

\begin{tabular}{|c|c|c|c|c|c|c|c|}
\hline \multirow{2}{*}{\multicolumn{2}{|c|}{ Período tributario }} & \multicolumn{2}{|c|}{ MYPE formal } & \multicolumn{3}{|c|}{ MYPE a formalizar } & \multirow{2}{*}{ Variac. Total } \\
\hline & & 2015 & 2016 & Año 1 & Año 2 & Año 3 & \\
\hline \multirow{4}{*}{ Recaudación } & MYPE & $12,451,065$ & $12,751,705$ & & & & \\
\hline & Micro AS & & & & & 65,849 & \\
\hline & Micro AA & & & 34,733 & 80,019 & 139,042 & \\
\hline & Pequeña & & & $1,132,541$ & $2,609,200$ & $4,533,780$ & \\
\hline \multicolumn{2}{|c|}{ Recaudación incrementada } & & & $13,918,979$ & $15,440,925$ & $17,490,376$ & \\
\hline \multicolumn{2}{|l|}{ Variac. \% } & & $2.4 \%$ & $9.2 \%$ & $10.9 \%$ & $13.3 \%$ & $37.2 \%$ \\
\hline
\end{tabular}

Nota: Información extraída de SUNAT.

Elaboración propia.

\subsection{Evaluación de las Autoridades de la Institución Pública de la Política Pública propuesta}

La evaluación de la política propuesta es positiva dado que coadyuvaría a lograr dos objetivos de interés de la SUNAT: Ampliar la base tributaria e incrementar la recaudación. No obstante, se precisa que la exoneración tributaria para el 53\% de las microempresas de la población objetivo, genera un reto a la administración tributaria para implementar los mecanismos necesarios para prevenir un mal uso del beneficio, así como brindar la capacitación y gestionar el monitoreo de la presentación de declaraciones. Al respecto, requerirían ajustar el modelo de control de las acciones de control masivo, a fin de equilibrar los mayores costos en recursos humanos, frente a los beneficios que se observarían en el mediano plazo. 
Por otra parte, al iniciar el actual Gobierno, el Superintendente de la SUNAT, en base al conjunto de medidas económicas y tributarias anunciadas, en Perú 21, indica que "aumentar la presión tributaria y la recaudación, ampliando la base tributaria y reduciendo la informalidad, es un objetivo realista" (2016, s. p.). Desde entonces y hasta la fecha, para acompañar en este propósito, la Administración se ha focalizado principalmente en reducir los costos de los contribuyentes y simplificar sus procesos para dar mejores servicios, en una búsqueda por priorizar la facilitación más que la sanción.

En el presente año, el objetivo de formalizar y ampliar la base tributaria sobre procedimientos simplificados, conjuntamente con la modernización e integración de los canales de atención y programas de educación tributaria, ha tenido el apoyo de los cambios normativos impulsados por el MEF, como es el Régimen MYPE Tributario del Impuesto a la Renta (RMT), orientado a incentivar la formalización de las MYPEs mediante la gradualidad del IR, entre otras facilidades. Lo que de acuerdo a los resultados presentados por la SUNAT hasta el mes de Junio del presente año, no demostraba un ingreso significativo de nuevas empresas, sino más bien un reordenamiento de la base tributaria con la migración de microempresas formales desde otros regímenes (Régimen General, Régimen Especial de Renta, Nuevo RUS) al RMT.

En ese contexto, para que la SUNAT logre una formalización masiva de MYPEs informales, reduciendo el tiempo proyectado para reducir la informalidad, es correcto que impulse la política pública expuesta a fin de implementar una estrategia integral que incentive la movilidad hacia el sector formal. 


\section{CAPÍTULO VII}

\section{EL ROL DE LAS ORGANIZACIONES DE LA SOCIEDAD CIVIL - OSC EN LAS POLÍTICA PÚBLICAS}

La Sociedad Civil desempeña un rol importante en la generación de políticas con valor público, porque las políticas públicas deben estar orientadas a satisfacer las necesidades de la ciudadanía.

En la política pública propuesta, todos los actores de la sociedad civil identificados, están a favor de la misma.

A fin de evaluar, el rol de los gremios MYPE en las políticas relacionadas a este sector, a continuación, se detallan algunos hechos importantes, en los que participaron:

El 2008, los gremios MYPE solicitaron que sea el Ministerio de Producción PRODUCE el que atienda su sector, en lugar del Ministerio de trabajo y Promoción del Empleo - MINTRA, ese mismo año, se encargó las funciones relacionadas al Sector a PRODUCE.

El Comité de la Pequeña Empresa (COPEI) y ForoMype se presentaron ante la comisión de Producción, Micro y Pequeña Empresa y Cooperativas, para dar sus opiniones institucionales, sobre las compras estatales, y las micro y pequeña empresa en el país.

En enero 2017, la Asociación Nacional de MYPEs que agrupa a un sector de emprendedores del Emporio Comercial de Gamarra en La Victoria, se pronunció a favor de las nuevas normas tributarias dictadas por el Gobierno para impulsar el sector, además, plantean la instalación de una mesa de diálogo en la que participen el Gobierno Central y los Gobiernos Locales, esto con la finalidad de hacerle seguimiento a la aplicación de estas medidas. 
Por otro lado, en mayo de este año, el Consejo de Ministros aprobó en una de sus sesiones, un proyecto de norma para modificar las relaciones colectivas de trabajo y el sistema de inspección laboral, en el que se busca que no se aplique la misma escala de multas de la gran empresa a las MYPEs, sino que exista una escala de sanciones.

Estas modificaciones fueron debatidas en el Consejo Nacional de Trabajo y Promoción del Empleo con representantes de los empleadores y gremios sindicales y presentados por el Ministerio de Trabajo y Promoción del Empleo (MTPE).

También se propusieron las siguientes modificaciones:

- Que se fortalezca la inspección laboral y que se apliquen las sanciones correspondientes por incumplimiento.

- Que no exista duplicidad de inspecciones laborales al mismo empleador por un tema que ya fue sancionado.

- Que se fomente el diálogo entre empleadores y trabajadores, para la solución de conflictos laborales.

- Que se establezca un mínimo de 3 meses de negociación directa, antes de acudir a un arbitraje.

Las propuestas de los gremios de las MYPEs son escuchadas y debatidas en las mesas de diálogo que fueron establecidas por el Ejecutivo con el fin de dar sostenibilidad a los acuerdos de las negociaciones realizadas y al monitoreo de su cumplimiento. 


\section{CAPÍTULO VIII}

\section{CONCLUSIONES Y RECOMENDACIONES}

\subsection{Conclusiones}

1. Las intervenciones de política para promover la formalización de las micro y pequeñas empresas en los últimos años no han tenido el impacto esperado, debido a que no se adecuan mayormente a las limitaciones, necesidades y riesgos específicos de estas unidades económicas, además de carecer de un monitoreo adecuado.

2. La estrategia de la SUNAT de simplificar sus procesos de negocio para dar mejores servicios y reducir los costos, conjuntamente con la modernización e integración de los canales de atención y programas de educación tributaria, no es suficiente para reducir la informalidad en el sector MYPE y alcanzar su objetivo de ampliar la base tributaria.

3. En el año 2016, las MYPEs existentes en el Perú se estimaban en 3 millones 708 mil, de las cuales el $53 \%$ eran informales y el $47 \%$ formales; de estas últimas el $95.7 \%$ son microempresas y el 4,3\% pequeñas empresas. Asimismo, según el rango de venta anual en UIT, aproximadamente el $40 \%$ de las microempresas formales tienen ventas no mayores a 2 UIT, lo que las ubica en el segmento de microempresas de subsistencia, con un pobre aporte a la recaudación tributaria.

4. La población objetivo de la política propuesta comprende a las MYPEs informales de acumulación, postergándose a las de MYPEs informales de Subsistencia. Se identifica como MYPE de acumulación aquéllas con un volumen de ventas superior a 17 UIT al año, volumen de ventas mínimo que debe generar una microempresa para cubrir los costos de una canasta básica de consumo mensual. Se determinó que el 77,6\% de las MYPEs son de Subsistencia y el 22,4\% son MYPEs de Acumulación, este último grupo estaría en capacidad de acumular cierto nivel de ingresos y a capitalizarse. 
5. Bajo el supuesto de que la composición según rango de ventas del sector formal se repite en el informal, se estima que las MYPE de Acumulación en el sector informal ascienden a 442, 683 empresas (población objetivo). De éstas, el 53\% calificaría como una MYPE de Acumulación Simple, con ventas anuales mayor a 17 UIT hasta 50 UIT, y el 47\% restante como MYPE de Acumulación Ampliada, con volumen de ventas por encima de 50 UIT al año.

6. Las MYPE de acumulación formalizadas con el programa crecen en $15 \%$ en promedio anual, alcanzando un crecimiento de $52 \%$ culminados los tres primeros años del programa.

7. La recaudación en el segmento Mype se incrementa en $11 \%$ en promedio anual durante los tres primeros años del programa, considerando la exoneración tributaria de las MYPE de acumulación simple durante los dos primeros años. Al tercer año la recaudación MYPE se incrementa en $37,2 \%$.

8. La baja participación de las microempresas en la recaudación, permiten explicar porque a pesar del crecimiento de la base tributaria, la recaudación tributaria ha caído en los dos últimos años; de ahí la necesidad aplicar una política de incentivos que no culmine con el solo registro en el padrón RUC, si no que apunten a incentivar el crecimiento y rentabilidad de las MYPE, a fin de impactar en una efectiva ampliación de la base tributaria.

9. La política propuesta genera valor público, dado que contempla los tres factores del triángulo estratégico de Moore. Así, responde a las necesidades de la población y se sostiene en la gestión de los stackeholders, traducido en un mapa político, basado en los intereses y poderes de los grupos de interés, de los cuales se ha obtenido información que ha influido en el planteamiento de las estrategias para logar el reposicionamiento de los actores y lograr el balance político, además de evaluar los recursos financieros, humanos y logísticos para su implementación; cumpliéndose con la dimensión sustantiva, dimensión política y dimensión operativa. 


\subsection{Recomendaciones}

1. La SUNAT debe incluir en su Plan Estratégico Institucional, objetivos y actividades estratégicas orientadas a promover los incentivos propuestos para la formalización de las MYPEs, así como el monitoreo, seguimiento y control de las mismas, según corresponda.

2. Derivar la propuesta al MEF para su evaluación y aprobación a fin de seguir con el proceso de implementación.

3. Sociabilizar la política propuesta con los actores públicos, privados y de la sociedad civil involucrados. 


\section{BIBLIOGRAFÍA}

Aguilar, F. (1992). Estudio introductorio, en Antología de políticas públicas. México D. F.: Miguel Ángel Porrúa Grupo Editorial. Recuperado el 25 de noviembre, 2017.

Aguilar, F. (1993). La implementación de las políticas públicas. Recuperado el 25 de noviembre, 2017

http://www.inap.mx/portal/images/RAP/la\%20implementacion\%20de\%20las\%20poli ticas.pdf

Alter Chen, M. (2012). La economía informal: definiciones, teorías y políticas: Documento de Trabajo de WIEGO No 1. Recuperado el 25 de noviembre, 2017 de http://www.wiego.org/sites/default/files/publications/files/Chen-Informal-EconomyDefinitions-WIEGO-WP1-Espanol.pdf

América economía (2013, 28 de agosto). OIT: América Latina registra 47\% de empleo informal [americaeconomia.com]. Recuperado de https://www.americaeconomia.com/economia-mercados/finanzas/oit-america-latinaregistra-47-de-empleo-informal

Andina. Agencia peruana de noticias (2014, 20 de octubre). Tasas de interés para pymes pueden ser más competitivas [andina.com.pe]. Recuperado de http://www.andina.com.pe/agencia/noticia-tasas-interes-para-pymes-pueden-ser-mascompetitivas-528147.aspx

Arellano, S. (2014, 09 de Setiembre). Plan de Peña para "enganchar" a informales [Milenio.com]. Recuperado de http://www.milenio.com/politica/Plan_de_Pena_Nieto_para_enganchar_informalesCrezcamos_Juntos_0_369563061.html

Armijo, M. (2011). Planificación estratégica e indicadores de desempeño en el sector público. Serie Manuales CEPAL, 69, 9. Recuperado de https://www.cepal.org/ilpes/publicaciones/xml/8/44008/SM_69_MA.pdf

Ballart, X. (1997). Evaluación de políticas: Marco conceptual y organización institucional. Recuperado el 25 de noviembre, 2017 https://dialnet.unirioja.es/descarga/articulo/27215.pdf

Benavides, S. ; Muñoz, J. \& Parada, A. (2004). El enfoque de competitividad sistémica como estrategia para el mejoramiento del entorno empresarial. Economía y sociedad, 24, 119 - 137. Recuperado http://revistas.una.ac.cr/index.php/economia/article/viewFile/1097/1021

Borja, C. (2010). El contrato de colaboración entre el sector público y el sector privado. Recuperado el 25 de noviembre, 2017 https://books.google.com.pe/books?id=oPZy8WecIBcC\&pg=PA48\&lpg=PA48\&dq= El+gobierno+basado+en+\%22Libert\%C3\% A9,+\%C3\%A9galit\%C3\%A9,+fraternit\% 
C3\%A9\&source=bl\&ots=HqVof1D6m_\&sig=Sqf9h1p24g8OoMcoIIrTUun4YnI\&hl =es-

419\&sa=X\&ved=0ahUKEwjw_PagzYXXAhWDH5AKHZVaBzwQ6AEIQTAH\#v= onepage \&q=El\%20gobierno\%20basado\%20en\%20\%22Libert\%C3\%A9\%2C\%20\%C 3\%A9galit\%C3\%A9\%2C\%20fraternit\%C3\%A9\&f=false

Calua, N., \& García, N., (2017). Factores que desalientan la formalización de los empresarios de las micro y pequeñas empresas del sector de manufactura del rubro textil en el Emporio Comercial de Gamarra (Tesis de licenciatur a). Recuperada de http://repositorioacademico.upc.edu.pe/upc/bitstream/10757/621084/6/GARCIA_GN. pdf

Celle, M., Sotomarino, N. \& Ugarte, Mayen (2011). Medidas para mejorar la gestión operativa de las entidades públicas: ¿cómo pasar de un marco normativo rígido de cumplimiento "flexible" a un marco flexible de cumplimiento obligatorio?.

Recuperado el 25 de noviembre, 2017

http://www2.congreso.gob.pe/sicr/cendocbib/con3_uibd.nsf/0C389ABE8DEAE8B00

$5257856005518 \mathrm{EC} / \$ \mathrm{FILE} / \mathrm{Gesti} \% \mathrm{C} 3 \% \mathrm{~B} 3 \mathrm{nP} \% \mathrm{C} 3 \%$ BAblicaDocumento.pdf

Centro Nacional de Planeamiento estratégico (2017). Economía informal en Perú: situación actual y perspectivas [ceplan.gob.pe]. Recuperado de https://www.ceplan.gob.pe/documentos_/economia-informal-en-peru/

CEPAL (1996). Competitividad sistêmica: nuevo desafío para las empresas y la política. Revista de la CEPAL, 56, 7-148. Recuperado de h0ttp://archivo.cepal.org/pdfs/revistaCepal/Sp/059039052.pdf

CEPLAN (2016). Economía informal en Perú: Situación actual y perspectivas. . Recuperado el 25 de noviembre, 2017 https://www.ceplan.gob.pe/wpcontent/uploads/2013/09/economia_informal_en_peru_11-05-2016.pdf

Consejo Nacional para el Desarrollo de la Micro y Pequeña empresa (2009). Plan nacional de promoción y formalización nacional de promoción y formalización para la competitividad y desarrollo de la competitividad y desarrollo de la micro y pequeña empresa micro y pequeña empresa 2005-2009 [Diapositiva]. Lima: CODEMYPE.

Corzo, F. (2014, 14 de octubre). ¿Cuál es el ciclo de vida de las políticas públicas? [iexe.edu.mx]. Recuperado de https://www.iexe.edu.mx/blog/cual-es-el-ciclo-de-vidade-las-politicas-publicas.html

Datum Internacional (2017). Estudios [Datum.com.pe]. Recuperado de http://www.datum.com.pe/estudios

De la Roca, J. \& Hernandez, M. (2004). Evasión tributaria e informalidad en el perú: una aproximación a partir del enfoque de discrepancias en el consumo (Proyecto de Investigación Breve - CIES). GRADE: Lima. Recuperado de http://cies.org.pe/sites/default/files/investigaciones/evasion-tributaria-e-informalidaden-el-peru-una-aproximacion-a-partir-del-enfoque-de-discrepanscias-en-elconsumo.pdf 
Decreto de Urgencia No. 008-2017 Dictan medidas complementarias para la atención de emergencias generadas por el fenómeno del niño costero y para la reactivación y fortalecimiento productivo de la micro y pequeña empresa (2017). En Diario Oficial El Peruano. Perú. Recuperado de http://busquedas.elperuano.pe/normaslegales/dictanmedidas-complementarias-para-la-atencion-de-emergenci-decreto-de-urgencia-n-0082017-1512132-1/

Decreto Supremo No. 006-22017 - PRODUCE Decreto Supremo que aprueba el Reglamento del Decreto Legislativo $\mathrm{N}^{\circ}$ 1332, Decreto Legislativo que facilita la constitución de empresas a través de los Centros de Desarrollo Empresarial - CDE (2017). En Diario Oficial El Peruano. Perú. Recuperado de http://busquedas.elperuano.pe/

Decreto Supremo No. 013- 2013- PRODUCE (2013). En Diario Oficial El Peruano. Perú. Recuperado de http://www2.produce.gob.pe/dispositivos/publicaciones/ds013-2013produce.pdf

Decreto Supremo No. 1269 El régimen mype tributario del impuesto a la renta (2017). En Diario Oficial El Peruano. Perú. Recuperado de http://busquedas.elperuano.pe/normaslegales/decreto-legislativo-que-crea-el-regimenmype-tributario-del-decreto-legislativo-n-1269-1465277-1/

El Peruano. (2017). Perú. Recuperado de http://busquedas.elperuano.pe/normaslegales/decreto-supremo-que-aprueba-elreglamento-del-decreto-legisl-decreto-supremo-n-006-2017-produce-1510285-3/

Esser, Hillebrand, Messner \& Meyer-Stamer (1996). Competitividad sistémica: nuevo desafío para las empresas y la política. Revista de la CEPAL, 56, 7-148. Recuperado de http://archivo.cepal.org/pdfs/revistaCepal/Sp/059039052.pdf

Gestión (2017). Bajo la lupa: Las cifras del régimen mype tributario [gestion.pe]. Recuperado de https://gestion.pe/economia/lupa-cifras-regimen-mype-tributario-139908

Gestión (2017). Cofide otorgaría tasas de hasta 5\% a entidades financieras para créditos a mypes [gestion.pe]. Recuperado de https://gestion.pe/tu-dinero/cofide-otorgaria-tasas5-entidades-financieras-creditos-mypes-135354

Gestión (2017, 13 de junio). Régimen Mype Tributario: ¿Está ampliando la base de contribuyentes? [gestion.pe]. Recuperado de https://gestion.pe/economia/regimenmype-tributario-ampliando-base-contribuyentes-137136

Gestión (2017, 13 de junio). Régimen Mype Tributario: ¿Está ampliando la base de contribuyentes? [gestion.pe]. Recuperado de https://gestion.pe/economia/regimenmype-tributario-ampliando-base-contribuyentes-137136

Gonzales, E. (2007, 16 de abril). Economía política de la era neoliberal peruana: 1990 2006. [blog.pucp.edu.pe]. Recuperado de http://blog.pucp.edu.pe/blog/economiaperuana/2007/04/16/economia-politica-de-laera-neoliberal-peruana-1990-2006/ 
Instituto Nacional de Estadística e Informática (2014). Producción y empleo informal en el Perú: Cuenta satélite de la economía informal 2007-2012. Perú: INEI. Recuperado de https://www.inei.gob.pe/media/MenuRecursivo/publicaciones_digitales/Est/Lib1154/1 ibro.pdf

Instituto Nacional de Estadística e Informática (2015). Perú - Encuesta Nacional de Empresas 2015 [http:webinei.inei.gob.pe]. Recuperado de http://webinei.inei.gob.pe/anda_inei/index.php/catalog/340

Instituto Nacional de Estadística e Informática (2016). Características de la actividad empresarial en el perú encuesta nacional de empresas, 2015 principales resultados [Diapositiva]. Lima: INEI. Recuperado de https://www.inei.gob.pe/media/MenuRecursivo/boletines/encuesta-nacional-deempresas-2015-presentacion-26-09-16-proyectar.pdf

Instituto Nacional de Estadística e Informática (2016). Evolución de la pobreza monetaria en el perú, 2015. Recuperado de https://www.inei.gob.pe/media/cifras_de_pobreza/exposicion_inei_pobreza2015.pdf

Instituto Nacional de Estadística e Informática (2016). Producción y empleo informal en el perú. Cuenta satélite de la economía informal 2007-2015[Diapositiva]. Lima: INEI. Recuperado de http://www.inei.gob.pe/media/MenuRecursivo/boletines/economia_informal_peru.pd $\underline{\mathrm{f}}$

Instituto Nacional de Estadística e Informática (2016, 15 de enero). Perú - Encuesta Nacional de Empresas 2015 [webinei.inei.gob.pe]. Recuperado de http://webinei.inei.gob.pe/anda_inei/index.php/catalog/340

Instituto para la Democracia y la Asistencia Electoral - IDEA Internacional \& Asociación Civil Transparencia (2009). Gestión pública. Material de trabajo. Recuperado el 25 de noviembre, 2017 http://www2.congreso.gob.pe/sicr/cendocbib/con4_uibd.nsf/8453BD9D9F574894052 57C0C0014A7FC/\$FILE/Gesti\%C3\%B3n_P\%C3\%BAblica.pdf

Instituto Peruano de Economía (2012). Presión tributaria [Ipe.org.pe]. Recuperado de http://www.ipe.org.pe/content/presion-tributaria

Ley No. 29566 Ley que modifica las diversas disposiciones con el objeto de mejorar el clima de inversión y facilitar el cumplimiento de obligaciones tributarias (2010). En Diario Oficial El Peruano. Perú. Recuperado de http://geo.vivienda.gob.pe/dnv/documentos/Normatividad/2.pdf

Ley No. 29903 Ley de reforma del sistema privado de pensiones (2012). En Diario Oficial El Peruano. Perú. Recuperado de https://www.mef.gob.pe/contenidos/prensa/boletines/reforma_spp/Ley29903.pdf 
Ley No. 30056 Ley que modifica diversas leyes para facilitar la inversión, impulsar el desarrollo productivo y el crecimiento empresarial (2013). En Diario Oficial El Peruano. Perú. Recuperado de http://busquedas.elperuano.pe/normaslegales/ley-quemodifica-diversas-leyes-para-facilitar-la-inversion-ley-n-30056-956689-1/

Loayza, N. (2008). Causas y consecuencias de la informalidad en el Perú (Estudios económicos). Lima: BCRP. Recuperado de http://www.bcrp.gob.pe/docs/Publicaciones/Revista-EstudiosEconomicos/15/Estudios-Economicos-15-3.pdf

Marino, M. (2007). Análisis de los factores causantes de la informalidad y evasión tributaria de las MYPE comercializadoras de ropa en Piura (Tesis de maestría). Recuperada de http://repositorio.unp.edu.pe/bitstream/handle/UNP/869/POS-MARADR.pdf? sequence $=1 \&$ is Allowed $=\mathrm{y}$

Mendiburu, O. (2016). Factores que propician la informalidad de las pymes y su incidencia en el desarrollo de estas en la provincia de Trujillo, distrito de Victor Larco (Tesis de maestría). Recuperada de http://dspace.unitru.edu.pe/bitstream/handle/UNITRU/4579/Tesis\%20Maestr\%C3\%A Da\%20-\%20Angel\%20Mendiburu\%20Rojas.pdf?sequence $=1 \&$ isAllowed=y

Moore, M. (1998). Gestión estratégica y creación de valor en el sector público. Barcelona : Paidós, 1998 [reimpresión 2011].

Murakami, Y. (2012, marzo). Aquí las personas cambian, teniente, nunca las cosas: una reflexión sobre la política peruana actual desde una perspectiva institucional [revistaargumentos.iep.org.pe]. Recuperado de http://revistaargumentos.iep.org.pe/articulos/aqui-las-personas-cambian-tenientenunca-las-cosas-una-reflexion-sobre-la-politica-peruana-actual-desde-unaperspectiva-institucional/

OCDE (2016). Caminos de Desarrollo Estudio multidimensional del Perú Volumen 2. Análisis detallado y recomendaciones. Mensajes principales. Recuperado el 25 de noviembre, https://www.oecd.org/dev/americas/RESUMEN_EJECUTIVO_MDCR_Peru.pdf

Olavarría, M. (2007). Documentos de trabajo nº 11 - diciembre - 2007 . conceptos básicos en el análisis de políticas públicas. Santiago : Universidad de Chile, Instituto de Asuntos Públicos. Recuperado de http://repositorio.uchile.cl/bitstream/handle/2250/123548/Conceptos_\%20Basicos_Po liticas_Publicas.pdf?sequence $=1$

Organización Internacional de Trabajo (2015, 22 de junio). 104 ${ }^{\mathrm{a}}$ Conferencia Internacional del Trabajo : La OIT adopta una histórica norma del trabajo para hacer frente a la economía informal [Ilo.com]. Recuperado de http://www.ilo.org/ilc/ILCSessions/104/media-centre/news/WCMS_375640/lang-es/index.htm 
Organización Internacional del Trabajo (2015, 12 de junio). R204 - Recomendación sobre la transición de la economía informal a la economía formal [ilo.org]. Recuperado de http://www.ilo.org/dyn/normlex/es/f?p=NORMLEXPUB:12100:0::NO::P12100_ILO CODE:R204

Organización Internacional del Trabajo (2017). Sobre informalidad y productividad: breves reflexiones para el caso del Perú. Recuperado el 25 de noviembre, 2017 http://www.ilo.org/wcmsp5/groups/public/---americas/---ro-lima/---srolima/documents/publication/wcms 561234.pdf

Parodi, C. (2013, 02 de agosto). ¿Influye la política en la economía? [blogs.gestion.pe]. Recuperado de http://blogs.gestion.pe/economiaparatodos/2013/08/influye-la-politicaen-la-econ.html

Perú. Ministerio de Economía y Finanzas (2016). PERÚ Economía y formalización. [Diapositiva]. Lima: MEF. Recuperado de https://www.mef.gob.pe/contenidos/inversionistas/presentacion_economia_formaliza cion_23082016.pdf

Perú. Ministerio de producción (2017). Las MIPYME en cifras 2015. Recuperado el 25 de noviembre,

http://demi.produce.gob.pe/images/publicaciones/publi09f3585ea5d4c9eb9_27.pdf

Piras, C. (2006). Mujeres y Trabajo en América Latina. Recuperado el 5 de agosto, 2013 de http://site.ebrary.com/lib/bibliosil/docDetail.action?docID=10201116\&p00=investiga ci\%C3\%B3n/

Resolución Ministerial No. 202-2017-EF/15 (2017). En Diario Oficial El Peruano. Perú. Recuperado de http://www.produce.gob.pe/produce/descarga/dispositivoslegales/73980_1.15

Roth, N. (2002). Políticas públicas: formulación, implementación y evaluación. Recuperado el 25 de noviembre, 2017 de https://adep2011.files.wordpress.com/2011/09/roth_andre-politicas-publicas1.pdf

Sistema Integrado de Apoyo a la Pequeña Empresa BMI \& Banco Multisectorial de Inversiones (1997). Libro Blanco de la Microempresa: Síntesis. El Salvador: AMPES. Recuperado de http://www.redmujeres.org/biblioteca\%20digital/libro_blanco_microempresa.pdf

Sulca, S. G. (2015). Análisis de los instrumentos de la política pública destinada a la pequeña minería y minería artesanal en perú (2009-2013) (Tesis de maestría). Recuperada de http://repositorio.flacsoandes.edu.ec/bitstream/10469/8732/2/TFLACSO2015DGSH.pdf

Superintendencia de Banca y Seguros y AFP (2017, 15 de enero). Tasa de interés promedio del sistema financiero para créditos a la microempresa [sbs.gob.pe]. Recuperado de https://www.sbs.gob.pe/app/stats/TasaDiaria_3micro.asp 
Superintendencia de banca, seguros y AFP (2017). Carpeta de Información del Sistema Financiero [sbs.gob.pe]. Recuperado de http://www.sbs.gob.pe/app/stats_net/stats/EstadisticaBoletinEstadistico.aspx?p=14\#

Superintendencia Nacional de Aduanas y de Administración Tributaria (2017).

Estadísticas y estudios. Recuperado el 25 de noviembre, 2017

http://www.sunat.gob.pe/estadisticasestudios/busqueda_ingresos.html

Superintendencia Nacional de Aduanas y de Administración Tributaria (2014). Memoria anual 2014. Recuperado el 25 de noviembre, 2017 de http://www.sunat.gob.pe/cuentassunat/planestrategico/memoria/memoria2014.pdf

Superintendencia Nacional de Aduanas y de Administración Tributaria (2017, 10 Octubre). Iniciando mi negocio [emprender.sunat.gob.pe]. Recuperado de http://emprender.sunat.gob.pe/como-me-conviene-tributar

Superintendencia Nacional de Aduanas y de Administración Tributaria (2017, 09 marzo). Iniciando mi negocio [emprender.sunat.gob.pe]. Recuperado de http://emprender.sunat.gob.pe/como-me-conviene-tributar

Superintendencia Nacional de Aduanas y de Administración Tributaria (2017, 16 de abril). Plan Estratégico Institucional de la Superintendencia Nacional de Aduanas y de Administración Tributaria - SUNAT. Plan estratégico 2018 - 2020 [sunat.gob.pe]. Recuperado de http://www.sunat.gob.pe/cuentassunat/planestrategico/plan_estrategico.html\#pei2017 $\underline{-2019}$

Superintendencia Nacional de los Registros Públicos (2016). En 24 horas se puede inscribir una empresa en la Sunarp [sunarp.gob.pe]. Recuperado de https://www.sunarp.gob.pe/PRENSA/inicio/post/2016/10/31/en-24-horas-se-puedeinscribir-una-empresa-en-la-sunarp

Tamayo, M. (1997). La nueva Administración Pública. Recuperado el 25 de noviembre, 2017 http://politicas.typepad.com/files/tamayo_el-analisis.pdf

Van Sint Jan Fabry, M. (1990). La tierra, un planeta dinámico [Diapositiva]. Santiago: Pontificia Universidad Católica de Chile [Diapositiva]. Lima: INEI. Recuperado https://www.inei.gob.pe/media/cifras_de_pobreza/exposicion_inei_pobreza2015.pdf

Webb,R. (2015, 06 de diciembre). La informalidad [elcomercio.pe]. Recuperado de https://elcomercio.pe/opinion/rincon-del-autor/informalidad-richard-webb-250104 